\title{
EQUIPAMENTOS NUCLEARES NA DETERMINAÇÃO DOS COEFICIENTES DE ATENUACCÃO DE MASSA DE SOLOS E DA ÁGUA
}

\author{
ORGHÊDA LUIZA ARAUUJO DOMINGUES ZUCCHI
}

Orientador: VIRGÍLIO F. NASCIMENTO Fo

Dissertação apresentada à Escola Superior de Agricultura "Luiz de Queiroz", da Universidade de São Paulo, para obtenção do título de Mestre em Energia Nuclear na Agricultura.

\author{
P I R A I C A B A \\ Estado de São Paulo - Brasil \\ Fevereiro - 1981
}


$-i-$

Aos meus pais,

Ao Roberto, Tiago e Juliana,

DED I C O 


\section{AGRADECIMENTOS}

- Ao Prof. Virgilio F. Nascimento FO, pela orientação, dedicação e estímu lo no desenvolvimento deste trabalho,

- ao Prof. Epcominondas S. B. Ferraz, pelas sugestões e utilização da blin dagem e sistema de colimação,

- ao Prof. Admar Cervellini, Diretor do Centro de Energia Nuclear na Agrí cul tura, e ao Dr. Peter B. Vose, Diretor do Projeto UNDP/IAEA/BRA78/006, pelos recursos obtidos junto à Comissão Nacional de Energia Nuclear e Agência Internacional de Energia Atômica,

- ao Centro de Energia Nuclear na Agricultura e à Escola Superior de Agri cultura "Luiz de Queiroz", pela oportunidade de aperfeiçoamento,

- ao Plano de Formagão e Aperfeigoamento de Pessoal de Nïvel Superior PLANFAP/CNEN, pela concessão de bolsas de estudos,

- ao funcionário José Osório Bertoli, pela amizade, ajuda na realização de experimentos e serviços de datilografia e

- a todos os funcionários do CENA, que de uma forma ou de outra, contribuíram para a execução deste trabalho. 
Pägina

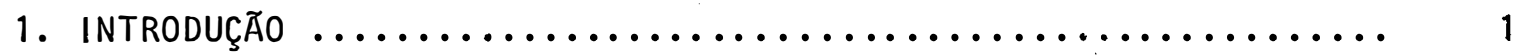

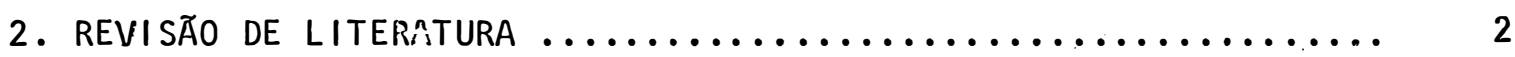

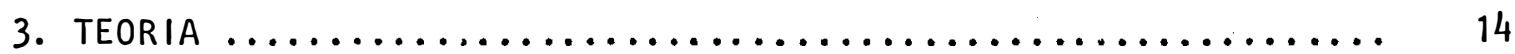

3.1. Atenuação de um feixe de radiação gama monoenergético ... 14

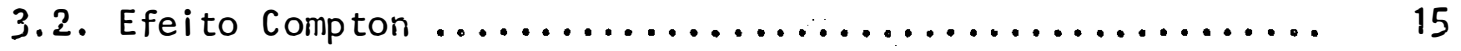

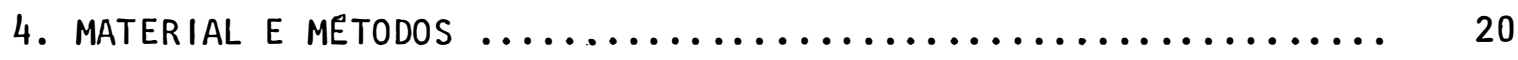

4.1. Geometria ................................ 20

4.2. Equi pamentos e deteç̧ão $\ldots . \ldots \ldots \ldots \ldots \ldots \ldots \ldots \ldots . . \ldots \ldots$

4.3. Correção do tempo morto $\ldots \ldots \ldots \ldots \ldots \ldots \ldots \ldots \ldots \ldots .30$

4.4. Tipos de solos e preparação das amostras $\ldots . \ldots \ldots \ldots . . . . .31$

4.5. Determinação do coeficiente de atenuação de massa ...... 33

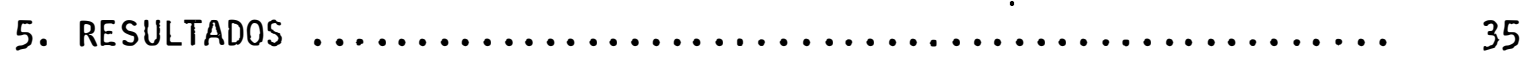

5.1. Coeficientes de atenuação de massa para solos ........ 35

5.2. Coeficientes de atenuação de massa para água $\ldots . . . . . . .54$

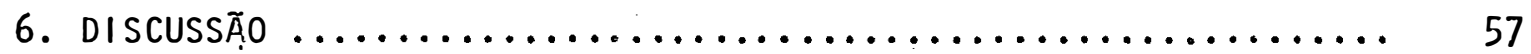

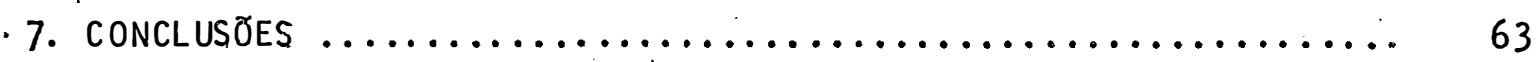

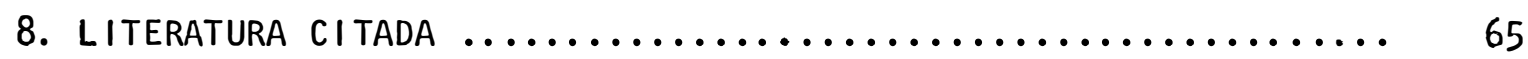




\section{LISTA DE FIGURAS}

Figura

Pägina

1 - Representação esquemätica do efei to Compton ..........

2 - Energia do raio gama espalhado e perda percentual da energia para o raío gama de $0,662 \mathrm{MeV}$ emitido pelo Cs-137, nos diferentes ângulos de espalhamento ..............

3 - Esquema da bliridagem e colimação utilizâdas - dimensões

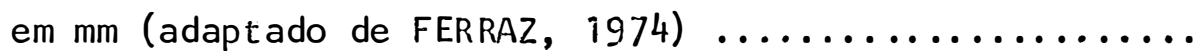

4 - Detalhe do posicionamento da amostra para anālise ......

5 - Vista geral do equipamento utilizado; à direita, espectrômetro gama e à esquerda o sistema Nuclear Chicago ...

6 - Curva para obtenção da alta voltagem de operação (V.0.) do sistema Nuclear Chicago, para os raios gama do Cs-137.

7 - Espectro de pulsos eletrônicos devido aos raios gama do Cs-137 obtidos com e sem lâmina de $\mathrm{Pb}$ na saída do fei-

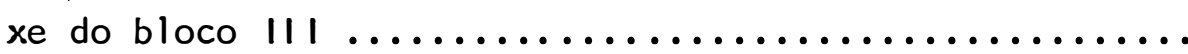

8 - Curvas de taxa de contagem do feixe emergente em função da densidade superficial para determinação do coeficiente de atenuação de massa do solo Podzol Vermelho Ama

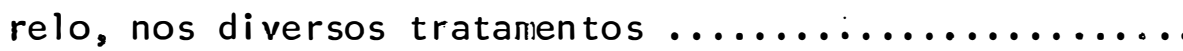

9 - Curvas de taxa de contagem de feixe emergente em função da densidade superficial para a determinação do coeficien 
te de atenuação de massa do solo Podzolisado ivar. Marilia,nos diversos tratamentos $\ldots \ldots \ldots \ldots \ldots \ldots$

10 - Curvas de taxa de contagem do feire emergente em função da densidade superficial para a determinação do coeficiente de atenuação de massa do solo Latosol Vermelho Escuro,nos diversos tratamentos $\ldots \ldots \ldots \ldots \ldots \ldots \ldots \ldots$

11 - Curvas de taxa de contagem do feixe emergente em função da densidade superficial para determinação do coeficiente de atenuação de massa do solo Terra Roxa Estrutu-

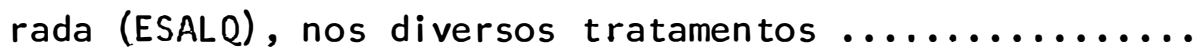

12 - Curvas de taxa de contagem do feixe emergente em função da densidade superficial para determinação do coeficiente de atenuação de massa do solo Latosol Roxo,nos di versos tratamentos $\ldots \ldots \ldots \ldots \ldots \ldots \ldots \ldots \ldots \ldots \ldots \ldots$

13 - Curvas de taxa de contagem do feixe emergente em função da densidade superficial para determinação do coeficiente de atenuação de massa do solo Regosol (Cerrado),

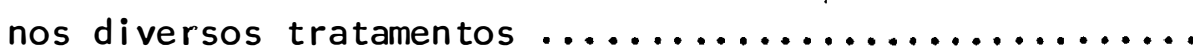

14 - Curvas de taxa de contagem do feixe emergente em função da densidade superficial para determinação do coeficiente de atenuação de massa do solo Terra Roxa Estruturada (Jaboticabal - horizonte $0-30 \mathrm{~cm}$ ), nos diversos tra tamentos $\ldots \ldots \ldots \ldots \ldots \ldots \ldots \ldots \ldots \ldots \ldots \ldots \ldots \ldots \ldots \ldots$ 
15 - Curvas de taxa de contagem do feixe emergente em função da densidade superficial para determinação do coeficiente de atenuação de massa do solo Terra Roxa Estruturada (Jaboticabal - horizonte $30-60 \mathrm{~cm}$ ), r.os diversos trạ

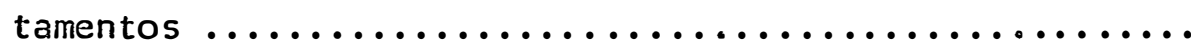

16 - Curvas de taxa de contagem do feixe emergente em função da densidade superficial para determinação do coeficiente de atenuação de massa do solo Terra Roxa Estruturada (Jaboticabal - horizonte $60-90 \mathrm{~cm}$ ), nos diversos tra

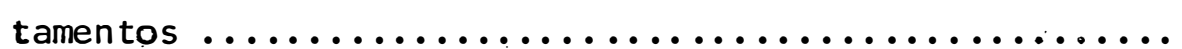

17 - Curvas de taxa de contagem do feixe emergente em função da densidade superficial para determinação do coeficiente de atenuação de massa do solo Terra Roxa Estruturada (Jaboticabal - horizonte $90-120 \mathrm{~cm}$ ), nos diversos

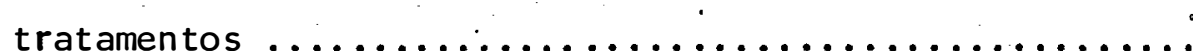

18 - Distribuição dos coeficientes de atenuação de massa obti dos para os diferentes solos, em cada um dos tratamentos.

19 - Curvas de taxa de contagem do feixe emergente em função da densidade superficial para determinação do coeficiente de atenuação de massa da água nos 6 tratamentos.. 
LISTA DE TABELAS

Tabela

Pägina

1 Taxa de contagen do feixe de raios gama em função da alta voltagem aplicada à vălvula fotomultiplicadora do sis

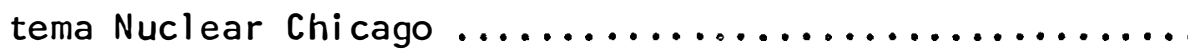

2 - Relação dos solos estudados com as respectivas siglas e ho

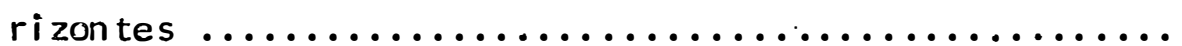

3 - Características dos tubos plásticos utilizados para colo cação das amostras de solo ..................... . 32

4 - Características dos tubos plásticos utilizados para colo cação das amostras de ăgua ...................... 33

5 - Coeficientes lineares $\left(\ln 1_{0}\right)$ e angulares ( $\mathrm{M}$, respectivos desvios padrões (s) e coeficientes de correlação $(r)$ para o tratamento 1 (Nuclear Chicago com proteção de $\mathrm{Pb}$ ), para os diferentes solos ........................

6 - Coeficientes lineares $\left(\ln 1_{0}\right)$ e angulares ( $(\mu)$, respectivos desvios padrões $(s)$ e coeficientes de correlação $(r)$ para o tratamento 2 (Nuclear Chicago sem proteção de $\mathrm{Pb}$ ), para os diferentes solos .........................

7 - Coeficientes lineares $\left(\left.\ln \right|_{0}\right)$ e angulares $(\bar{\mu})$, respectivos desvios padrões (s) e coeficientes de correlação ( $r$ ) para o tratamento 3 (Espectrômetro gama, contagem integral com proteção de $\mathrm{Pb})$, para os diferentes solos ...... 
8 - Coeficientes lineares $\left(\ln 1_{0}\right)$ e angulares $(\bar{\mu})$, respectivos desvios padrões ( $s$ ) e coeficientes de correlação $(r)$ para 0 tratamento 4 (Espectrômetro gama, contagem integral, sem proteção de $\mathrm{Pb}$ ), para os diferentes solos ......

9 - Coeficientes 1 ineares $\left(\ln 1_{0}\right)$ e angulares $(\bar{\mu})$, respectivos desvios padrões (s) e coeficientes de correlação $(r)$ para o tratamento 5 (Espectrômetro gama, contagem na região do fotopico, com proteção de $\mathrm{Pb}$ ), para os diferentes

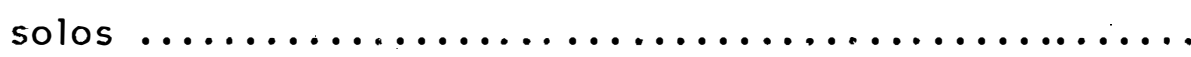

10 - Coeficientes lineares $\left(\ln 1_{0}\right)$ e angulares $(\bar{\mu})$, respectivos desvios padrões (s) e coeficientes de correlação $(r)$ para o tratamento 6 (Espectrồmetro gama, contagem na região do fotopico, sem proteção de $\mathrm{Pb}$ ), para os diferentes solos $\ldots \ldots \ldots \ldots \ldots \ldots \ldots \ldots \ldots \ldots \ldots \ldots \ldots \ldots$.

11 Distribuição dos valores dos coeficientes de atenuação de massa obtidos para cada tratamento e diferentes solos

12 - Valores médios da taxa de contagem (cpm) do feixe emergente e da densidade superficial $\left(\mathrm{g} / \mathrm{cm}^{2}\right)$ para a ăgua, nos diferentes tratamentos $\ldots \ldots \ldots \ldots \ldots \ldots \ldots \ldots \ldots \ldots$

13 - Coeficientes lineares $\left(\ln 1_{0}\right)$ e angulares $(\bar{\mu})$, respectivos desvios padrões (s) e coeficientes de correlação $(r)$ para a água, obtidos para os diversos tratamentos ....... 
14 - Coeficientes de atenuação de massa para solos, obtidos por diferentes autores para uma fonte de radios gama

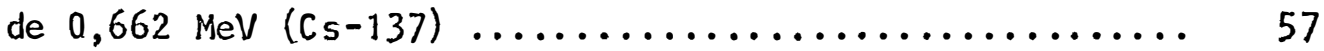

15 - Coeficientes de atenuação de massa da ägua, obtidos por SAXENA et alii (1970), para uma fonte de r.adiação gama monoenergética do $\mathrm{Cs}_{\mathrm{s}}-137 \ldots \ldots \ldots \ldots \ldots \ldots \ldots \ldots \ldots$

16 - Valores relativos de intensidade dos feixes incidentes medidos ( $\left.1_{0 \text { med }}\right)$ e calculados ( $\left.1_{0 \text { calc }}\right)$, para os solos e á gua, nos diversos tratamentos utilizados ............ 


\section{APENNTCES}

Apêndice

Pägina

1 - Valores mëdios da taxa de contagem (cpm) do feixe emergen te e incidente e da densidade superficial $\left(\mathrm{g} / \mathrm{cm}^{2}\right)$ para as diferentes amostras de solos nos diferentes tratamentos . 72

2 - Contrastes entre os valores dos coeficientes de atenuação de massa dos diferentes solos para o tratamento $1 \ldots . . .76$

3 - Contrastes entre os valores dos coeficientes de atenuação de massa dos diferentes solos para o tratamento $2 \ldots . . .77$

4 - Contrastes entre os valores dos coeficientes de atenuação de massa dos diferentes solos para o tratamento $3 \ldots \ldots 78$

5 - Contrastes entre os valores dos coeficientes de atenuação de massa dos diferentes solos para o tratamento 4 ...... 79

6 - Contrastes entre os valores dos coeficientes de atenuação de massa dos diferentes solos para o tratamento $5 \ldots \ldots .80$

7 - Contrastes entre os valores dos coefi cientès de atenuação de massa dos diferentes solos para o tratamento $6 \ldots \ldots 8$

8 - Contrastes obtidos entre os valores dos coeficientes de atenuação de massa geral (10 solos) para os diversos tra-

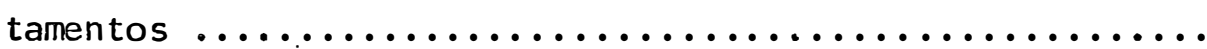

9 - Contrastes entre os coeficientes de atenuação de massa da ăgua para os 6 tratamentos $\ldots \ldots \ldots \ldots \ldots \ldots \ldots \ldots$ 
EQUIPAMENTOS NUCLEARES NA DETERMINAÇÃO DOS COEFICIENTES DE ATENUAÇAOO DE MASSA DE SOLOS E DA AGGUA

Orghêda L. A. D. Zucchi

Virgizio F. Nascimento FO

- Orientador -

\section{RESUMO}

Com o intuito de se difundir e fácilitar o uso da técnica de atenuação da radiação gama, foi desenvolvido um estudo para se determinar a viabilidade de substituição do espectrômetro gama monocanal, tra dicionalmente usado nesta técnica, por um sistema de contagem integral de custo mais baixo, capaz de ser operado por pessoal com menor especialização.

Fez-se um estudo da determinação dos coeficientes de atenuação de massa para värios tipos de solo e para ãgua, empregandose três sistemas de detecção: (1) espectrômetro gama monocanal, operando em contagem no fotopico $(0,66 \pm 0,07 \mathrm{MeV}) ; \quad$ (2) operando em contagem integral $(0,1$ a $1,0 \mathrm{MeV})$ e (3) um "scaler" conectado diretamente à fotomultiplicadora. Também foi levado em consideração a eliminação dos raios-X de $32 \mathrm{keV}$ proveniente do $\mathrm{Ba}-137 \mathrm{~m}$, raios gama retroespalhados na blindagem e na fonte e a correção do tem po morto.

Concluiu-se que a substituição do espectrômetro gama mono canal pelo "scaler" é perfeitamente viävel. 
MUCLEAR EQUIPMENT TO DETERMINE SOIL AND WATER MASS ATTENUATIOR COEFFICIENTS

Orghêda L. A. D. Zucchi

Virgizio F. Nascimento F?

- Adviser -

\section{SUMAMARY}

A study was carried out to determine the feasibility of substituting the monochannel gamma spectrometer, traditionally used in the gamma ray attenuation technique, for a less sophisticated and less expensive system of integral counting, which could be operated by a non-specialized person. This was done to make this technique better known and used.

Three detection systems were used in the determination of the mass attenuation coefficients for different types of soil and for water: (1) monochannel gamma spectrometer, operating at photopeak counting $(0.66 \pm$ $0.07 \mathrm{MeV}),(2)$ operating at integral counting $(0.1-1.0 \mathrm{MeV})$, and (3) a scaler directly connected to the photomultiplier. Also taken into consideration were: the elimination of X-rays of $32 \mathrm{keV}$ from the $\mathrm{Ba}-137 \mathrm{~m}$, gamma-rays back-scattering in the shield and in the source, and correction of dead time.

After analysis of the results we came to the conclusion that it is perfectly feasible to substitute the monochannel gamma spectrometer for the system using a scaler. 


\section{INTRODUÇATO}

A técnica de atenuação da radiação gama tem sido empregada, como método não destrutivo, em estudos estáticos e também na estimativa de värios parâmetros de processos dinâmicos de transferência de massa. Na área agronômica, tem sido utilizada principalmente na determinação da umidade e densidiade de solos e madeiras.

0 equipamento empregado na detecção da radiação gama é normalmente um espectrômetro gama monocanal, sendo necessärio pessoal especializado para o seu manuseio. Além disso, esté equipamento é importado, tornando esta técnicà pouco disseminada entre nós. Recentemente, a indūstria brasileira colocou esse equipamento no mercado, mas ainda a um preço elevado. Para tornar essa técnica mais usual, torna-se necessário o empre go de um sistema detector mais simples e de custo mais acessivel.

Este trabalho teve por finalidade verificar a possibilidade de substituição do espectrômetro gama monocanal por um sistema de contagem integral, atravēs da escimativa do coeficiente de atenuação de massa para värios tipos de solo e para ăgua. 


\section{REVISÃO DE LITERATURA}

BERNHARD e CHASE'K (1955), conforme FERRAZ e MANSELL (1977), determinaram a densidade do solo no campo com uma fonte não colimada de Co-60 e um detector Geiger-Mülller para medida da intensidade da radiação. A fonte de radiação foi colocada dentro de um tubo introduzido verticalmente no solo e o detector colocado em outro tubo paralelo. No campo as deter minações da densidade foram efetuadas entre os dois tubos.

DAVISSON (1955) tabelou o coeficiente de absorção para di versos elementos em diferentes energias de radiação.

VOMOCIL (1954) descreveu um método räpido para determinação da densidade de solos, usando uma fonte emissora gama de Co-60 de 1 mCi e um detector Geiger-Müller, "in situ"

BAVEL (1959) apresentou uma técnica para se determinar a densidade do solo "in situ" atravēs da atenuação gama. Foi feito uma adap tação no equipamento bāsico para determinação da densidade em laboratório, de modo a ser usado em campo. A variação encontrada para o coefici ente de atenuação linear nos dois sistemas acreditaram ser devido à incer 
teza no valor da distância entre a fonte e o detector. Foi utilizado uma fonte de $\mathrm{Cs}-137$ de $5 \mathrm{mCi}$ e um cristal cintilador de $\mathrm{Nal}(\mathrm{Tl})$.

REICHARDT (1960) descreveu um método para determinação da densidade do solo "in loco" por dispersão de raios gama. Essas determina ções podem ser feitas na superfície e sub-superfície pela introdução do conjunto fonte-detector no solo. Foi utilizada uma fonte radioativa de $0,5 \mathrm{mC} \mathbf{i}$ de Co-60, um detector Geiger-Muller protegido da radiação direta por $\mathrm{Pb}$ e um "scaler" para registro dos pulsos. 'A fonte, a proteção de $\mathrm{Pb}$ e o detector foram ajustados de maneira a formar uma geometria constante. Introduzindo-se esse conjunto no solo foi possível relacionar as contagens obtidas com a densidade do solo, através de curvas de calibragem. 0 autor conclui que para se determinar a densidade do solo no campo é necessário um sistema de contagem sensivel e portảtil.

BAVEL (1960) discutiu os princípios físicos da atenuação da radiação gama. Apresentou os problemas para a seleção de uma fonte emissora, atividade da fonte, distância do detector, tempo e precisão nas medi das. Analisou os distúrbios que o hidrogênio do solo ocasiona na determ: nação do coeficiente de atenuação de massa.

BERRY (1961) relacionou graficamente o coeficiente de atenu ação de massa teōrico com o número atômico do material absorvedor para diferentes energias da radiação gama.

FERGUSON e GARDNER (1962) descreveram o procedimento para obtenção da umicade contida em colunas de solo através da atenuação da radiação gama. Utilizaram uma fonte de $\mathrm{Cs}_{\mathrm{s}}-137$ e um detector cintila 
dor de $\mathrm{Nal}(\mathrm{Tl})$, sendo necessärio para as medidas uma boa colimação e um tempo pequeno para contagens.

GURR (1962) descreveu uma técnica pầ medida da àgua em colunas de solo us ando atenuação dos raios gama. Foi utilizado um feire col imado de $\mathrm{Cs}-157$ de $25 \mathrm{mCi}$ e um cristal cintilador de $\mathrm{Nal}(\mathrm{Tl})$. Foram selecionados e co.ntados todos os pulsos correspondentes a uma energia maior que $0,55 \mathrm{MeV}$. Os valores dos coeficientes de atenuação de massa obtidos para o solo e para a água foram 0,07785 e $0,08559 \mathrm{~cm}^{2} / \mathrm{g}$, respectivamente.

DAVIDSON et alii (1963) determinaram o coeficiente de atenuação de massa da ăgua e do solo com uma fonte de Cs-137 de $200 \mathrm{mCi}$ e um cristal cintilador de $\mathrm{Nal}(\mathrm{Tl})$. 0 feixe de radiação era colimado e somen te raios de energias de $0,66 \pm 0,15 \mathrm{MeV}$ eram contados. Foram apresenta dos alguns resultados experimentaís satisfatōrios para a ägua movendöse dentro de uma coluna de solo seco ao ar.

REGINATO e BAVEL (1964) descreveram um mētodo para determi nação do volume da ägua contida em amostras de solo "in situ", sem a coli mação do fèixe de radiação gama. Usaram um cristal cintilador de Nal (Tl) e uma fonte de $\mathrm{Cs}-137$ de $5 \mathrm{mC}$ de atividade. Foram realizadas contagens integrais com o nível mínimo do discriminador fixado no limiar do fotopico. Os coeficientes de atenuação de massa obtidós para o feixe de radia ção gama não colimada foi de $0,0699 \pm 0,004 \mathrm{~cm}^{2} / \mathrm{g}$ para o solo, e de $0,0748 \pm 0,006 \mathrm{~cm}^{2} / \mathrm{g}$ para ägua. Foi possível determinarem o teor de ägua contido nas amostras de solo com feixe de radiação gama não colimada ao admitirem que os coeficientes de atenuação de massa (solo e água) não 
di ferem entre si (vạiação 6,5\%).

ROSE (1964) elaborou tabelas de coeficientes de atenuação e de absorção de massa para diversos materiais em diferentes energias. Para alguns desses materiais, foram dados a sua composição química, em porcentagem.

REICHARDT (1965 a,b) utilizou uma fonte de Cs-134 de ativi dade de $30 \mathrm{mCi}$ para determinação da densidade e umidade de três perfis de solos do município de Piracicaba. Para deteç̧ão das radiações gama, empregou-se um detector de cintilação (modelo DS-5) e um analisador de impulsos (modelo 132-B), ambos fabricados pela Nuclear Chicago Corporation. Durante as determinações foram detectadas radiações gama de energias $0,58 \pm 0,01 \mathrm{MeV}$. As amostras foram colocadas em posição horizontal e o feixe de radiação passava atravēs de um orifício de colimação de $4 \mathrm{~mm}$ de diâmetro. As amostras de solo foram secas à sombra e depois destorroadas em peneira de $2 \mathrm{~mm}$. Para cada tipo de solo, com três diferentes teo res de umidade, foram determinadas curvas de absorção da energia da radia ção gama, variando-se a.espessura da amostra de solo. . Foi realizado um estudo da variação dos coeficientes de atenuação linear com o teor de àgua contida nas amostras. Foi determinado,também, a densidade do solo através do método gravimétrico e os teores de umidade foram obtidos em es tufa a $105^{\circ} \mathrm{C}$.

GARDNER e CALISSENDORFF (1967) analisaram a possibilidade de emprego de uma fonte emissora gama e neutrons rāpidos na determinação de densidade e umidade dos solos. Estudaram o erro nas medidas de dens dade e umi dade em função da espessura do absorvedor para as fontes gama 
de Am-241, Ce-144, Cs-137 e Co-60, alēm de uma fonte de neutrons rāpidos. concluíram que os neutrons räpidos podem ser combinados com os raios ga ma para a determinação de umidade e densidade, com resultados satisfatōrios.

KING (1967) comparou as vantagens e desvantagens de se $\underline{\mathbf{u}}$ sar a fonte de Am-241 ou a de Cs-137 na determinação da umidade do solo em laboratōrio atravēs da atenuação da radiação gama. A maior vantagem apresentada pelo Am-241 sobre o Cs-137 estā na menor espessura necessāria para blindagem da fonte, tornando-a mais leve. Alēm disso, possui grande sensibilidade quando se utiliza colunas de solos de espessura em torno de $4,5,6,0 . \mathrm{cm}_{0} \ldots$ Suas desvantagens, entretanto, estão no prē-amplificador especial necessärio para os pulsos produzidos pelos raios de $60 \mathrm{keV}$, na impossibilidade de utilização de colunas de grande diâmetro devido à e levada atenuação dos raios gama pelo solo e impossibilidade de fabricação de fontes intensas (auto-absorção). Para esse experimento, foi utilizado um cristal cintilador de $\mathrm{Nal}(\mathrm{Tl})$ de $1 \mathrm{~mm}$ de espessura e um espectrômetro gama monocanal.

SOANE (1967) discutiu a viabilidade de se determinar simul taneamente a densidade e umidade do solo atravēs de duas fontes emissoras de raios gama ( $\mathrm{Cs}_{\mathrm{S}-137}$ e Am-241). A atividade do $\mathrm{Cs}_{\mathrm{S}}-137$ utilizada foi de $30 \mathrm{mCi}$ e a do Am-241 de $350 \mathrm{mCi}$. A detecção dos raios gama de cada fonte foi feita separadamente. 0 cristal cintilador empregado foi o Nal (TI) de $5 \mathrm{~cm}$ de espessura.

WACK (1967) descreveu um protōtipo para determinação da densidade e umidade de solos. Tal instrumento consta de um tubo metāli - 
co que é inserido nọ solo com duas fontes radioativas: una fonte de $\mathrm{Cs}_{\mathrm{s}}-137$ de $20 \mathrm{mCi}$ e outra de $A m-B e$ de $300 \mathrm{mCi}$. 0 detector de raios gama foi um Geiger-Müller a gás halogênio e o de neutrons um detector proporcional de $\mathrm{BF}_{3}$ inserido em um cilindro de parafina. Ambos os detectores foram protegidos por um filiro de cādmo.

FRITTCN (1969) utilizou uma fonte de $251 \mathrm{mCi}$ de Cs-13.7 e um detector de cintilação de $\mathrm{Nal}(\mathrm{Tl})$ de $2,5 \times 2,5^{\prime \prime}$, acoplado a uma fotomultiplicadora, para estıdar o fator de correção nas determinações devido ao tempo morto do equipamento eletrônico. Comparou alguns valores jā cita-. dos em literatura de coeficiente de atenuação de massa do solo e da āgua quando feita tal correção, para altas taxas de contagem.

GROENEVELT et alii (1969) discutiram os problemas que ocor rem quando se utiliza uma fonte emissora de raios gama de baixa energia, como o Am-241 de $60 \mathrm{keV}$. Dentre as dificuldades estão a determinação do coeficiente de atenuação de massa da āgua, além do problema de contagens perdidas pelo sistema detector devido ao tempo morto e à geometria do equipamento. Foi utilizada uma fonte de Am-241 de 231. mCi.

SAXENA et alii (1970) utilizaram uma fonte de: Cs-137 de $250 \mathrm{mCi}$ e um cristal cintilador de Nal (Tl) para determinação do coeficien te de atenuação de massa da água. Tais coeficientes foram determinados para radiações gama na faixa de $0,66 \pm 0,15 \mathrm{MeV}, 0,66 \pm 0,033 \mathrm{MeV}$, e tam bém para o detector conectado diretamente ao "scaler". Foi observado o valor do coeficiente de atenuação de massa da água quando se usa a colima ção na fonte e detector, somente colímação na fonte ou no detector para os três modos de operação. 
REGINATO E STOUT (1970) verificaram que o equipamento usado para medir densidade e umidade pelo método de atenuação gama em labora tōrio não apresenta bom desempenho quando usado "in situ", devido às flutuações no nümero de contagens, em função das variações de temperatura.

VACHA'JD et alii (1970) determinaram o valor do coeficiente de absorção da āgua urando uma fonte de Am-241 de $100 \mathrm{mCi}$. Para isso fi zeram um estudo da colimação ideal do feixe de radiação para obtenção do coeficiente de atenuação de massa prōximo ao teórico.

COREY et alii (1971) determinaram simultaneamente, em condições de laboratório, a densidade e umidade do solo por atenuação da radiação gama. Foram utilizadas fontes emissoras gama de Cs-137 e Am-241, cujas atividades eram $70 \mathrm{mCi}$ e $29 \mathrm{mCi}$, respectivamente. Para essa deter minação simultânea foi utilizado um espectrômetro gama multicanal, além de um cristal cintilador de $\mathrm{Nal}(\mathrm{TI})$ e um detector de Ge(Li). Para a obtenção do feixe, a fonte de Cs-137 foi colocada atrás da de Am-241.

SWART e GROENEVELT (1971) determinaram a umidade do solo em colunas,utilizando uma fonte de $A m-241$ de $231 \mathrm{mCi}$ de atividade. Foi utilizado um cristal cintilador de $\mathrm{Nal}\left(\mathrm{TI}_{1}\right)$ de $3 \mathrm{~mm}$ de espessura e um espectrômetro gama monocanal. Discutiu também a movimentação automảtica da fonte e detector ao longo da coluna e, a fim de se reduzir a influência da gravidade no fluxo horizontal da água a coluna foi movimentada radialmente.

GOPAL E SANJEVAIAH (1973) utilizaram um cristal cintilador de $\mathrm{Nal}(\mathrm{T} 1)$ e uma fonte de $\mathrm{Cs}-137$ de $500 \mathrm{mCi}$ para determinar o coeficiente 
de atenuação de massa do carbono, alumínio, cobre, estanho e chumbo para diversas espessuras. Os resultados demonstraram que a resolução do espectrômetro e os coeficientes de atenuação de massa permaneceram constantes quando o produto da espessura pelo prōprio coeficiente de atenuação de massa é menor qun a unidade, indicando que a condição de feixe colimado é preservado e o rümero de fótons espalhados, que chegam ao detector, è insignificante.

KIRKHAN e COREY (1973) analisaram os recentes progressos instrumentais nucleares usados na deteç̧ão da radiação e a di sponibilida de comercial de amostras radioativas.

OLESEN (1973) estudou a varíação da umidade volumétrica do solo com e sem correções na densidade, usando uma. fonte de Am-241, de 100 mCi e um cristal cintilador de $\mathrm{Nal}(\mathrm{Tl})$. Sugeriu a utilização do equipamento com dupla fonte para reduzir os erros nas medidas de densidade e umidade a níveis aceitáveis, para solos expansíveis.

REGINATO (1974 a) determinou a densidade e umidade do solo utilizando três tipos de configuração para as fontes de Am-241 e Cs-137: Am separadamente, Cs separadamente e ambas as fontes. 0 equipamento nuclear de deteç̧ão (método 2 gama) básico foi modificado com a adição de um segundo analisador e um "scaler" para que os fotons provenientes do Am mais Cs fossem contados simuitaneamente. Foi utilizado um cristal cinti lador de $\mathrm{Nal}(\mathrm{Tl})$ de $1 \mathrm{~cm}$ de espessura e as atividades das fontes de Cs137 e Am-241 eram de $5 \mathrm{mCi}$ e $100 \mathrm{mCi}$, respectivamente. Foram obtidos va lores absurdos de densidade e umidade quando utilizadas ambas as fontes emissoras. 
REGINATO ( 1974 b) fez um estudo dos erros que podem influenciar 'as medidas de densildade e umidade do solo atravēs de um feixe monoenergētico de radiação gama. Utilizou para isso uma fonte de $100 \mathrm{mC}$ de Am-241, distante $14,3 \mathrm{~cm}$ de um detector de $\mathrm{Nal}(\mathrm{TI})$ de $1 \mathrm{~cm}$ de espessura.

COPPOLA e REINIGER (1974) investigaram a dependência do co eficiente de atenuação de massa para solos de diferentes composições. Utilizaram energias de $10 \mathrm{kel}$ a 3 Mev e concluiram que há influência da composição química do solo para determinação desse coeficiente de atenuação. Tal influência é apreciável quando se utiliza fontes emissoras de de energias inferiores a $300 \mathrm{keV}$.

FERRAZ (1974 e 1976) desenvolveu um sistema para determinação simultânea da densidade e umidade do solo. Usou para ísso duas fontes emissoras gama, Am-241 e Cs-137, cujas atividades eram 100 e 130 $\mathrm{mCi}$, respectivamente. Foi usada uma geometria de 2 feixes paralelos e horizontais, distantes as fontes radioativas $10 \mathrm{~mm}$ de centro a centro. Os colimadores eram de secção reta circular em blocos de chumbo. 0 colimador do Am-241possuia uma secção reta de $12,4 \mathrm{~mm}^{2}$, enquanto que o do Cs-137, 4, $\dot{5} \mathrm{~mm}^{2}$. A detecção foi realizada com um cristal de $\mathrm{Nal}(\mathrm{Tl})$, de $2 \times 2^{\prime \prime}$, acoplado a uma fotomultiplicadora, sendo os impulsos analisados e contados num sistema de dois canais. Nesses trabalhos foram feitos estudos da sensibilidade do método 2 gama para determinação da densidade e umidade de solos. Comentou, ainda, a geometria utilizada e a escolha das fontes de radiação gama mais adequada para se obter uma sensibilidade māxima. 
FERRAZ et alii (1974) discutiram os problemas ocorridos na utilização de uma fonte colimada de Am-241, tais como a colimação, resolu ção do detector, os interferentes e os problemas na anālise das contagens obtidas. Discutiram, também, as vantagens e desvantagens do método na determinação da densidade e umidade de solos.

GYURCSik et alii (1976) discutîram as técnicas para medidas de umidade e densidade do solo, usando dois detectores independentes, um para raios gama e outro para neutrons térmicos, espaçados a diferentes distâncias da fonte. A resposta do duplo detector è pouco influenciada por fatores como composição do solo, espessura do solo e distürbios na es trutura do solo causado pela mudança do tubo. Por outro lado, è muito sensível a variação de densidade e umidade.

HERKELRATH e MILLER (1976) demostraram a viabilidade da utîlização de cintiladores plásticos, de tempo morto da ordem de nano se-' gundos, para detecção de radiações gama emitidas por fontes de 2 Ci de atividade, ao se adaptar um diodo estabilizador no circuito divisor de tensão na vālvula fọtomultiplicadora. Observaram a influência da temperatura no nümero de contagens, bem como os fōtons espalhados devido ao es palhamento Compton.

SING e CHANDRA (1976) descreveram um experimento para determinar a espessura do solo colocado entre a fonte e o detector, para me lhor exatidão do método de atenuação gama.

FERRAZ e MANSELL (1976) descreveram a importância do mētodo de atenuação da radiação gama para determinação simultânea da umidade 
e densidade do solo. Discutiram a importância da espessura do material com relação à energia dos raios gama das fontes utilizadas. As fontes emissoras de raios gama utilizadas foram o Cs-137 (0,662 MeV) e Am-241 $(60 \mathrm{keV})$.

FERRAZ e PINTO (1977) estudaram a possibilidade de se de terminar a densidade ou umidade do solo "in situ" pcrr atenuação da radiação gama não col imada. Demonstraram, também, que nï̉o é necessārio conhecimento dos parâmetros densidade e umidade iniciais, bem como o coeficiente de atenuação de massa do solo, para determinação da variação da umi dade. :Foi utilizada uma fonte de radiação gama de $\mathrm{Cs}-137$ de $5 \mathrm{mCi}$, e como dector, um cristal de cintilação de $\mathrm{Nal}(\mathrm{T} !)$ de $3,81 \mathrm{~cm}$ de diâmetro por $1,27 \mathrm{~cm}$ de altura, com $23 \%$ de resolução, acoplado a um equipamento de contagem portätil.

KANE et alii (1977) utilizaram um detector semicondutor de Ge(Li) para determinação do coeficiente de atenuação de alguns elementos. Para o chumbo foram determinados os, valores do coeficiente de atenuação para energias de radiação gama de $0,6 € 2 \mathrm{MeV} ; 1,116 \mathrm{MeV}$ e 1,33 MeV e, no caso do tântalo e molibdênio, foram usados energias de 0,662 MeV e - $1,116 \mathrm{MeV}$. Os valores experimentais foram comparados com valores jä cita dos em literatura.

SANTO e SUJO (s.d.) determinaram o coeficiente de atenuação de massa para o solo Molokai e o compararam com. valores jä publicados e atribuíram as diferenças encontradas à composição mineral do solo. Determinaram também o coeficiente de atenuação de massa da água 
fażendo as devidas correções para o tempo morto do equi pamento. Citaram que, embora o mëtodo não. seja destrutivo, possui algumas limitações, tais como ser välido somente para solos não expansivos, equipamento caro e necessidade de uma fonte de $\mathrm{Cs}-137$ de $220 \mathrm{mCi}$ de atividade. 


\section{TEORIA}

3.1. Atenuação de um feixe de radiação gama monoenergētico

0 método de atenuação da radiação gama è baseado na medida das intensidades dos feixes incidente e emergente ou seja, antes e depois dos raios gama colimados passarem atravēs de um material absorvedor. A atenuação de um feixe de radiação gama monoenergētica para uma amostra de solo seco pode ser descrita pela lei de BEER:

$$
1=1_{0} \cdot e^{-\bar{\mu}_{s} \rho x}
$$

onde:

$$
\begin{aligned}
1, I_{0}= & \text { intensidade ou taxa de contagem }(\mathrm{cpm}) \text { do feixe emergente e inci- } \\
& \text { dente, respectivamente, } \\
\bar{\mu}_{\mathrm{s}}= & \text { coeficiente de atenuação de massa }\left(\mathrm{cm}^{2} / \mathrm{g}\right) \text { para a energia gama con } \\
& \text { siderada, } \\
\rho= & \text { densidade }\left(\mathrm{g} / \mathrm{cm}^{3}\right) \text { e } \\
x= & \text { espessura }(\mathrm{cm}) \text { do solo seco. }
\end{aligned}
$$


Quando o solo for úmido e a radiação gama colimada e monoe nergētica, a equação passa a ser expressa da seguinte maneira:

$$
1=I_{0} \cdot e^{-x\left(\bar{\mu}_{s} \rho+\bar{\mu}_{a} \theta\right)}
$$

onde:

$$
\begin{aligned}
& \bar{\mu}_{a}=\text { coeficiente de atenuação de massa da ägua }\left(\mathrm{cm}^{2} / \mathrm{g}\right) \text {, } \\
& \Theta=\text { umidade volurnẻtrica }\left(\mathrm{crir}^{3} \text { de } a g \text { gua } / \mathrm{cm}^{3} \text { de solo ou } \mathrm{g} \text { de ấgual } \mathrm{cm}^{3}\right. \text { de } \\
& \text { solo) e } \\
& l, I_{0}, x, \bar{\mu}_{s} \text { e } \rho=j a ̄ \text { definidos. }
\end{aligned}
$$

Deve ser notado que as equações (1) e (2) são vālidas somente para feixes colimados de radiação gama monoenergética. Quando se têm feixes não colimados de radiação gama monoenergētica de 0,2 a 2,0 MeV, o efeito Compton se torna de grande importância e devem ser feitas correções para que tais equações sejam vālidas.

\subsection{Efeito Compton}

O efeito Compton se caracteriza pela colisão elástica de um fōton com um elétron livre (Figura 1), ocasionando uma diminuição de sua energia em função do ângulo de espalhamento. Apesar do fóton ter sua energia diminuída, poderá atingir o detector e ser contado, como os demais fōtons que não sofreram interação com o material absorvedor, acarretando um acréscimo na intensidade do feixe emergente. Tal possibilida de dependerá da geometría do sistema utillizado, da faixa de energia de de 
tecção ou faixa de amplitude do pulso elētrico adotada para o analisador monocanal.

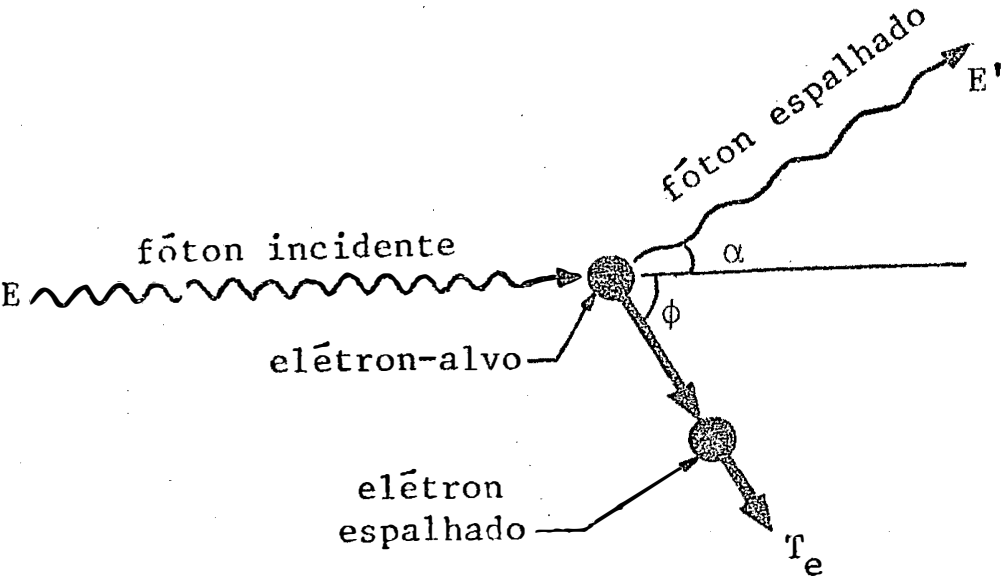

Figura 1 - Representaç̃̃o esquemätica do efeito Compton.

$E, E^{\prime}=$ energias dos fótons incidente e espalhado,

$T_{e}=$ energia cinética do elëtron ejetado,

$\phi=$ àngulo formado entre o sentido do föton incịdente e o elētron ejetado e

$\alpha=$ ângulo formado entre o sentido dos fötons incidente e espalhado.

A expressão que permite avaliar a variação do comprimento de onda e, consequientemente, a energia do fóton espalhado (KAPLAN, 1978), è:

$$
\lambda^{\prime}-\lambda=\frac{\text { hc }}{E_{0}}(j-\cos \alpha)
$$

ou

$$
E^{\prime}=\frac{E}{1+\frac{E}{E_{0}}(1-\cos \alpha)}
$$


onde:

$\lambda, \lambda^{\prime}=$ comprimento de onda do fóton incidente e espalhado, $\alpha=$ ângulo de espalhamento do föton em relação ao sentido original, $E_{0}=$ energia de repouso do elëtron $(0,511 \mathrm{MeV})$,

$\mathrm{h}=$ constante de Plank,

$c=$ velocidade da luz no văcuo $\left(3,0 \times 10^{8} \mathrm{~m} / \mathrm{s}\right)$ a

$E, E^{\prime}=$ energia do föton incidente e espalhado.

A equaçăo (4) pode ser escrita em termos de perda percentual de energia do raio gama incidente, isto é:

$$
\frac{\Delta E}{E} \cdot 100=\frac{\frac{E}{E_{0}}(1-\cos \alpha)}{1+\frac{E}{E_{0}}(1-\cos \alpha)} \cdot 100=
$$

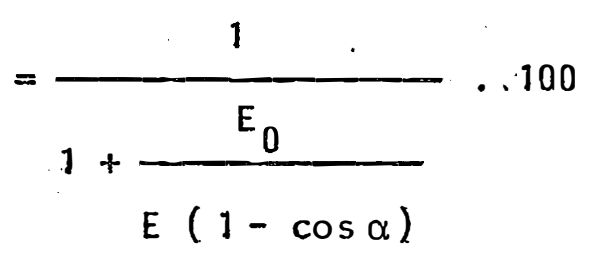

onde $\Delta E=E-E^{\prime}$.

Atravēs dessas duas ūl timas equações pode-se verificar que:

- para fótons de baixa energia, a razão $E / E_{0} \bar{e}$ muito menor que 1 e, conse qüentemente, $E^{\prime} \sim E$, isto é, a energia do fötón espalhado è quase igual 
à̀ energía do fōton incidente,

- para fótons de alta energía, a razão $E / E_{0}$ é muito maior que 1 e, conseqüentemente, $\triangle E / E \approx 3$, ocasionando quase que perda total da energia.

A energia do raio gama espalhado (equação 4) e a perda percentual de energia (equação 5) do raio gama em função do ângulo de espalhamento $(\alpha)$ são apresentadas na Figura 2 .

0 efeito Compton pode ser contornado utilizando-se um espectrômetro gama monocanal e fazendo-se a detecção do fotopico. Além desse tipo de detecção, normalmente é utilizado uma colimação no feixe emergente con a finalidade de absorver os fótons espalhados, minimizando a detecção dos raios Compton pelo si stema de contagem,

E provāvel que a eliminação do efeito Compton possa ser feita utilizando-se um espectrômetro gama monocanal com contagem no foto pico e uma colimação pobre ou, então, com um sistema detector com conta gem integral e uma colimação adequada. Esse ültimo sistema de detecção, contagem integral, è bem menos requintado do que o espectrômetró gama mo nocanal, com conseqüente facilidade de utilização por pessoal não especia lizado, alēm de ser de um custo mais acessivel. 


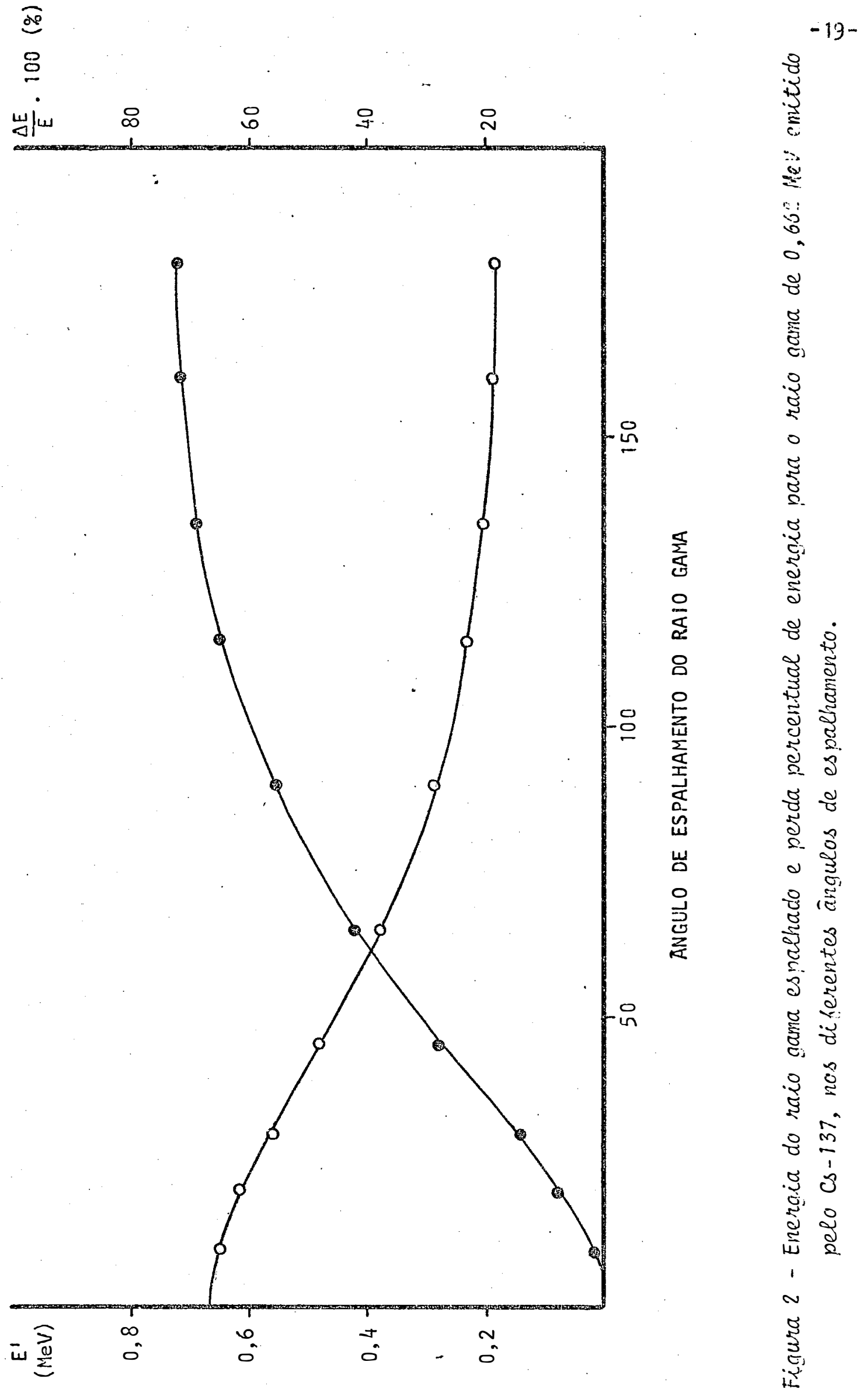




\section{MATERIAL E METODOS}

\subsection{Geometria}

Foi utilizada uma fonte radioativa emissora de raios gama de Cs-137, cujas características, segundo FERRAZ (1974), sao:

- Energia do raio gama $\ldots \ldots \ldots \ldots \ldots \ldots \ldots, 0,662 \mathrm{MeV}$

- Atividade nominal $(01 / 01 / 66) \ldots \ldots \ldots \ldots 130 \mathrm{mC}$

- Atividade atual $(01 / 03 / 79) \ldots \ldots . . .696 \mathrm{mCi}$

- Cápsula cilíndrica de aço inoxidāvel:

$$
\begin{aligned}
& \text { diâme tro externo } \ldots \ldots \ldots \ldots .66,00 \mathrm{~mm} \\
& \text { altura } \ldots \ldots \ldots \ldots \ldots \ldots . \ldots 6,00 \mathrm{~mm} \\
& \text { espessura da parede de saída } \\
& \text { do feixe } \ldots \ldots \ldots \ldots \ldots .0,80 \mathrm{~mm}
\end{aligned}
$$

- Dimensões efetivas da fonte:

$$
\begin{aligned}
& \text { diâmetro } \ldots \ldots \ldots \ldots \ldots \ldots \text { 3,00 mm } \\
& \text { al tura } \ldots \ldots \ldots \ldots \ldots \ldots \ldots 3,00 \mathrm{~mm} \\
& \text { ärea transversal ........ 7,07 } \mathrm{mm}^{2}
\end{aligned}
$$


A blindagem e colimador (Figura 3 ) são constituídas por 3 blocos de chumbo montados sobre uma base de aço de 12,5 mm de espessura, a qual encontra-se sobre um cavalete de vigas de aço em "U" de 3'", com $1,40 \times 0,60 \mathrm{~m}$ de largura. A fonte de $\mathrm{Cs}-137$ situa-se no bloco 111 , cujas dimensões são $200 \times 100 \times 200 \mathrm{~mm}$. Tanto o bloco I como o II atuam como col imadores, para fonte de $\mathrm{Cs}^{-137}$, com $4,45{\mathrm{~m} . \mathrm{I}^{2}}^{2}$ de secção reta circú lar. A distância que o feixe de raios gama percorre até atingir o detector é de $400 \mathrm{~mm}$ (FERRAZ, 1974). A amostra a ser anali isada é colocada em um suporte situado entre os blocos $r$ e rl.

$\mathrm{Na}$ desintegração do $\mathrm{Cs}-137$, meia vida de 30,23 anos, após a emissão da partícula beta de $0,511 \mathrm{MeV}$ ( $94 \%$ de intensidade de emissão), há formação do estado meta-estāvel do Ba-137m (meia vida de 2,55 minutos), passando a Ba-137 por emissão de raios gama de 0,662 MeV ou por emissão de elétrons da camada $K$ (conversão interna), com aproximadamente a mesma energia. A percentagem de decaimento por ga ma é de $84,8 \%$, enquanto que por conversão. interna, é de $9,2 \%$ (NASCIMENTO Fọ, 1977). Apōs a conversão interna, ocorre o preenchimento da lacuna da camada $K$ com a emissão de raios-X característicos de 32,19 ; 31,$82 ; 36,4$ e $37,3 \mathrm{keV}$, com intensidades relativas de $100 ; 52 ; 28$ e 6\%, respectivamente (LEDERER et alii, 1967). Por simplicidade, a energia desses raios-X será referida doravante como $32 \mathrm{keV}$. Outro proces so de desintegração do $\mathrm{Cs}_{-137}$ é por emissão de partículas $\beta^{-}$de 1,18 MeV, com intensidade de emissão de $6 \%$, decaindo diretamente a Ba-137. 

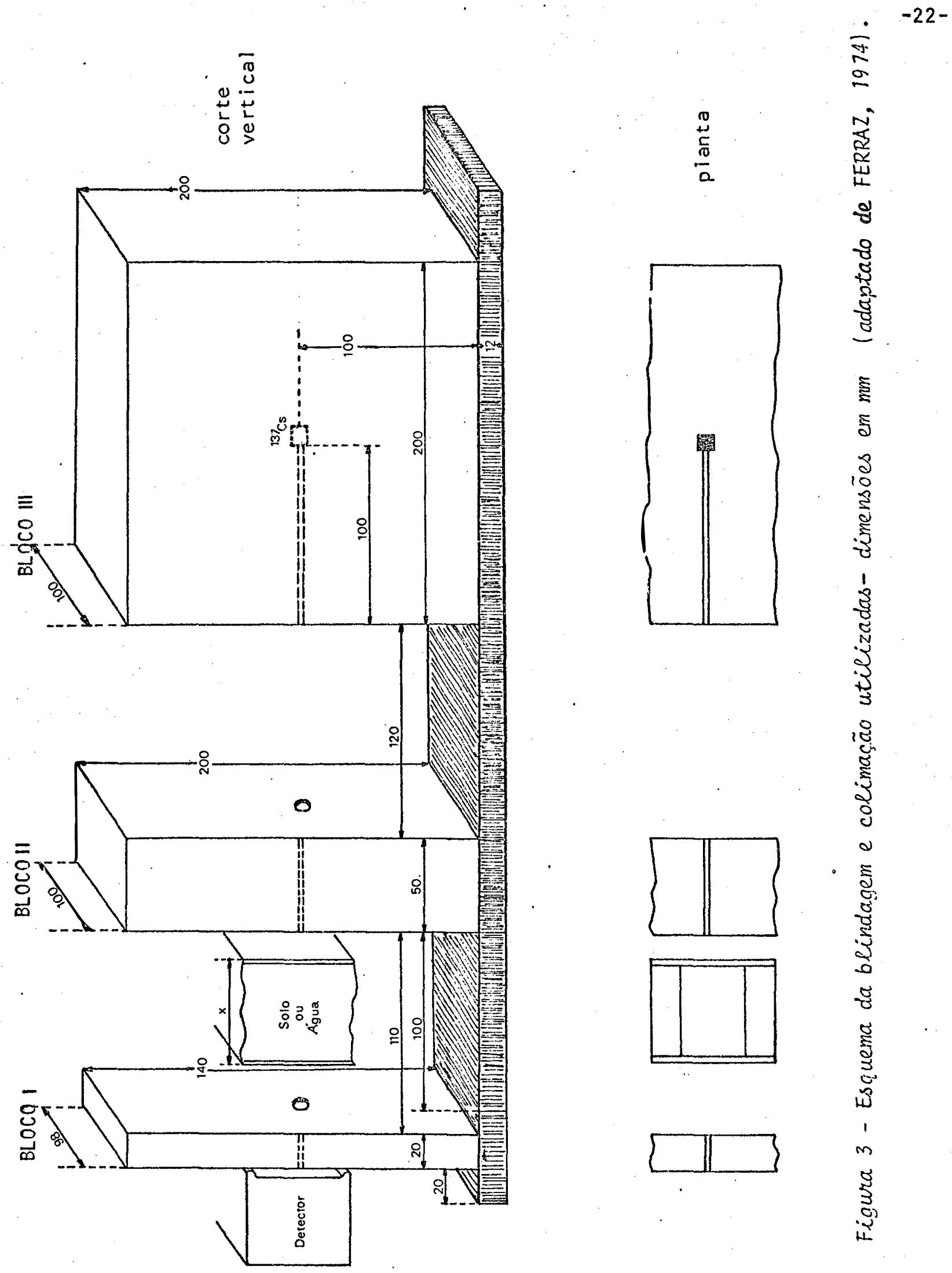
Devido à alta atividade da fonte de Cs-137, estes raios-X emitidos poderiam ser detectados no sistema Nuclear Chicago de contagem integral, onde o discriminador de entrada é de 0,25 volts, podendo ocasio nar desvios na lei de BEER, principalmente na região de baixa densidade superficial. Conforme BERRY (1961), o coeficiente de atenuação de massa do ferro, para uma energía de $30 \mathrm{keV}$, ē de $8,0 \mathrm{~cm}^{2} / \mathrm{g}$, e como a cápsula ra dioativa tem uma espessura de aço inoxidável na janela de saída do feixe de $0,8 \mathrm{~mm}$, a transmíssão desses raios $-X$ de $32 \mathrm{keV}$ ë da ordem de $0,7 \%$.

Na tentativa de se eliminar totalmente este raio-X de 32 keV, na saída do feixe de radiação do bloco 111 , foi colocada uma pequena lâmina de $\mathrm{Pb}$, de $3,175 \mathrm{~mm}$ de espessura. A transmissão dessa lâmina de $\mathrm{Pb}$ para a energia de $32 \mathrm{keV}$ è da ordem de $10^{-37 \%}\left(\bar{\mu}=25 \mathrm{~cm}^{2} / \mathrm{g}-\mathrm{BERRY}\right.$, 1961), enquanto que para o raio gama de $0,662 \mathrm{MeV}$, a transmissão é de $67,4 \%\left(\bar{\mu}=0,11 \mathrm{~cm}^{2} / \mathrm{g}-\mathrm{BERRY}, 1961\right)$.

A lēm da função de se eliminar o raio-x de $32 \mathrm{keV}$, esta lâmina teria tambēm a função de barrar os raios gama retro-espalhados pelo efei to Compton dentro da blindagem.

\subsection{Equipamentos e detecção}

Para detecção das radiações gama foram montados dois siste mas constituídos de:

a) Conjunto Nuclear Chicago (NC8770), com cristal cintilador de Nal(TI) de $1 \times 1{ }^{\prime \prime}$, tipo plano, acoplado a uma vālvula fotomulti- 
pli cadora (N.C. - sẹrie 009786), comandado por um cronômetro digital.

b) Espectrômetro gama monocanal:

- cristal cintilador de $\mathrm{Nal}(\mathrm{T} 1)$ de $3 \times 3^{\prime \prime}$, tipo plano, acoplado à vālvula fotomultiplicadora (Harshaw Chemical Company, modelo $12 \mathrm{~S} 12 / 3$, sērie GW 422),

- diviror de tensão e prē-amplificador (ORTEC, modelo 276),

- fonte de alta voltagem (HP, modelo 6516 DC);,

- ampli;icador/analisador monocanal (ORTEC, modelo 490 B),

- contador de pulsos (ORTEC, modelo 775) e

- relógio eletrônico (ORTEC, modelo 719).

Antes de se iniciar as leituras no sistema Nuclear Chicago determinou-se o valor da alta voltagem de operação, a fim de detectar o maior número possível de pulsos eletrônicos, devido à interação da radiação gama com o cristal cintilador. Para isso, levantou-se a curva de ta xa de contagem do feixe de raios gama em função da alta voltagem aplicada à fotomultiplicadora. $\quad 0 s$ dados obtidos encontram-se na Tabela 1 , e são mostrados na Figura 6. A voltagem de operação escolhida foi de $900 \mathrm{~V}$.

Para esse sistema, as amostras de solo seco foram colocadas em um suporte de plástico entre os blocos I e II (Figuras 4 e 5). Lo go na saída do feixe de raios gama do bloco 111 , foi colocada a lâmina de Pb de 3,175 mm de espessura e, para cada amostra, efetuadas uma série de 10 determinações de 1 minuto, em diferentes posições, e outra série sem a lâmina de Chumbo. 


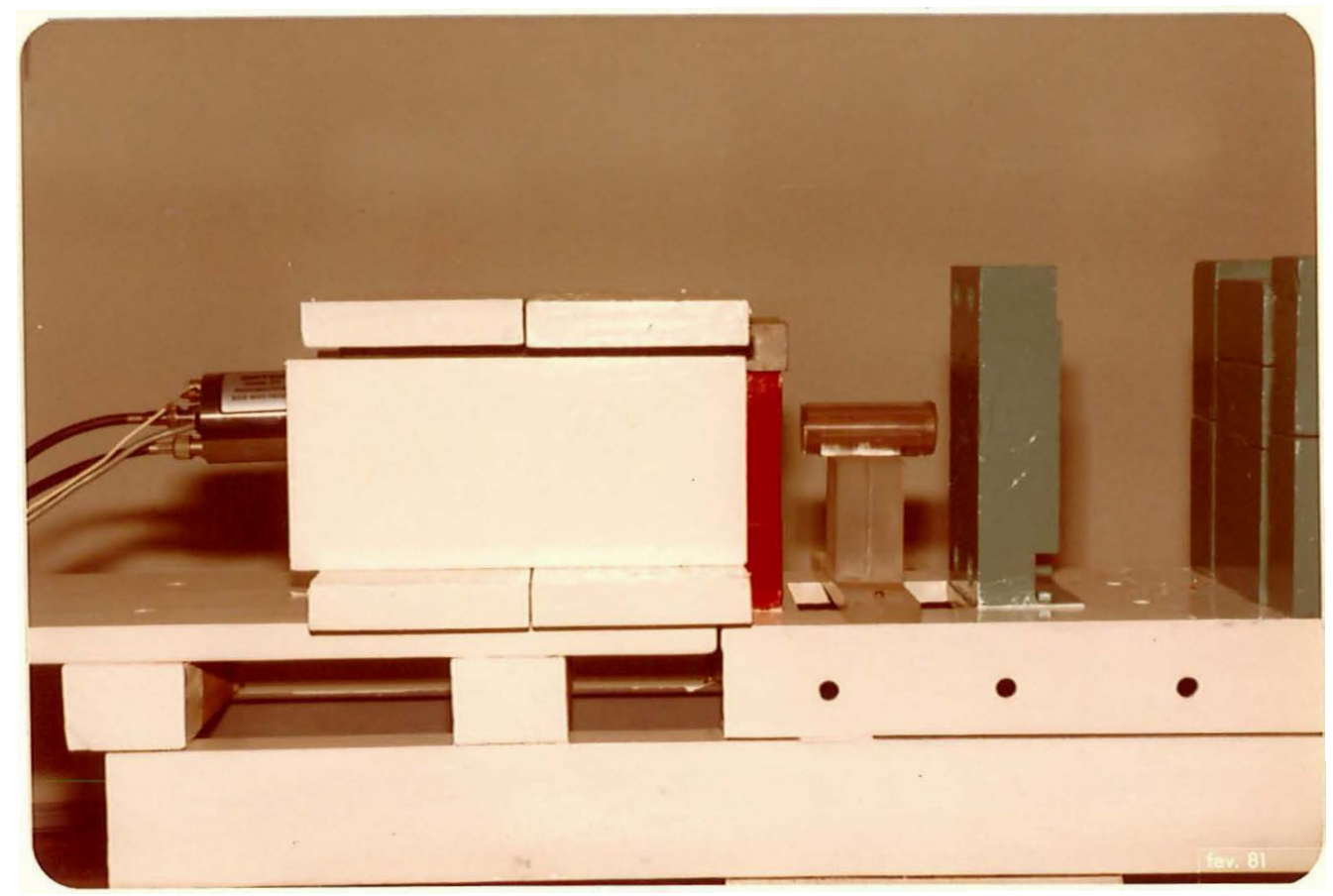

Figura 4 - Detalhe do posicionamento da amostra para anälise.

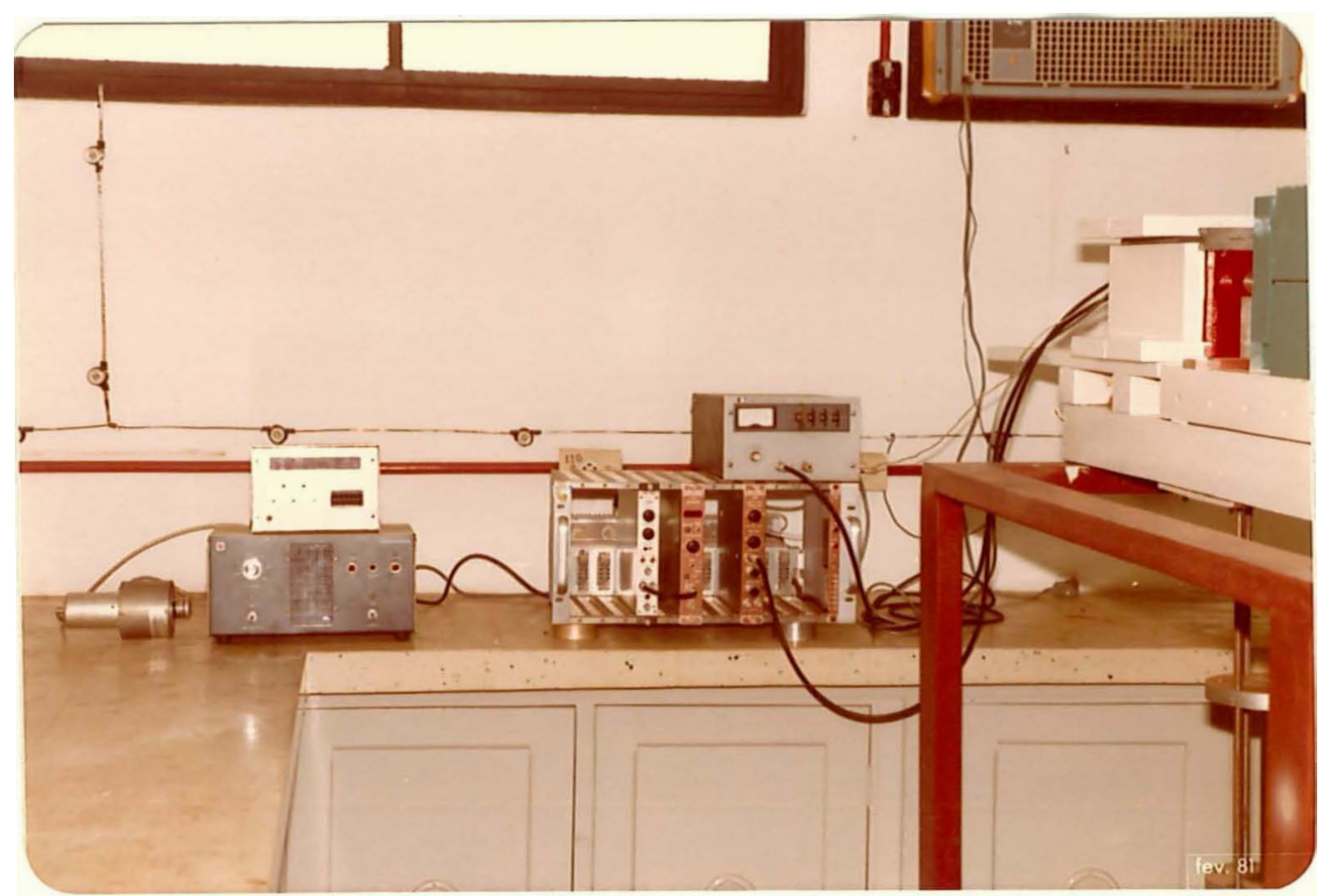

Figura 5 - Vista geral do equipamento utilizado; à direita, espectrômetro gama e à esquerda o sistema Nuclear. Chicago. 
Tabela 1 - Taxa de contagem do feixe de raios gama em função da alta voltagem aplicada à vālyula fotomultiplicadora do sistema Nuclear Chicago.

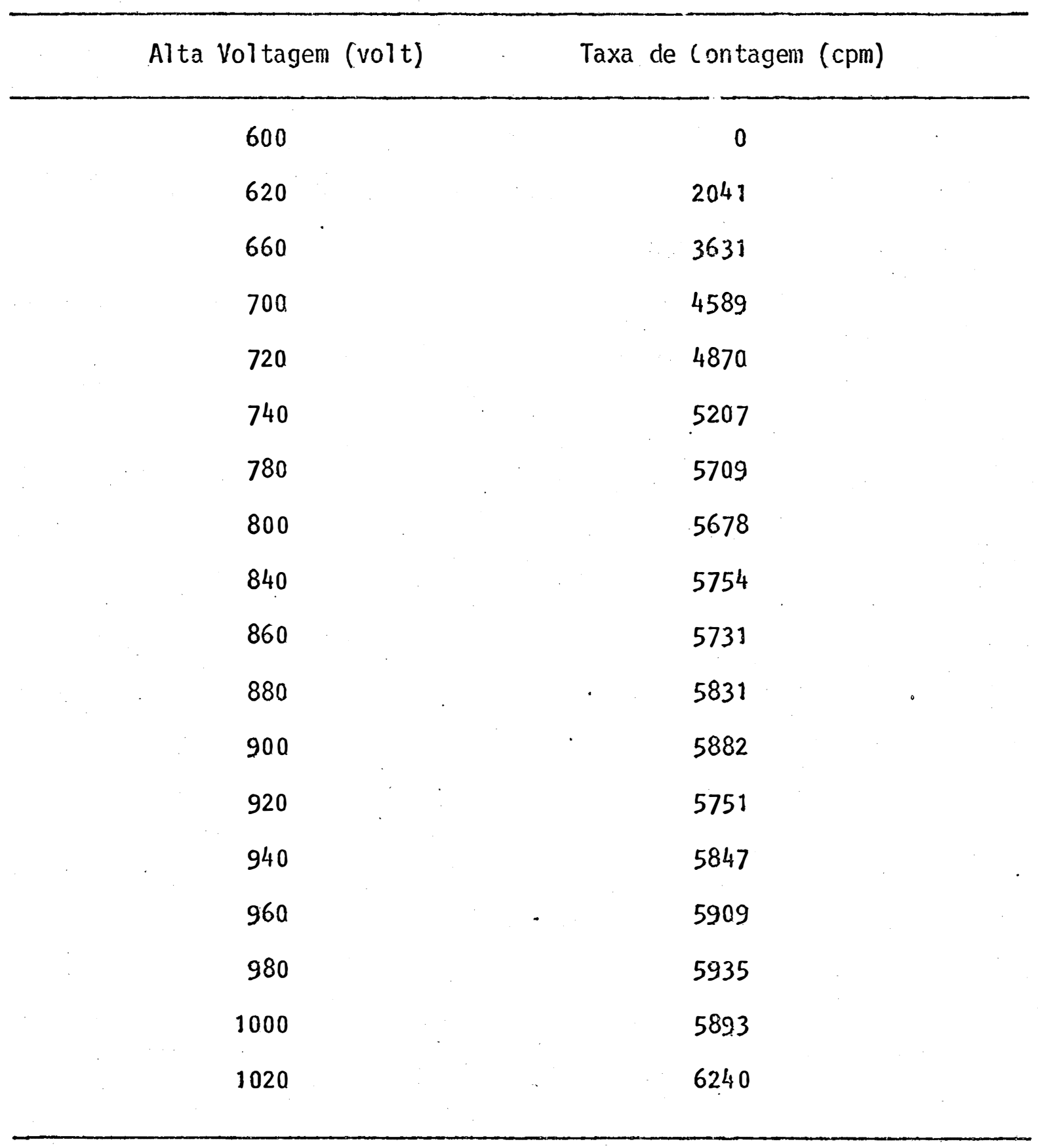




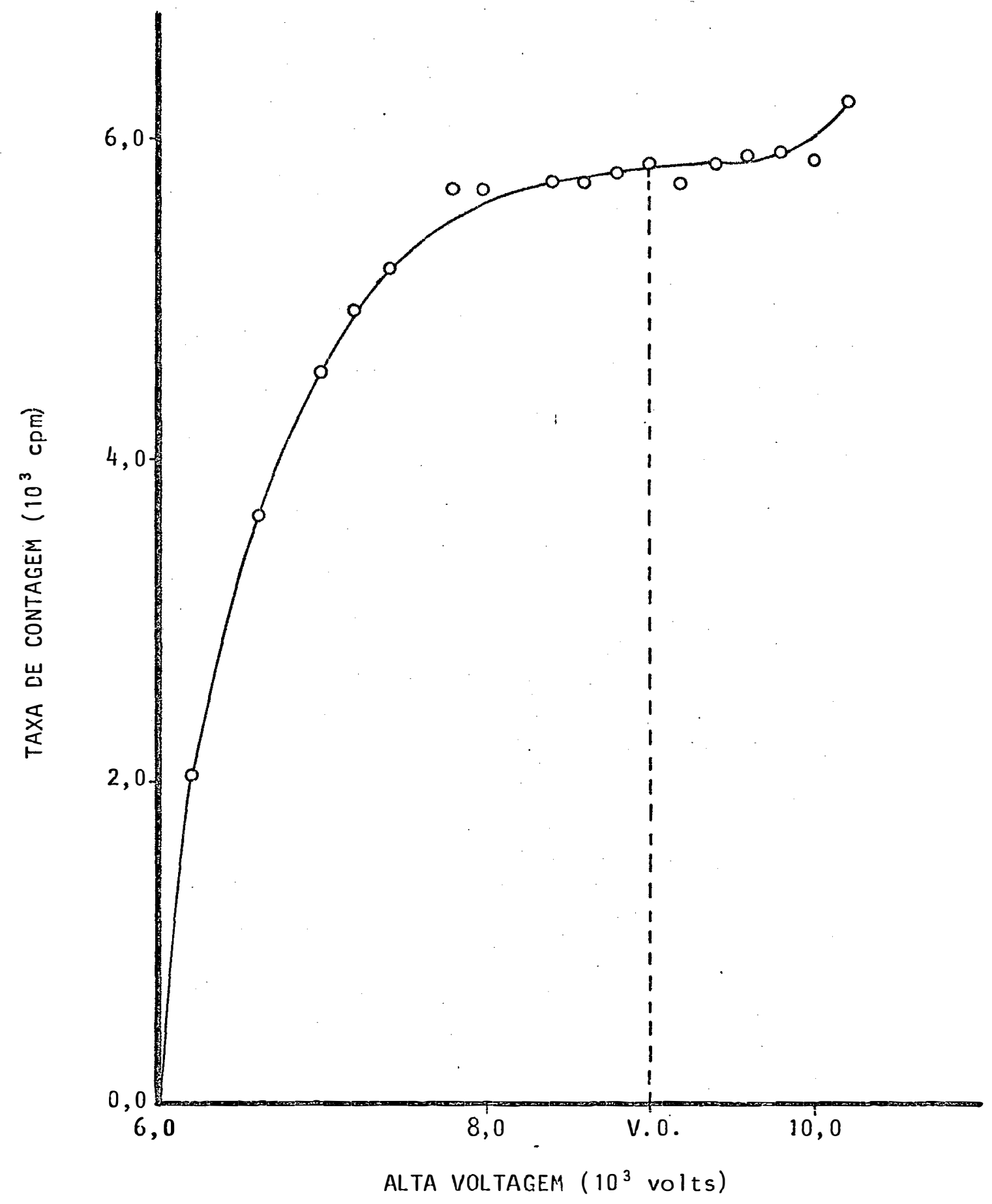

Fiqura 6 - Curva para obtenção da alta voltanem de operação $(V .0$.$) do sis-$ tema Nuclear Chicago, para os raios riama do Cs-137. 
Para o sistema gama monocanal levantou-se inicialmente o espectro de pulsos dos raios gama do $\mathrm{Cs}-137$, para um fundo de escala de 1,0 MeV (Figura 7). Fixando-se também o tempo em um minuto, foram efetuadas as contagens para duas situações distintas do espectrômetro gama monocanal: uma denominada de contagem integral (base $=1,0 \mathrm{~V}$ e janela $=$ 9, a V) e outra denominada de contagem no fotopico (base $=5,9 \mathrm{~V}$ e janela $=$ 1,4 v). Para essas duas situações as leituras foram efetuadas com e sem a lâmina protetora de $\mathrm{Pb}$, tambëm numa sērie de 10 determinações em diferentes posições.

Portanto, foram utilizados 6 tratamentos distintos, assim denominados:

Tratamento $1\left(T_{1}\right)$ - sistema Nuclear Chicago, cristal cintilador de Nal (TI), $1 \times 111$, tipo plano, com proteção de chumbo,

Tratamento $2\left(T_{2}\right)$ - idem, sem proteção de chumbo,

Tratamento $3\left(T_{3}\right)$ - sistema espectrômetro gama monocanal, cristal cintila dor de $\mathrm{Nal}(\mathrm{Tl}), 3 \times 3^{\prime \prime}$, tipo plano, contagem integral, com proteção de chumbo,.

Tratamento $4\left(\mathrm{~T}_{4}\right)$ - idem, sem proteção de chumbo,

Tratamento $5\left(\mathrm{~T}_{5}\right)$ - sistema espectrômetro gama monocanal, cristal cintila dor de $\mathrm{Nal}(\mathrm{TI}), 3 \times 3^{\prime \prime}$, tipo plano, contagem no foto pi co, com proteção de chumbo,

Tratamento $6\left(\mathrm{~T}_{6}\right)$ - idem, sem proteção de chumbo,

Para os tratamentos 3 e 4, a alta voltagem utilizada foi de 900 volts, ganho grosso 32 vezes e ganho fino de 6,6 vezes. Jà para 


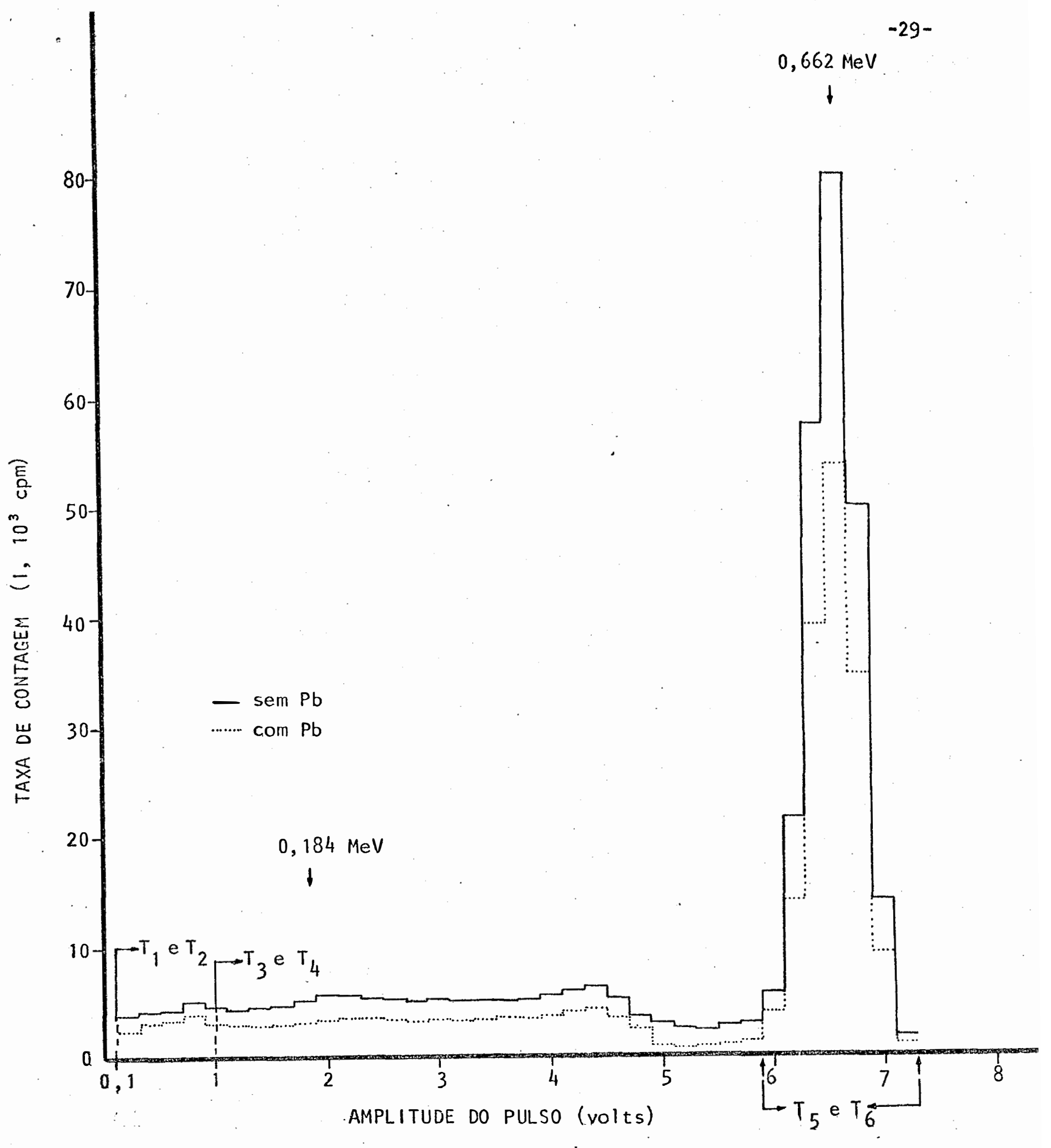

Figura 7 - Espectro de pulsos eletrónicos devido aos raios gama de Cs-137 abtidos com e sem a lâmina de $\mathrm{Pb}$ na saỉda do feixe do bloco III. 
os tratamentos 5 e 6 houve variações no ganho fino devido ao deslocamento do fotopico, enquanto que os outros thens permaneceram constantes.

Em todos os tratamentos a temperatura da sala foi mantida em $22 \pm 2^{\circ} \mathrm{C}$.

\subsection{Correção do tempo morto}

Segundo FERRAZ (1974), o tempo morto obtido para espectrômetro monocanal foi de 5,02 $\mathrm{s}$. Utilizando-se desse valor na equação (6), pôde-se determinar que para a menor taxa de contagem do feixe obtido neste trabalho $(140.000 \mathrm{cpm})$, o acréscimo devido ao tempo morto não chega a $1 \%$, enquanto que para a maior taxa $(360.000 \mathrm{cpm})$, atinge a casa dos $3 \%$.

$$
1=\frac{11}{1-11 \tau}
$$

onde:

$$
\begin{aligned}
\mathbf{I}^{\prime}, \mathbf{I} & =\text { taxas de contagem (cpm) obtida e corrigida, respectivamente, } \\
\tau & =\text { tempo morto (minuto). }
\end{aligned}
$$

Como essa correção é relativamente pequena, optou-se pela não correção do tempo morto nas leituras das taxas de contagem. Além disso, utilizou-se o logarítmo da taxa de contagem, tornando essa correção insignificante.

0 acréscimo, em termos percentuais, na taxa de contagem devido ao tempo morto depende do valor desta taxa. Quanto menor o valor 
da taxa de contagem, menor serä o acréscimo percentual. A lâmina de chum bo de $3,175 \mathrm{~mm}$, alēm da finalidade de absorver os raíos-X de $32 \mathrm{keV}$ do Ba-137, como visto anterior mente, pode ser util izada com a finalidade de se diminuir a intensidade do feixe incidente da radiação gama.

\subsection{Tipos de solos e preparação das amostras}

Foram utilizados 10 diferentes tipos de solo (Tabela 2).

Tabela 2 - Relação dos solos estudados com as respectivas siglas e hori zontes.

\begin{tabular}{llr} 
Sigla & \multicolumn{1}{c}{ Solo } & Horizonte (cm) \\
\hline PVA & Podzölico Vermelho Amarelo & $0-30$ \\
PM & Podzolisado de Lins e Marilia, var. Marilia & $0-30$ \\
LVE & Latosolo Vermelho Escuro & $0-30$ \\
TRE & Terra Roxa Estruturada (ESALQ) & $0-30$ \\
LR & Latossol Roxo & $0-30$ \\
R & Regosol (Cerrado) & $0-30$ \\
TRE-1 & Terra Roxa Estruturada (Jaboticabal) & $0-30$ \\
TRE-2 & Terra Roxa Estruturada (Jaboticabal) & $30-60$ \\
TRE-3 & Terra Roxa Estruturada (Jaboticabal) & $60-90$ \\
TRE-4 & Terra Roxa Estruturada (Jaboticabal) & $90-120$ \\
& &
\end{tabular}


Primeiramente, o solo foi seco ao ar, destorroado em pene ra de $2 \mathrm{~mm}$ e depois seco, posteriormente, em estufa a $105^{\circ} \mathrm{C}$, por 24 horas. Foram utilizados 3 tubos plásticos para a colocação das amostras de solo, cujas características encontram-se na Tabela 3.

Tabela 3 - Caracterīsticas dos tubos plāsticos utilizados para colocação das amostras de solo.

\begin{tabular}{ccc}
\hline Diämetro $(\mathrm{cm})$ & Altura $(\mathrm{cm})$ & Area $\left(\mathrm{cm}^{2}\right)$ \\
\hline 2,50 & 3,40 & 4,9087 \\
2,90 & 5,90 & 6,6052 \\
2,90 & 7,20 & 6,6052 \\
\hline
\end{tabular}

Para cada tipo de solo foram preparadas 6 amostras, colocando-se o solo nos tubos plásticos com e sem compactação manual. Atravēs dessas compactações, conseguiu-se variações na densidade de 1,0 atē aproximadamerite $1,4 \mathrm{~g} / \mathrm{cm}^{3}$.

Para as amostras de água foram utilizados 5 tubos plästicos, sendo um de cada tamanho, alēm de uma testemunha, cujas características são mostradas na Tabela 4.

Depois de vedados os tubos com uma tampa fixa de polietile no, foram feitos 2 orifícios laterais para a injeção da água destilada. Para cada amostra, realizaram-se 4 determinações em diferentes pontos, tirando-se a mëdia aritmëtica. 
Tabela 4 - Características dos tubos plásticos utilizados para colocação das amostras de āgua.

\begin{tabular}{cccc}
\hline Tubo $(\mathrm{n} 0)$ & Diâmetro $(\mathrm{cm})$ & Altura $(\mathrm{cm})$ & Area $\left(\mathrm{cm}^{2}\right)$ \\
\hline 1 & 2,5 & 3,4 & 4,9087 \\
2 & 2,9 & 5,9 & 6,6052 \\
3 & 2,5 & 6,8 & 4,9087 \\
4 & 2,9 & 7,2 & 6,6052 \\
5 & 2,9 & 9,3 & 6,6052 \\
$T$ & 2,5 & 3,4 & 4,9082 \\
\hline
\end{tabular}

4.5. Dęteminação do coefíciente de atenuação de massa

Linearizando-se a equação de BEER (equação 1) da atenuação de um feixe de raios gama monoenergético e colimado, tem-se:

$$
\ln 1=\ln I_{0}-\bar{\mu} \rho x
$$

ou

$$
\ln 1=\ln 1_{0}-\overline{\mu^{x}}
$$

onde $\bar{x}=\rho x=$ densidade superficial $\left(\mathrm{g} / \mathrm{cm}^{2}\right)$. 
Correlacionando-se o logarítmo natual das intensidades mé dias do feixe emergente $(\ln 1)$ com as densidades superficiais $(\bar{x})$ do absor vedor, tem-se que o coeficiente angular da reta $\ln 1$ vs $\bar{x}$ é o coeficiente de atenuação de massa daquele absorvedor.

Devido a possíveis erros ocasionados pela não correção do tempo morto, as taxas de contagem do feixe de radiação gama para densidade superficial nula $(x=0)$ não foram utilizadas nas regressões para est mativa dos coeficientes lineares e angulares e, consequentemente, para ob tenção do coeficiente de atenuação de massa dos solos e da ãgua.

Para se verificar se os coeficientes de atenuação de massa obtidos diferem estatisticamente para os diversos solos, em um mesmo tratamento, fez-se o contraste através do teste "t" (STEEL e TORRIE, 1960). Verificou-se, também, através do teste "t", se o coeficiente de atenuação de massa geral (dos 10 solos) diferem estatisticamente nos diversos trata mentos.

Para ăgua, foi verificado se os coeficientes de atenuação de massa obtidos diferem estatisticamente para os diferentes tratamentos, pelo mesmo teste estatístico. 


\section{RESULTADOS}

5.1. Coeficientes de atenuação de massa para solos

0s valores médios da intensidade do feixe emergente para 10 posições distintas em cada amostra de solo, nos diferentes tratamentos, bem como os valores da densidade superficial, encontram-se no Apêndice 1. Esses dados são também mostrados graficamente nas Figuras 8 a 17 .

Os valores obtidos para os coeficientes lineares ( $\left.\ln 1_{0}\right)$ e angulares $(\bar{\mu})$ das retas, bem como seus desvios padrões e coeficientes de correlação para cada tratamento e diferentes solos, encontram-se nas Tabe las 5 a 10: Na Tabela 11 e Figura 18 encontram-se os valores dos coeficientes de atenuação de massa para os diferentes solos, em cada tratamento.

Os contrastes obtidos através do teste estatístico encontram-se nos Apêndices 2 a 7, para o mesmo solo e diferentes tratamentos e no Apêndice 8 estão os contrastes para os coeficientes de atenuação de massa geral (10 solos) para os diversos tratamentos. 


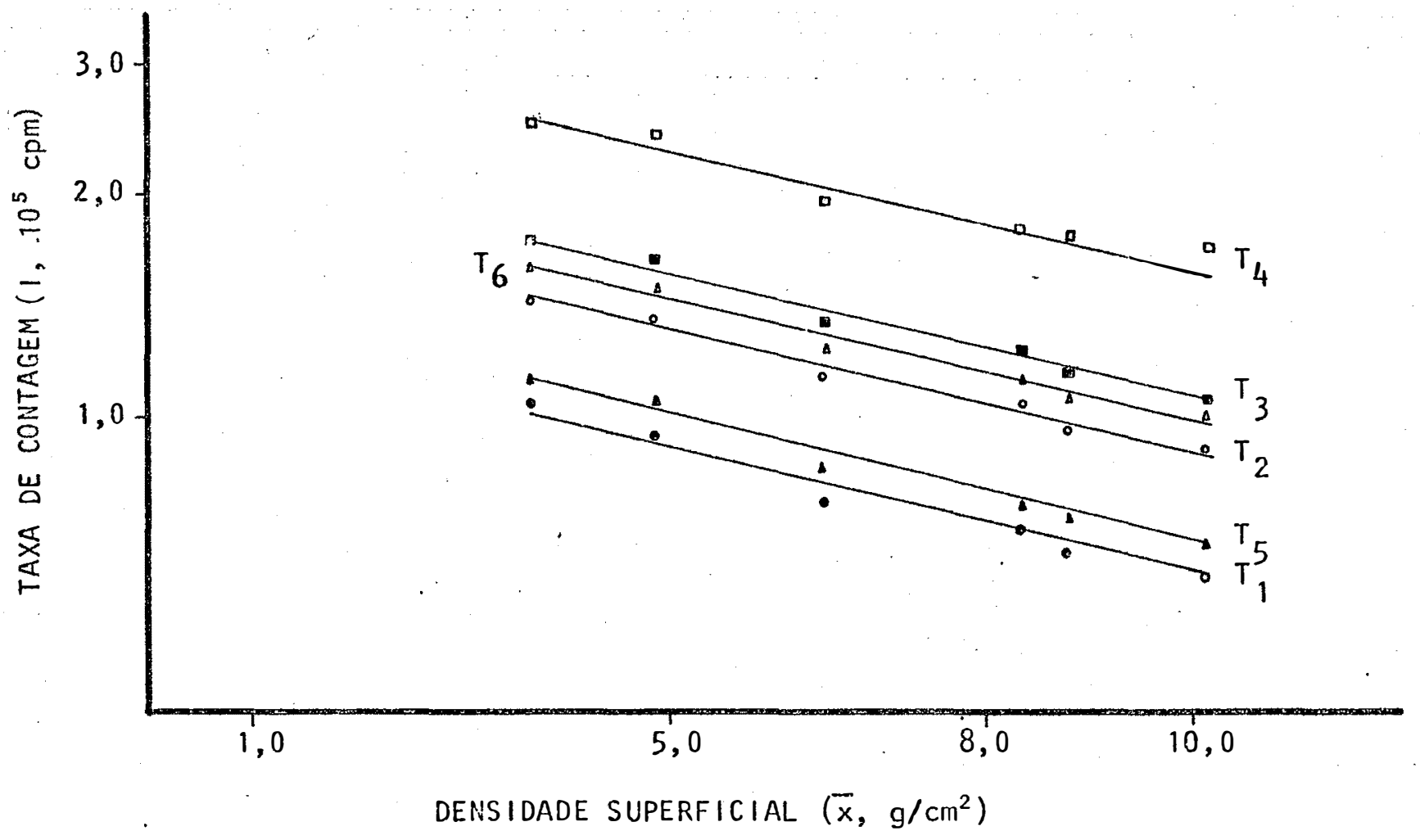

Figura 8 - Curvas de taxa de contagem do feixe emergente em função da densidade superficial para determinação do coeficiente de atenuação de massa do solo Podzol Vermelho Amarelo, nos diversos tratamentos. 


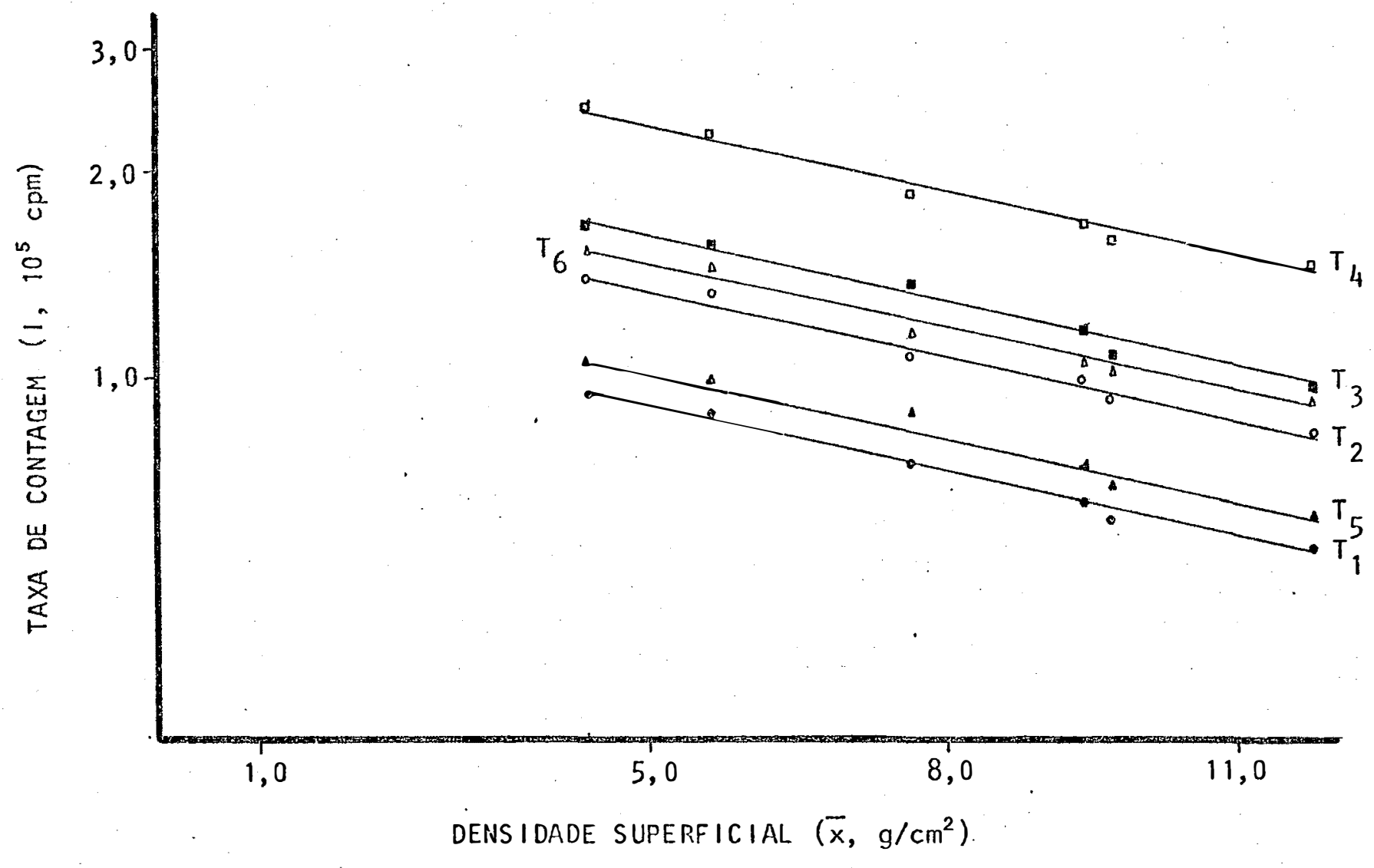

Figura 9 - Curvas de taxa de contagem do feixe emernente em função da densidade superficial para determinação do coeficiente de atenuação de massa do solo Podzolisado var. Marilia, nos diversos tratamentos. 


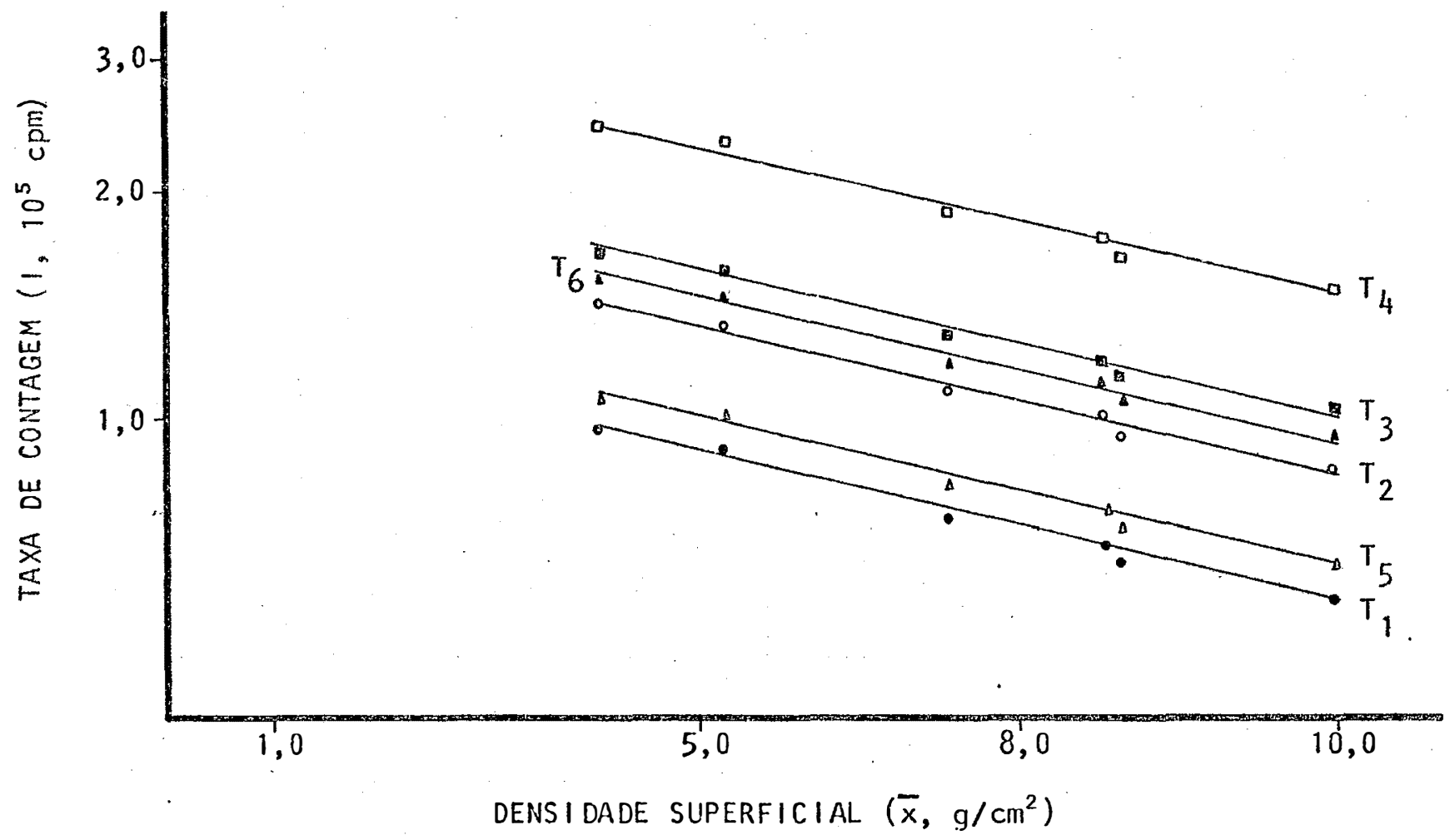

Figura 10 - Curvas de taxa de contagem do feixe emergente em função da densidade superficial para determinação do coeficiente de atenuação de massa do solo Latasol Vermel'o Escuro,nos diversos tratamentos. 


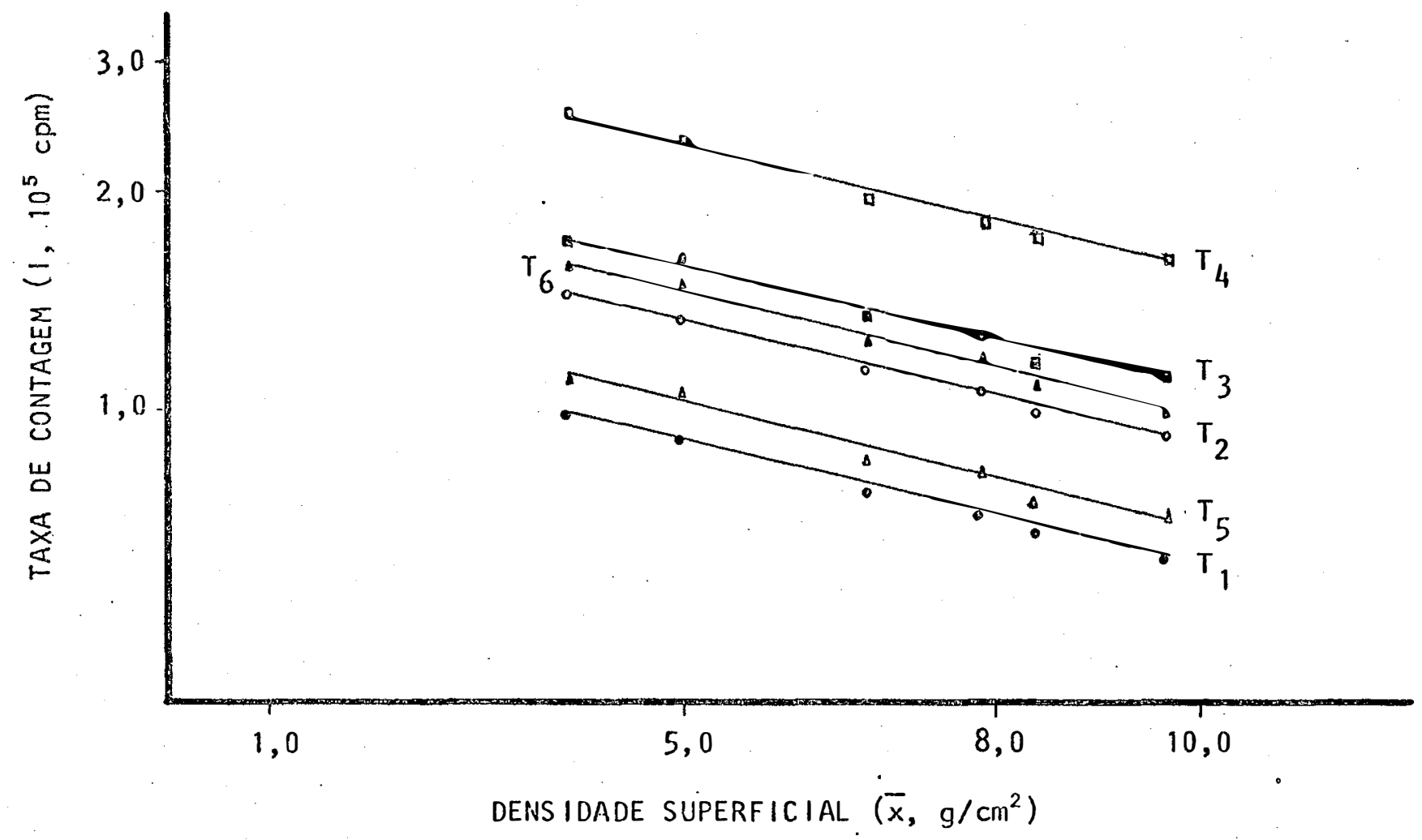

Figura 11 - Curvas de taxa de contagem do feixe emergente em funçäo da densidade superficial para determinação do cóeficiente de atenuação de massa do solo Terra Roxa Estruturada (ESALQ), nos diversos tratamentos. 


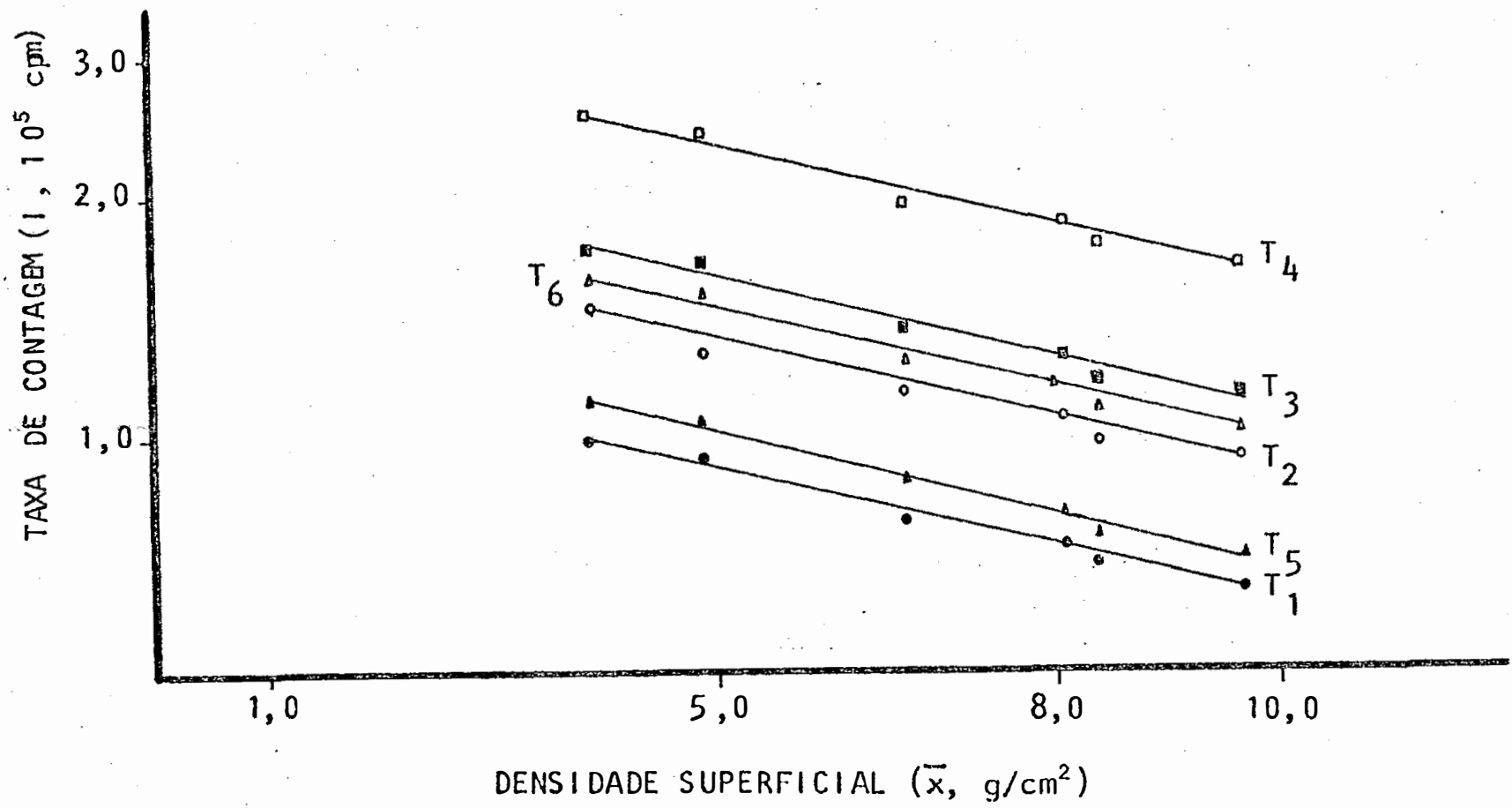

Figura 12 - Curvas de taxa de contanem do feixe emergente em função da densidade superficial para determinação do coeficiente de atenuação de massa do solo latosol Roxo, nos diversós tratamentos. 


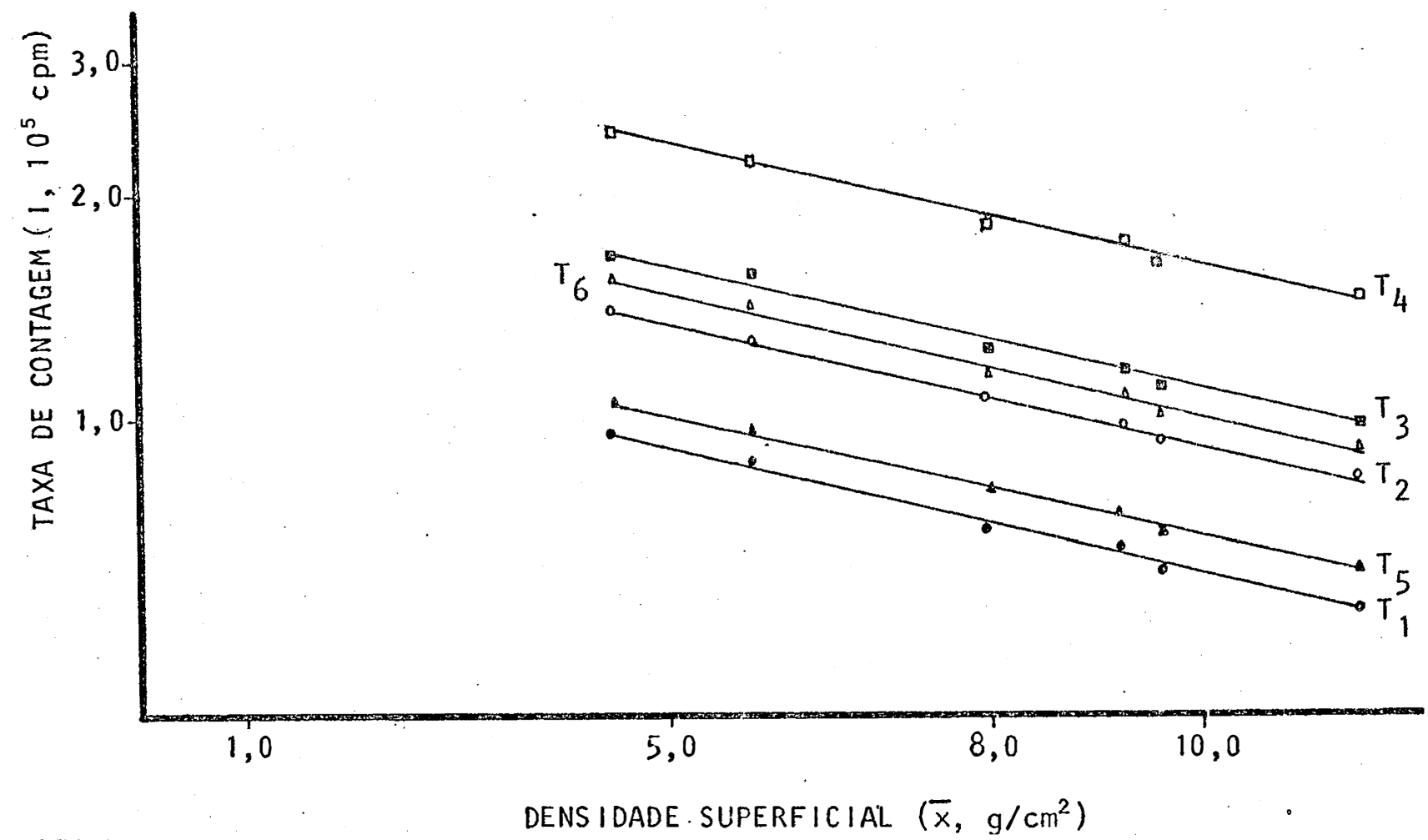

Fiaura 13 - Curvas de taxa de contagem do fjeixe emergente em função da densidade superficial para determinação do coeficiente de atenuação de massa do solo Regosol. (Cerrado), nos diversos tratamentos. 


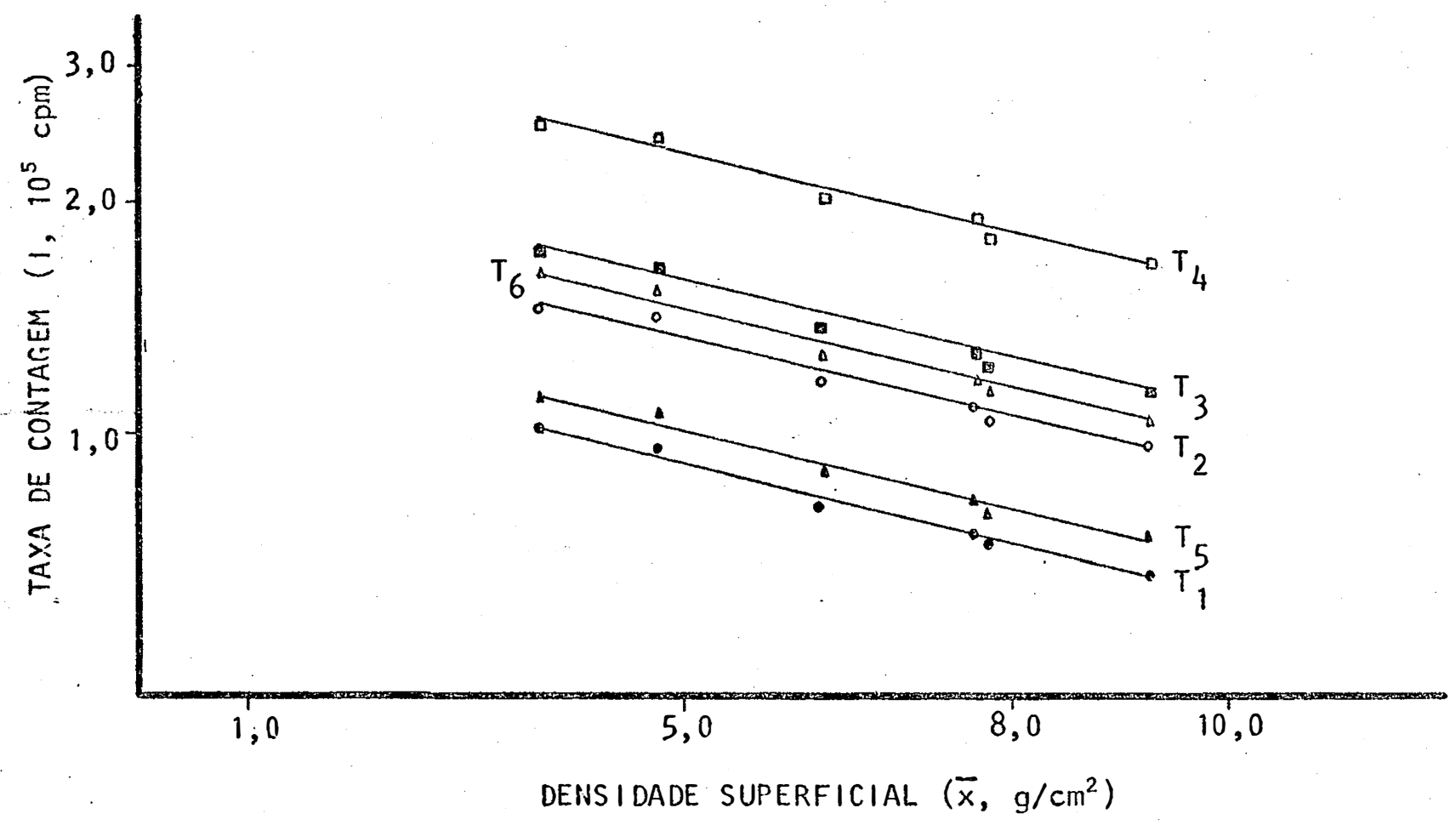

Figura 14 - Curvas de taxa de contagem do feixe emergente ein função da densidade superficial para determinação do coeficiente de atenuação de massa do solo Terra Roxa Estruturada (Jaboticabal-horizonte $0-30 \mathrm{~cm}$ ), nos diversos tratamentos. 


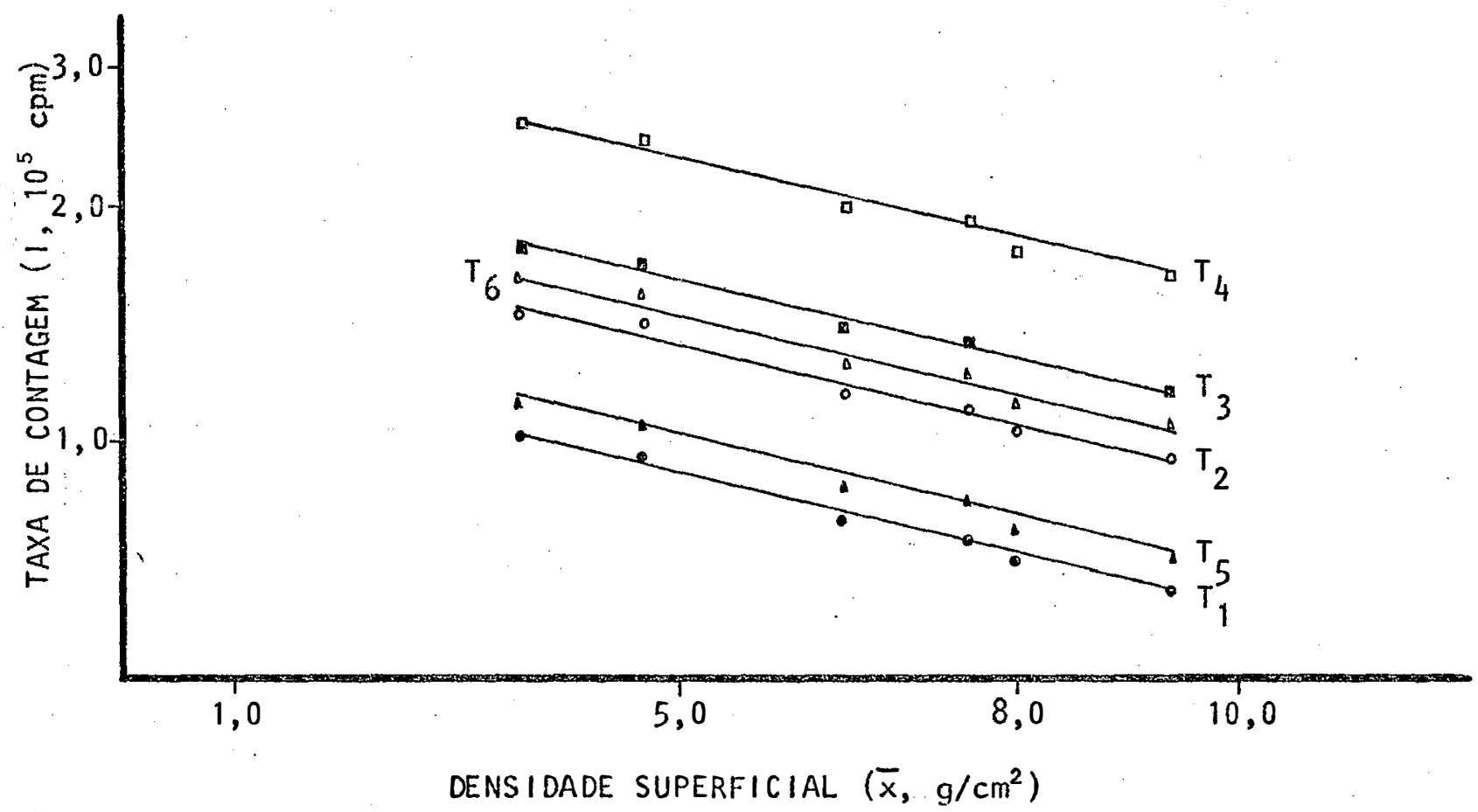

Figura 15 - Curvas de taxa de contagem do feixe emergente em função da densidade superficial para determinação do coeficiente de atenuação de massa do solo Terra Roxa Estruturada (Jaboticabal-horizonte $30-60 \mathrm{~cm}$ ), nos diversos tratamentos. 


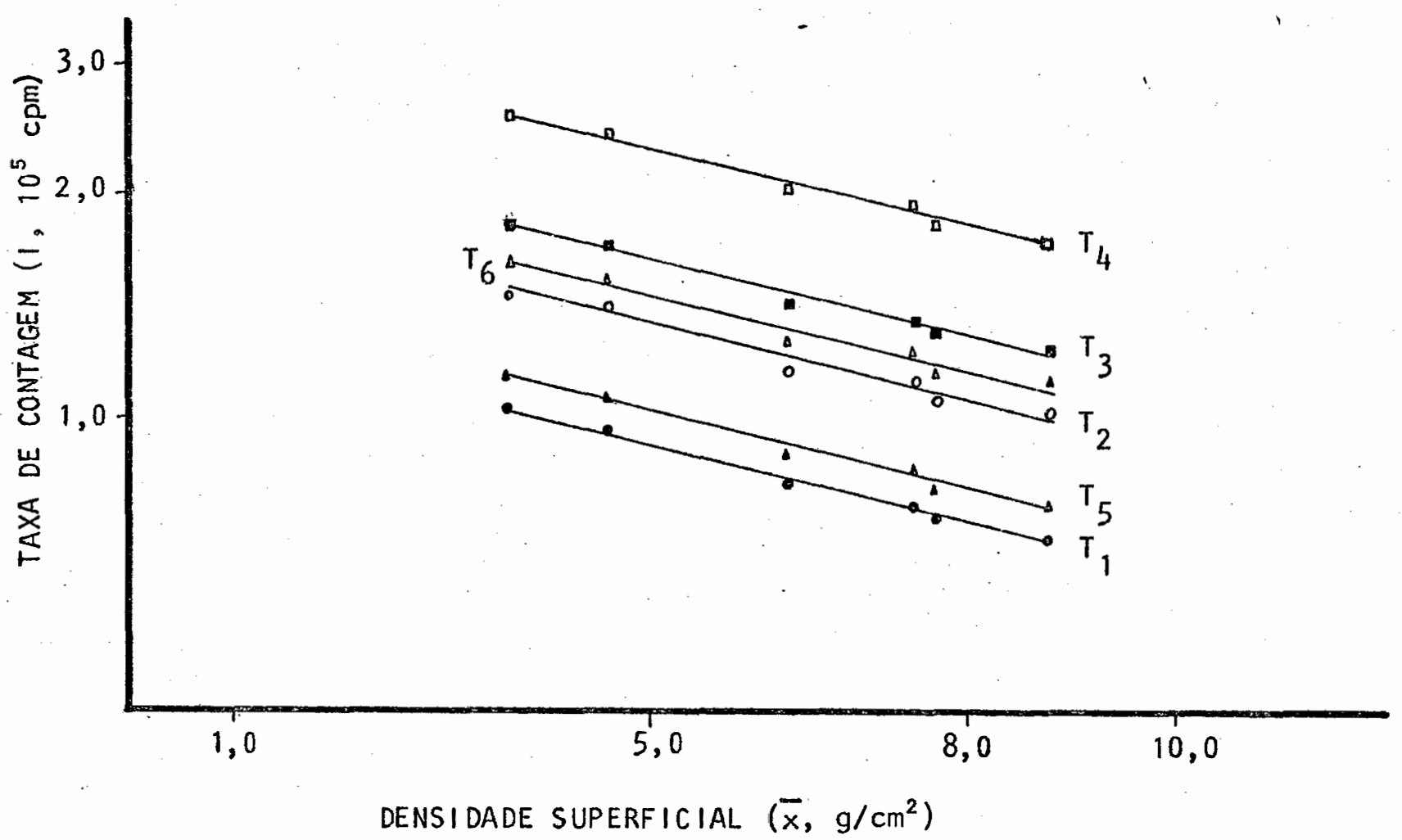

Figura 16 - Curvas de taxa de contagem do feixe emergente em função da densidade superficial para determinação do: coeficiente de atenuação de massa do solo Terra Roxa Estruturada (Jaboticabal-horizonte $60-90 \mathrm{~cm}$ ), nos diversos tratamentos. 


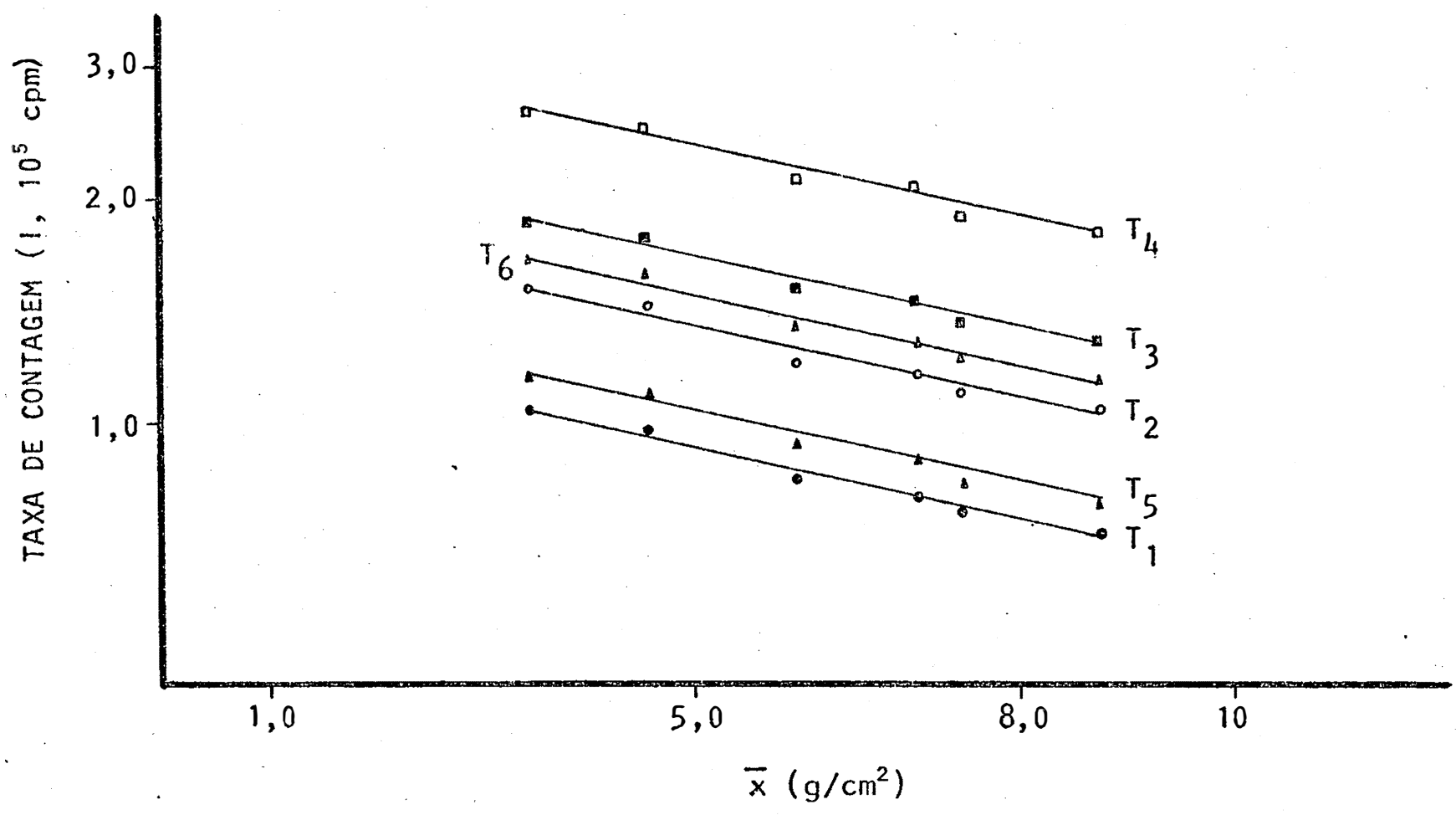

Figura 17 - Curvas de taxa de contagem do feixe emergente em funçäo da densidade superficial para determinação do coeficiente de atenuação de massa do solo Terra Roxa Estruturada (Jaboticabal-horizonte $90-120 \mathrm{~cm}$ ), nos diversos tratamentos. 
Tabela 5 - Coeficientes lineares ( $\ln \mathrm{I}_{0}$ ) e angulares $(\bar{\mu})$, respectivos des vios padrões (s) e coeficiente de correlação ( $r$ ) para o trata mento 1 (Nuclear Chicago com proteção de $\mathrm{Pb}$ ), para os diferen tes solos.

\begin{tabular}{lccccc}
\hline Solo & $\ln \mathrm{I}_{0}$ & $\bar{\mu}\left(\mathrm{cm}^{2} / \mathrm{g}\right)$ & $\mathrm{s} \ln \mathrm{I}_{0}$ & $\bar{s}\left(\mathrm{~cm}^{2} / \mathrm{g}\right)$ & $r^{1}$ \\
\hline PVA & 11,806047 & 0,077639 & 0,046516 & $n, 006270$ & $-0,987209$ \\
PM & 11,801076 & 0,076236 & 0,042631 & 0,005007 & $-0,991483$ \\
LVE & 11,806705 & 0,076837 & 0,043470 & 0,005468 & $-0,990020$ \\
TRE & 11,815725 & 0,077315 & 0,023345 & 0,003217 & $-0,996556$ \\
LR & 11,822012 & 0,078174 & 0,025942 & 0,003577 & $-0,995838$ \\
R & 11,824835 & 0,078055 & 0,030377 & 0,003607 & $-0,995757$ \\
TRE-1 & 11,826507 & 0,079464 & 0,031536 & 0,004593 & $-0,993385$ \\
TRE-2 & 11,826196 & 0,078953 & 0,029200 & 0,004213 & $-0,994353$ \\
TRE-3 & 11,827125 & 0,079439 & 0,021517 & 0,003228 & $-0,996715$ \\
TRE-4 & 11,820149 & 0,077917 & 0,025282 & 0,003873 & $-0,995095$ \\
\hline Geral & 11,816967 & 0,077928 & 0,009236 & 0,001248 & $-0,992642$ \\
\hline & & & & & \\
\hline
\end{tabular}

1- significativo a $0,1 \%$ 
Tabela 6 - Cofeficientes lineares ( $\ln \mathrm{I}_{0}$ ) e angulares $(\bar{\mu})$, respectivos des vios padrões e coeficiente de correlação $(r)$ para o tratamento 2 (Nuclear Chicago sem protetor de Pb), para os diferentes so10s.

\begin{tabular}{lccccc}
\hline Solo & $\ln \mathrm{I}_{0}$ & $\bar{\mu}\left(\mathrm{cm}^{2} / \mathrm{g}\right)$ & $\mathrm{s} \ln \mathrm{I}_{0}$ & $\bar{s} \bar{\mu}\left(\mathrm{cm}^{2} / \mathrm{g}\right)$ & $r$ \\
\hline PVA & 12,199801 & 0,078323 & 0,043103 & 0,005809 & $-0,989176$ \\
PM & 12,193806 & 0,076719 & 0,041476 & 0,004871 & $-0,992033$ \\
LVE & 12,196602 & 0,077254 & 0,040078 & 0,005042 & $-0,991589$ \\
TRE & 12,198582 & 0,077292 & 0,031807 & 0,004382 & $-0,993631$ \\
LR & 12,204661 & 0,078904 & 0,042539 & 0,005866 & $-0,989126$ \\
R & 12,205575 & 0,077677 & 0,030516 & 0,003623 & $-0,995677$ \\
TRE-1 & 12,202428 & 0,078513 & 0,037243 & 0,005424 & $-0,990590$ \\
TRE-2 & 12,197122 & 0,077654 & 0,036226 & 0,005227 & $-0,991059$ \\
TRE-3 & 12,210455 & 0,080216 & 0,034134 & 0,005120 & $-0,991950$ \\
TRE-4 & 12,195127 & 0,077849 & 0,037060 & 0,005677 & $-0,989531$ \\
\hline Geral & 12,196918 & 0,077497 & 0,009667 & 0,001304 & $-0,991883$ \\
\hline
\end{tabular}

I-significativo a $0,1 \%$ 
Tabèla 7 - Coeficientes lineares ( $\ln I_{0}$ ) e angulares $(\bar{\mu})$, respectivos des vios padrões ( $s$ ) e coeficiente de correlação $(r)$ para 0 tratamento 3 (Espectrômetro gama, contagem integral, com proteção de $\mathrm{Pb}$ ), para os diferentes solos.

\begin{tabular}{|c|c|c|c|c|c|}
\hline Solo & $\ln \mathrm{I}_{0}$ & $\bar{\mu}\left(\mathrm{cm}^{2} / \mathrm{s}\right)$ & $s \ln I_{0}$ & $s \bar{\mu}\left(\mathrm{cm}^{2} / \mathrm{g}\right)$ & $r^{7}$ \\
\hline PVA & 12,345280 & 0,074856 & 0,040978 & 0,005523 & $-0,989287$ \\
\hline PM & 12,353368 & 0,075524 & 0,041594 & 0,004885 & $-0,991736$ \\
\hline LVE & 12,356409 & 0,075928 & 0,037696 & 0,004742 & $-0,992288$ \\
\hline TRE & 12,345263 & 0,073966 & 0,04266 & 0,005282 & $-0,987828$ \\
\hline LR & 12,369847 & 0,078578 & 0,042450 & 0,005854 & $-0,989082$ \\
\hline$R$ & 12,367174 & 0,076539 & 0,032938 & 0,003911 & $-0,994819$ \\
\hline TRE -1 & 12,363323 & 0,077412 & 0,035442 & 0,005162 & $-0,991225$ \\
\hline TRE -2 & 12,380155 & 0,076582 & 0,037335 & 0,005387 & $-0,990248$ \\
\hline TRE -3 & 12,400606 & 0,078649 & 0,029851 & 0,004478 & $-0,993580$ \\
\hline TRE -4 & 12,396571 & 0,076805 & 0,034382 & 0,005267 & $-0,990726$ \\
\hline Geral & 12,373505 & 0,077244 & 0,011185 & 0,001509 & $-0,989109$ \\
\hline
\end{tabular}

I-significativo a $0,1 \%$ 
Tabela 8 - Coeficientes 1 ineares ( $\ln I_{0}$ ) e angulares $(\bar{\mu})$, respertivos des vios padrões ( $s$ ) e coeficiente de correlação $(r)$ para o tratamento 4 (Espectrōmetro gama, contagem integral, sem proteção de $\mathrm{Pb}$ ), para os diferentes solos.

\begin{tabular}{|c|c|c|c|c|c|}
\hline Solo & $\ln \mathrm{I}_{0}$ & $\bar{\mu}\left(\mathrm{cm}^{2} / \mathrm{g}\right)$ & $s \ln I_{0}$ & $s \bar{\mu}\left(\mathrm{cm}^{2} / \mathrm{g}\right)$ & $r^{1}$ \\
\hline PVA & 12,725527 & 0,074953 & 0,041433 & 0,005584 & $-0,989080$ \\
\hline PM & 12,740697 & 0,076584 & 0,044388 & 0,005213 & $-0,990859$ \\
\hline LVE & 12,728918 & 0,075150 & 0,045661 & 0,005744 & $-0,988515$ \\
\hline TRE & 12,750862 & 0,078003 & 0,032759 & 0,004511 & $-0,993370$ \\
\hline LR & 12,753708 & 0,078767 & 0,038700 & 0,005337 & $-0,990944$ \\
\hline $\mathrm{R}$ & 12,750684 & 0,077168 & 0,034319 & 0,004075 & $-0,994469$ \\
\hline TRE -1 & 12,744864 & 0,077540 & 0,038636 & 0,005627 & $-0,989632$ \\
\hline TRE-2 & 12,743809 & 0,077946 & 0,042015 & 0,006062 & $-0,988117$ \\
\hline TRE -3 & 12,756918 & 0,079486 & 0,033359 & 0,005004 & $-0,992167$ \\
\hline TRE -4 & 12,743683 & 0,077083 & 0,037131 & $0,0.05688$ & $-0,989285$ \\
\hline Geral & 12,741097 & 0,076808 & 0,010035 & 0,001354 & $-0,991106$ \\
\hline
\end{tabular}

1-significativo a $0,1 \%$ 
Tabela 9 - Coeficientes lineares $\left(\ln \mathrm{I}_{0}\right)$ e angulares $(\bar{\mu})$, respectivos desvios padrões ( $s$ ) e coeficiente de correlação $(r)$ para o tratamento 5 (Espectrômetro gama, contagem na região do fotopico, com proteção de $\mathrm{Pb})$, para os diferentes solos.

\begin{tabular}{lccccc}
\hline Solo & $\ln \mathrm{I}_{0}$ & $\bar{\mu}\left(\mathrm{cm}^{2} / \mathrm{g}\right)$ & $\mathrm{s} \ln \mathrm{I}_{0}$ & $\mathrm{~s} \bar{\mu}\left(\mathrm{cm}^{2} / \mathrm{g}\right)$ & $r^{\mathrm{l}}$ \\
\hline PVA & 11,920761 & 0,079267 & 0,045115 & 0,006080 & $-0,988435$ \\
PM & 11,906520 & 0,075746 & 0,049945 & 0,005866 & $-0,988217$ \\
LVE & 11,910781 & 0,076810 & 0,047756 & 0,006008 & $-0,987984$ \\
TRE & 11,933245 & 0,078300 & 0,036853 & 0,005078 & $-0,991694$ \\
LR & 11,952686 & 0,082992 & 0,045791 & 0,006315 & $-0,988619$ \\
R & 11,900626 & 0,074364 & 0,032937 & 0,003911 & $-0,994514$ \\
TRE-1 & 11,922293 & 0,078673 & 0,044601 & 0,006495 & $-0,986640$ \\
TRE-2 & 11,926067 & 0,078001 & 0,042040 & 0,006066 & $-0,988120$ \\
TRE-3 & 11,945573 & 0,081156 & 0,043445 & 0,006517 & $-0,987348$ \\
TRE-4 & 11,924481 & 0,077206 & 0,042098 & 0,006449 & $-0,986333$ \\
\hline Geral & 11,922789 & 0,077910 & 0,011454 & 0,001546 & $-0,988779$ \\
\hline
\end{tabular}

1 -significativo a $0,1 \%$ 
Tabela 10 - Coeficiortes lineares ( $\ln \mathrm{I}_{0}$ ) e angulares $(\bar{\mu})$, respectivos des vios padrões ( $s$ ) E meficiente de correlação $(r)$ para o trata mento 6 (Espectrōmetro gama, contagem na região do fotopico, sem proteção de $\mathrm{Pb}$ ), para os diferentes solos.

\begin{tabular}{lccccc}
\hline Solo & $\ln \mathrm{I}_{0}$ & $\bar{\mu}\left(\mathrm{cm}^{2} / \mathrm{g}\right)$ & $\mathrm{s} \ln \mathrm{I}_{0}$ & $s \bar{\mu}\left(\mathrm{cm}^{2} / \mathrm{g}\right)$ & $r^{\mathrm{T}}$ \\
\hline PVA & 12,274048 & 0,075495 & 0,040785 & 0,005497 & $-0,989563$ \\
PM & 12,263763 & 0,074029 & 0,046359 & 0,005445 & $-0,989353$ \\
LVE & 12,276464 & 0,075352 & 0,045845 & 0,005767 & $-0,988485$ \\
TRE & 12,286751 & 0,076597 & 0,033109 & 0,004562 & $-0,992980$ \\
LR & 12,285357 & 0,076825 & 0,041613 & 0,005738 & $-0,989025$ \\
R & 12,288505 & 0,076334 & 0,037894 & 0,004499 & $-0,993123$ \\
TRE-1 & 12,288850 & 0,077853 & 0,043322 & 0,006309 & $-0,987119$ \\
TRE-2 & 12,290728 & 0,078550 & 0,045762 & 0,006603 & $-0,986161$ \\
TRE-3 & 12,293314 & 0,078946 & 0,045764 & 0,006865 & $-0,985212$ \\
TRE-4 & 12,283490 & 0,077135 & 0,041240 & 0,006317 & $-0,986850$ \\
\hline Geral & 12,279086 & 0,076040 & 0,010854 & 0,001465 & $-0,989411$ \\
\hline
\end{tabular}

1- significativo a $0,1 \%$ 
Tabela 11 - Distribuição dos valores dos coeficientes de atenuação de mas sa obtidos para cada tratamento e diferentes solos.

\begin{tabular}{|c|c|c|c|c|c|c|}
\hline \multirow{2}{*}{ Solo } & \multicolumn{4}{|c|}{ Coeficientes de atenuação de massa $\bar{\mu}\left(\mathrm{cm}^{2} / \mathrm{g}\right)$} & \multicolumn{2}{|c|}{ para os tratamentos } \\
\hline & $T_{1}$ & $\mathrm{~T}_{2}$ & $T_{3}$ & $T_{4}$ & $T_{5}$ & $\mathrm{~T}_{6}$ \\
\hline PVA & 0,077639 & 0,078323 & 0,074856 & 0,074953 & 0,079267 & 0,075495 \\
\hline PM & 0,076236 & 0,076719 & 0,075524 & 0,076584 & 0,075746 & 0,074029 \\
\hline LVE & 0,076837 & 0,077254 & 0,075928 & 0,075150 & 0,076810 & 0,075352 \\
\hline TRE & 0,077315 & 0,077292 & 0,073966 & 0,078003 & 0,078300 & 0,076597 \\
\hline LR & 0,078174 & 0,078904 & 0,078578 & 0,078767 & 0,082992 & 0,076825 \\
\hline$R$ & 0,078055 & 0,077677 & 0,076539 & 0,077168 & 0,074364 & 0,076334 \\
\hline TRE -1 & 0,079463 & 0,078513 & 0,077412 & 0,077540 & 0,078673 & 0,077853 \\
\hline TRE -2 & 0,078953 & 0,077654 & 0,076582 & 0,077946 & 0,078001 & 0,078550 \\
\hline TRE-3 & 0,079439 & 0,080216 & 0,078649 & $a, 079486$ & 0,081156 & 0,078946 \\
\hline TRE -4 & 0,077917 & 0,077849 & 0,076805 & 0,077083 & 0,077206 & 0,077135 \\
\hline & & & . & & & \\
\hline
\end{tabular}




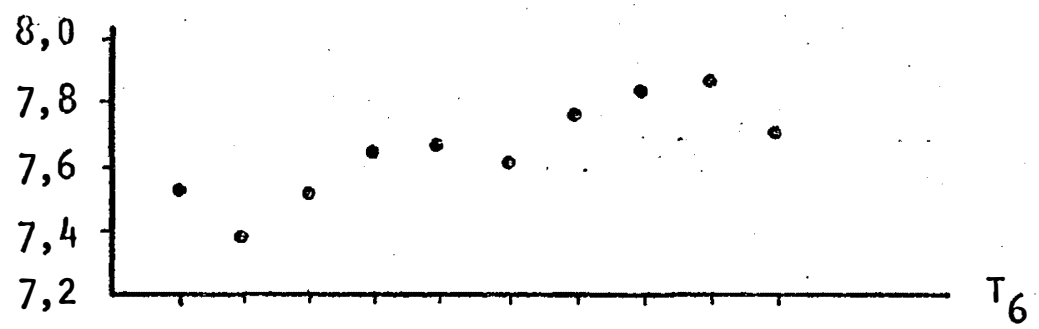

ช్

ฐ

今̊

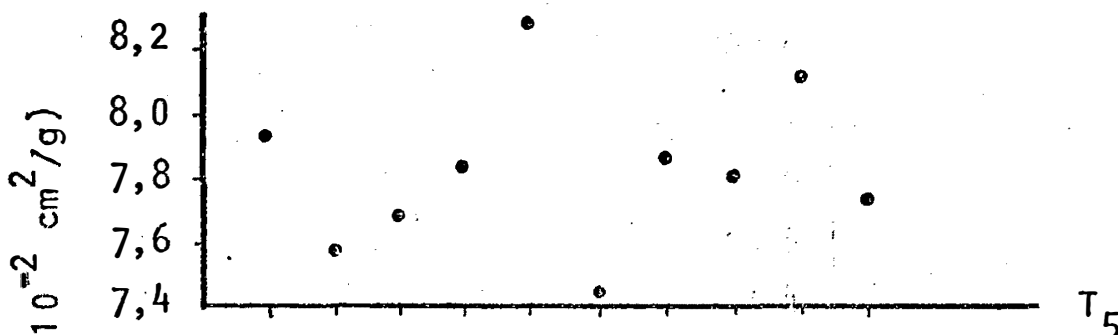

$1 \tilde{z}$
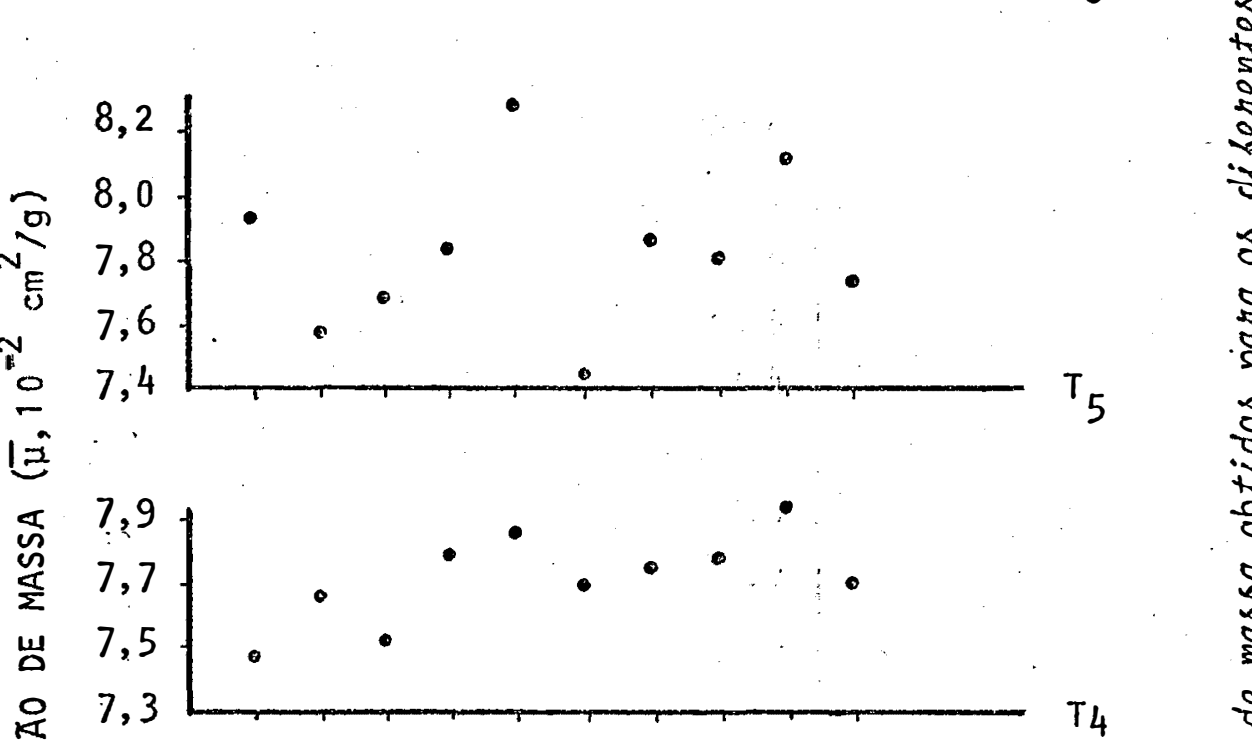

8

ک

§ิ

崖
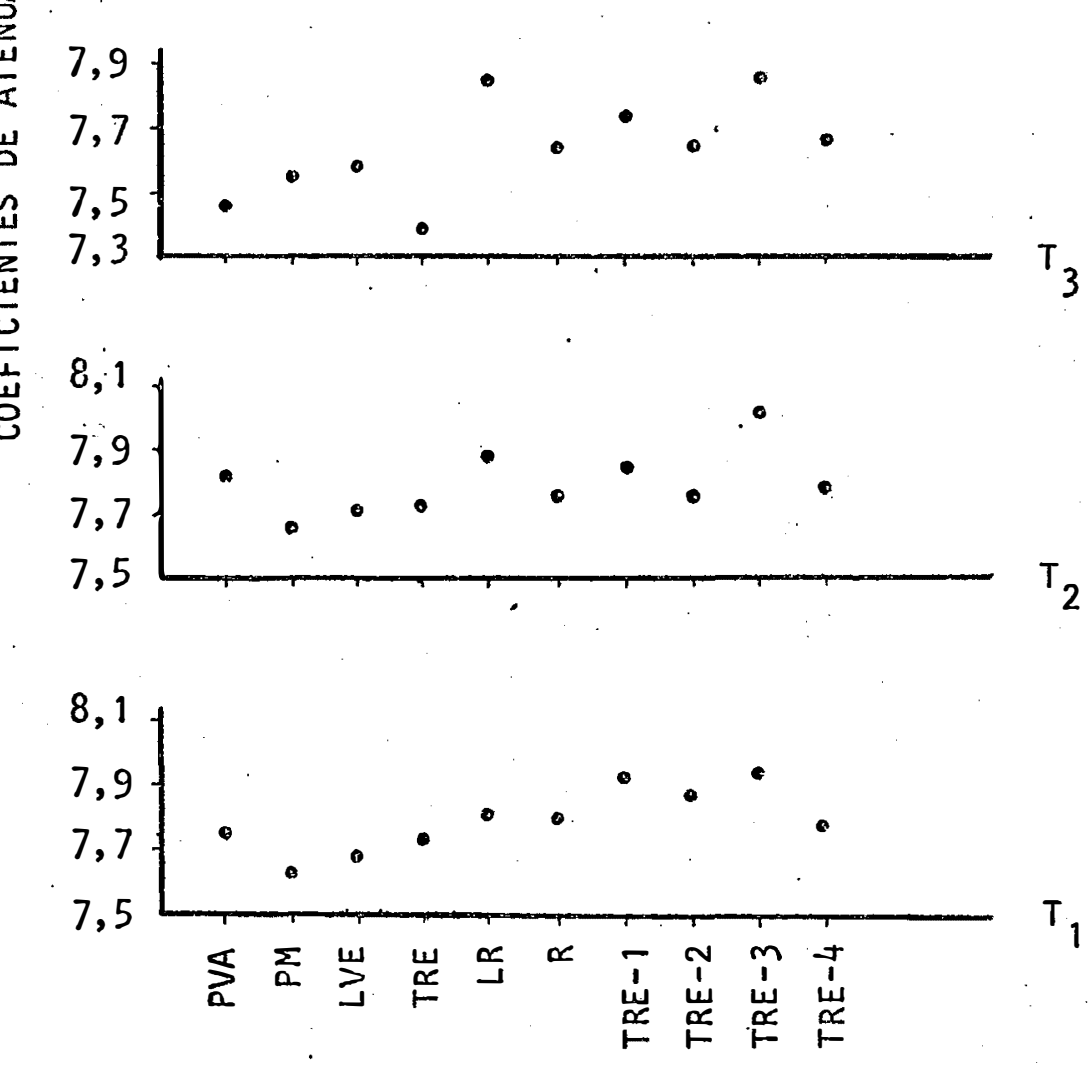

DIFERENTES TIPOS DE SOLOS 


\subsection{Coeficientes de atenuação de massa para ägua}

0 valor médio da taxa de contagem de 4 repetições obtidas para cada tratamento e o valor da densidade superficial, encontram-se na Tabela 12 e Figura 19.

Na Tab zla 13 encontram-se os valores dos coeficientes de a tenuação de massa para a água nos diferentes tratamentos. No Apêndice 9 encontram-se os contrastes obtidos para os coeficientes de atenuação de massa para os seis tratamentos utilizados.

Tabela 12 - Valores médios da taxa de contagem (cpm) do feixe emergente e da densidade superficial $\left(\mathrm{g} / \mathrm{cm}^{2}\right)$ para àgua, nos diferentes tratamentos.

\begin{tabular}{ccccccc}
$\bar{x}\left(\mathrm{~g} / \mathrm{cm}^{2}\right)$ & \multicolumn{5}{c}{ Tratamentos } \\
\cline { 3 - 6 } & $\mathrm{T}_{1}$ & $\mathrm{~T}_{2}$ & $\mathrm{~T}_{3}$ & $\mathrm{~T}_{4}$ & $\mathrm{~T}_{5}$ & $\mathrm{~T}_{6}$ \\
3,4 & 97149 & 143313 & 176166 & 259057 & 115233 & 167911 \\
& & & & & & \\
5,9 & 78500 & 115527 & 142303 & 208947 & 93017 & 135782 \\
6,8 & 72585 & 106904 & 131849 & 193032 & 86063 & 125178 \\
7,4 & 70411 & 103858 & 128519 & 188954 & 83932 & 122100 \\
9,3 & 58481 & 86018 & 107071 & 156672 & 69521 & 101476 \\
\hline
\end{tabular}




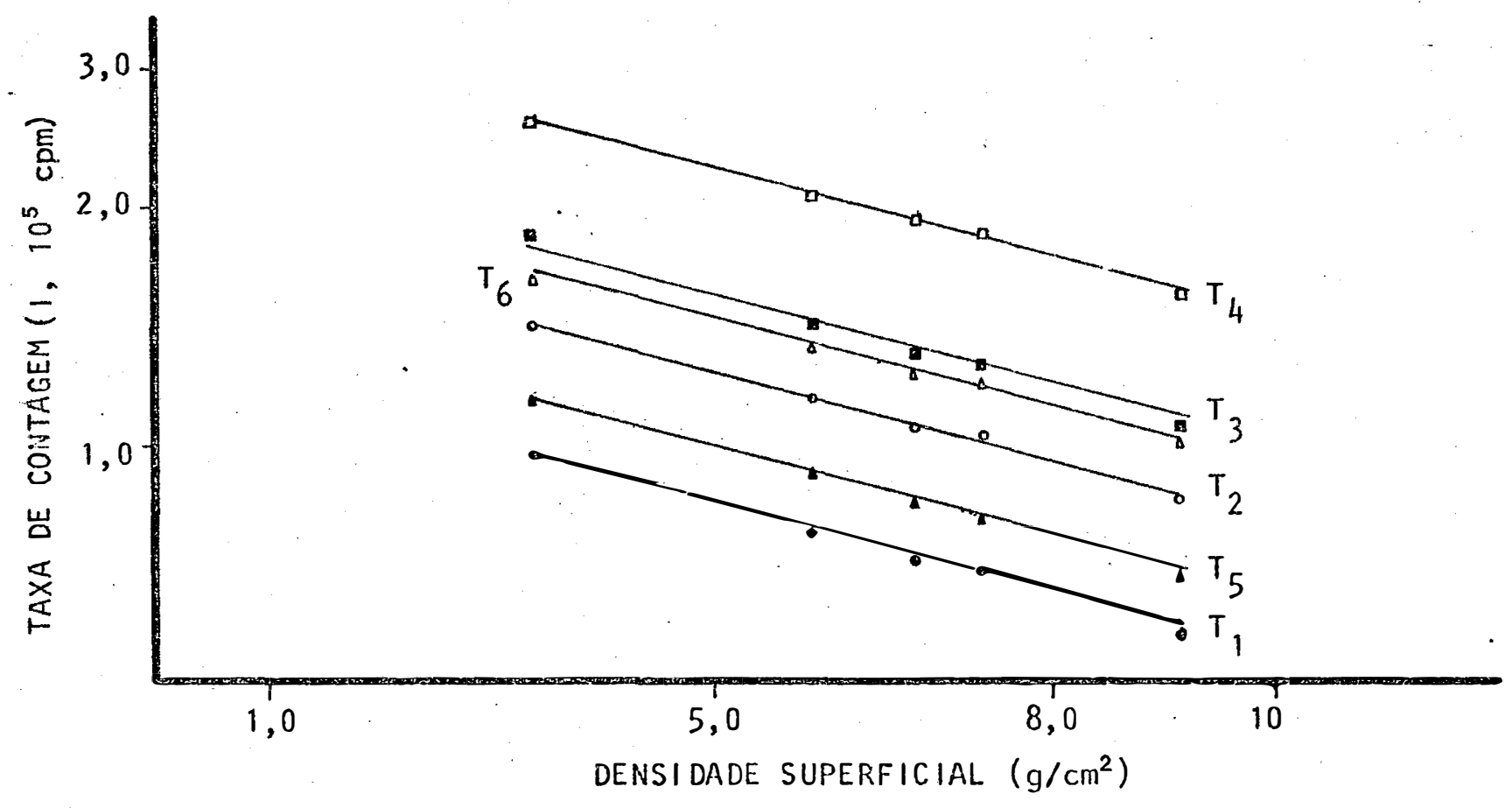

Figura 19 - Curvas de taxa de contanem do feixe emergente em função da densidade superficial para deterninação do coeficiente de atenuação de massa da ägua nos 6 tratamentos. 
Tabela 13 -Coeficientes lineares (ln $I_{0}$ ) e angulares $(\bar{\mu})$, respectivos des vios padrões ( $s$ ) e coeficiente de correlação ( $r$ ) para água, obtidos nos diversos tratamentos.

\begin{tabular}{lccccc}
\hline Trat. & $\ln \mathrm{I}_{0}$ & $\bar{\mu}(\mathrm{cm} / \mathrm{g})$ & $\mathrm{s} \ln \mathrm{I}_{0}$ & $\mathrm{~s} \bar{\mu}\left(\mathrm{cm}^{2} / \mathrm{g}\right)$ & $\mathrm{r}^{\mathrm{T}}$ \\
\hline $\mathrm{T}_{1}$ & 11,775321 & 0,085081 & 0,017203 & 0,002515 & $-0,998691$ \\
$\mathrm{~T}_{2}$ & 12,165135 & 0,085453 & 0,0188441 & $\mathrm{c}, 002755$ & $-0,998444$ \\
$\mathrm{~T}_{3}$ & 12,362623 & 0,083345 & 0,018949 & 0,002771 & $-0,998346$ \\
$\mathrm{~T}_{4}$ & 12,750880 & 0,084085 & 0,021803 & 0,003188 & $-0,997851$ \\
$\mathrm{~T}_{5}$ & 11,943386 & 0,084503 & 0,020612 & 0,003014 & $-0,998097$ \\
$T_{6}$ & 12,319275 & 0,084312 & 0,019048 & 0,002785 & $-0,998371$ \\
\hline Média & - & 0,084480 & - & - & - \\
\hline
\end{tabular}

I-significativo a $0,1 \%$ 


\section{DISCUSSÃO}

Conforme foi previsto anteriormente, item 4.2., a utilização de uma boa colimação para eliminação do efeito Compton, faz com que o uso de um equipamento simples (sistema Nuclear Chicago) e um menos requintado (Espectrômetro gama monocanal: contagem integral e no fotopico) forne çam os mesmos coeficientes de atenuação de massa para os diferentes tipos de solo. Alguns valores de coeficientes de atenuação de massa para solos, de diferentes autores, são dados na Tabela 14, sendo que o valor obtido neste trabalho è a mëdia aritmética geral dos 6 tratamentos utilizados $\left.\widetilde{\mu}_{M}=0,07724 \mathrm{~cm}^{2} / \mathrm{g}\right)$.

Tabela 14 - Coeficientes de atenuação de massa para solos obtidos por diferentes autores para uma fonte de raios gama de 0,662 MeV (Cs-137).

\begin{tabular}{ll}
\hline \multicolumn{1}{c}{ Autores } & $\bar{\mu}\left(\mathrm{cm}^{2} / \mathrm{g}\right)$ \\
\hline REGINATO e BAVEL, 1964 & $0,0772-0,0780$ \\
COREY et alii, 1971 & 0,07803 \\
\hline
\end{tabular}


Tabela 14 - continuação

\begin{tabular}{ll}
\hline \multicolumn{1}{c}{ Autores } & \multicolumn{1}{c}{$\left(\mathrm{cm}^{2} / \mathrm{g}\right)$} \\
\hline DAVIDSON et alii, 1963 & 0,07690 \\
GURR, 1962 & 0,07785 \\
KING, 1967 & 0,077 \\
FERRAZ, 1974 & $0,07676-0,08081$ \\
neste trabal ho & 0,07724 \\
\hline
\end{tabular}

SAXENA et alii (1970) determinaram o coeficiente de atenua ção de massa da água para uma fonte de Cs-137, de radiação gama monoenergëtica de 0,66 MeV, com três sistemas de detecção, onde: (1) somente pulsos entre as energias de $0,66 \pm 0,15 \mathrm{MeV}$ eram contados, (2) pulsos entre $0,66 \pm 0,033 \mathrm{MeV}$ e (3) quando o detector era conectado diretamente ao contador de pulsos (contagem integral). Para cada um desses sistemas, os coeficientes de atenuação de massa foram determinados com colimação na fonte e detector, somente com colimação no detector e somente na fonte (Tabela 15).

Através desses dados, pode-se observar que os coeficientes de atenuação de massa da água obtidos com a colimação usual (fonte e de tectorl e com colimação no detector para os três sistemas de deteç̧ão variam no máximo de 3,86\%: O valor médio obtido para esses dois tipos de col ímação foi de $0,0835 \mathrm{~cm}^{2} / \mathrm{g}$, muito prôximo do valor mêdio de $0,0845 \mathrm{~cm}^{2}$ / g obtido neste trabalho. 
Tabèla 15 - Coeficientes de atenuação de massa da āgua, obtidos por SAXENA et alii (1970), para uma fonte de radiação gama monoenergētica do Cs-137.

\begin{tabular}{lccc}
\hline Colimação & $\begin{array}{c}\text { Coeficiente de atenuação } \\
\text { de massa da ägua }\left(\mathrm{cm}^{2} / \mathrm{g}\right)\end{array}$ & $\begin{array}{c}\text { Sistemas de } \\
\text { Operação }\end{array}$ & $r^{7}$ \\
\hline fonte e & 0,0825 & 1 & $-1,0000$ \\
detector & 0,0854 & 2 & $-0,9999$ \\
& 0,0838 & 3 & $-0,9999$ \\
detector & 0,0830 & 1 & $-1,0000$ \\
& 0,0821 & 2 & $-0,9998$ \\
& 0,0843 & 3 & $-0,9998$ \\
fonte & 0,0710 & 1 & $-1,0000$ \\
& 0,0772 & 2 & $-0,9969$ \\
& 0,0744 & 3 & $-0,9993$ \\
\hline
\end{tabular}

1 - significativo a $0,1 \%$

Quando a colimação é feita somente na fonte, os valores dos coeficientes de atenuação de massá da āgua obtidos diferem dos outros tipos de colimação empregados (SAXENA et alii, l.c.), e também dos obtidos neste trabalho. 0 valor mais pröximo aos da literatura foi obtido com uma janela estreita (sistema 2). Quando se utilizau uma jànela larga (sistema 1) ou a contagem integral (sistema 3) com colimação na fonte, o valor do coeficiente de atenuação de massa afasta-se do teorica- 
mente esperado. Isso reforça o que foi salientado no inicio desse traba Tho, onde uma boa colimação, feita junto à fonte e no detector, possibili ta a substituição de um espectrômetro gama monocanal por um sistema de contagem integral, menos sofisticado e de custo mais baixo.

A utilização da lâmina de $\mathrm{Pb}$ para ạ eliminação do raio-X de $32 \mathrm{keV}$ do $\mathrm{Ba}-137 \mathrm{~m}$ e dos raios gama retroespalhados, principalmente quan do se emprega o sistema Nuclear Chicago, não influenciou nos valores obti dos para os coeficientes de atenuação de massa do solo e da ăgua, pois es tes não diferem entre si quando se troca os equipamentos.

No sistema onde se emprega o espectrômetro gama monocanalcontagem integral e no fotopico, os pulsos devido ao raio-X são discriminados pelo circuito analisador, mas no sistema Nuclear Chicago poderiam ser contados, pois o discriminador de entrada è de 0,25 volts, inferior à ampli tude esperada para os pulsos do raio-X.

Por outro lado, considerando-se como $100 \%$ a eficiência intrinseca do cristal cintilador de $1 \times 1^{\prime \prime}$ e de $3 \times 3^{\prime \prime}$ para os ràios-X de $32 \mathrm{keV}$, de $50 \%$ para os raios gama de $0,662 \mathrm{MeV}$ no cristal de $1 \times 1{ }^{\prime \prime}$ e de $66 \%$ para o de $3 \times 3^{\prime \prime}$ quando se realiza a contagem integral e de $35 \%$ para o mesmo cristal quando em contagem no fotopico (PRICE, 1958; HEATH, 1962), a razão entre a taxa de contagem para os raios gama e raios-X seria ao re dor de $660 ; 870$ e 460 para os três casos, respectivamente. Em termos percentuais, a taxa de contagem dos raios $-X$ seria de 0,$15 ; 0,11$ e $0,22 \%$ em relação a dos raios gama nos sistemas Nuclear Chicago e espectrômetro gama-contagem integral e no fotopico. Portanto, em termos de taxa de contagem, a contribuição dos raios-X seria mínima em todos os sistemas, em 
par.ticular no Nuclear Chicago, onde poderiam ter influêncía.

Quanto aos raios gama retroespalhados na fonte e na blinda gem, com uma energia em torno de $180 \mathrm{keV}$, poderiam ser detectados no sistema Nuclear Chicago e no sistema espectrômetro gama contagem integral. Entretanto, sua influência nos valores dos coeficientes de atenuação é mi nima, devido à sua intensidade desprezível, que pode ser veríficado no espectro de pulsos do Cs-137 (Figura 7), por volta le 1,8 volts.

A utilização da lâmina de chumbo com intuito de se evitar a correção devido ao tempo morto, também é desnecessária. Isto pode ser mostrado através da comparação relativa da intensidade dos feixes inciden tes medidos e calculados (Tabela 16). Os valores calculados foram obtidos através do coeficiente linear da reta $\ln 1 \times \mathrm{x}$ para cada tratamento, enquanto que os medidos são valores médios de 10 determinações (Apêndice 1) por tratamento. Com exceção dos tratamentos 5 e 6 (espectrômetro gama monocanal-contagem no fotopico com e sem a lâmina de $\mathrm{Pb}$ ) para agua, a taxa de contagem do feixe incidente medido experimentalmente foi. maior que o calculado; o inverso sería esperado, raso a correção devido ao tempo morto fosse significativa. 
Tabela 16 - Valores relativos da intensidade dos feixes incidentes medidos ( $\mathrm{I}_{\text {Omed }}$ ) e calculados $\left(\mathrm{I}_{0 \text { calc }}\right)$, para os solos e àgua, nos diversos tratamentos utîlizados.

\begin{tabular}{ccccc}
\hline \multirow{2}{*}{ Tratamento } & \multicolumn{2}{c}{ Solo } & \multicolumn{2}{c}{ Agua } \\
\cline { 2 - 5 } & $\mathrm{I}_{\text {Ocalc }}$ & $\mathrm{I}_{\text {Omed }}$ & $\mathrm{I}_{\text {Ocalc }}$ & $\mathrm{I}_{\text {Omed }}$ \\
\hline T1 & 98,1 & 100,0 & 94,2 & 100,0 \\
T2 & 97,5 & 100,0 & 94,4 & 100,0 \\
T3 & 98,9 & 100,0 & 97,7 & 100,0 \\
T4 & 97,0 & 100,0 & 98,0 & 100,0 \\
T5 & 96,6 & 100,0 & 101,2 & 100,0 \\
T6 & 96,5 & 100,0 & 102,3 & 100,0 \\
\hline
\end{tabular}




\section{CONCLUSOES}

Da discussão dos resultados permite-se concluir que:

1) Através do teste " $t$ " tem-se que os coeficientes de atenuação de massa obtidos para os diversos solos não diferem estatisticamen te para um mesmo tratamento,

2) os coeficientes de atenuação de massa dos solos não diferem estatisticamente para os diversos tratamentos. 0 mesmo ocorre com o coeficiente de atenuação de massa da ăgua,

3) é desnecessāria a utilização da lâmina de $\mathrm{Pb}$ com o obję tivo de se eliminar os raios- $X$ de $32 \mathrm{keV}$ do feixe de raíos gama de 0,662 MeV provenientes do Ba-137m,

4) também é desnecessária a utilização da lâmina de $\mathrm{Pb}$ com o objetivo de se evitar a correção do tempo morto, pois mesmo para altas taxas de contagem $(350.000 \mathrm{cpm})$ não foi necessāria esta correção e

5) na determinação da umidade e densidade do solo pode-se 
utilizar um sistema de contagem integral, menos sofisticado e de custo mais baixo, em substituição ao espectrômetro gama monocanal. 


\section{LITERATURA CITADA}

BAVEL, C.H.M. van, 1959. Soil densitometry by gamma-ray transmission. Soil Sci., New Brunswick, 87: 50-58.

GAVEL, C.H.M. van, 1960. Soil density measurement with gamma radiation. In: International Congress of Soil Science, 7’, Ariz., 1960. Anais, Ariz., p. 284-289.

BERNARD, R.K: e M. CHASEK, 1955: Soil density determination by direct transmission of gamma ray. ASTM Philadelphia, Pa. Preprint No 86. BERRY, P.F., 1961. Gamma-ray attenuation coefficients. Nucleonics, New York, 19: 62 .

COPPOLA, M. A P. REININGER, 1974. Influence of the chemical composition on the gamma-ray attenuation by soils. Soiz Sci., Baltimore, 117(6): $331-335$.

COREY, J.C.; S.F. PETERSON E M.A. WAKAT, 1971. Measurement of at tenuation of ${ }^{137} \mathrm{Cs}$ and ${ }^{241} \mathrm{Am}$ gamma-rays for soil density and water content determinations. Soil Sci. Soc. Amer. Proc., Madison, 35: 215-219. 
DAVIDSON, J.M.; J.W. BIGGAR e D.R. NIELSEN, 1963. Gamma radiation attenuation for measuring bulk density and transient water flow in porous materials. J. Geophys. Res., Washington, 68(16): 477-483.

DAVISSON, C.M., 1955. $\gamma$-ray absorption coefficients: In: SIEGBAHN., ed. Beta and gamma ray spectroscopy. Amsterdan, cap. II, p. 858-873.

FERGUSON, H. e W. H. GARDNER, 1962. Water content measurement in soil columns by gamma ray absorption. Soil Sci. Soc. Amer. Proc., Madison, $26: 11-14$.

FERRAZ, E.S.B., 1974. Determinação simultânea de densidade e umidade de solos por atenuação de raios gama do ${ }^{137} \mathrm{Cs}$ e ${ }^{241} \mathrm{Am}$. Piracicaba, ESALQ/USP, 120 p. (Tese de Livre Docência).

FERRAZ, E.S.B.; M.L. ALMEIDA e I.A. GUERRINI, 1974. Uso de uma fonte de radiação gama de $60 \mathrm{keV}$ para determinação de umidade e densidade de solos. In: Reunião da Sociedade Brasileira para o Progresso da Ciên cia, 26a., Recife, p. 569-570 (Resumo).

FERRAZ, E.S.B., 1976. A sensibilidade do método $2 \gamma$ de medida simultānea de densidade e umidade de solos. In: CONGRESSO BRASILEIRO DE CIENCIA DO SOL0, 15:, Campinas, 1976. Anais, Campinas, p. 43-49.

FERRAZ, E.S.B. e R.S. MANSELL, 1976. Gamma-ray at tenuation methods for determining water content and bulk, density of soil. CENA-PLANFAP, Piracicaba, $69 \mathrm{p}$.

FERRAZ, E.S.B. e F.A. PINTO, 1977. Determinação de variação de umidade 
do solo "in situ"' por atenuação gama. Cientifica, Jaboticabal, (NO Especial): 49-52.

FRITTON, D.D., 1969. Resolving time, mass absorption coefficient and water content with gamma-ray attenuation. Soil Sci. Soc. Amer. Proc., Madison, 33: 651-654.

GARDNER, W.H. e C. CALISSENDORFF, 1967. Gamma-ray and neutron attenuation in measurement of soil bulk density and water content. In: Symposium on the soil Physics and Irrigation Studies, Istambul, 1967. Anais, Vienna, IAEA, p. 101-113.

GOPAL, S. E B. SANJEVAIAH, 1973. A method to determine the $\gamma$-ray attenuation coefficients. Nucl. Instrom. Meth., Amsterdan, 107: $221-225$.

GROENEVELT, P.H.; J.G. de SWART e J. CISLER, 1969. Water content measurement with $60 \mathrm{keV}$ gamma ray attenuation. Bulz. int. Ass. scient. Hydral., London, 14(2): 67-77.

GURR, C.G., 1962. Use of gamma rays in measurement water content and permeability in insaturated columns of soil. Soil Sci., New Brunswick, 94: 224-229.

GYURCSAK, J.; R. KRASOWSKI; A. KREFT e J. WOZNIAK, 1976. Two-detector gauges for measuring soil density and water content. INT-97/I, (s.1.) 9-29. (opud ATOMINDEX, 1977, Vienna, 8(8): 2198).

HEATH, 1962. Scintillation spectrometry gamma-ray spectrum. Catalogue, I daho Falls, Philips Petrolium Company, Atomic Energy Division, ID0-16408. 
HERKELRATH, W.N. e E.E. MILLER, 1976. High performance gamma system for soil columns. Soil Sci. Soc. Am. J., Madison, 40: 331-332.

KANE, P.P.; G. BASAVARAJU e K. M. VARIER, 1977. Gamma ray attenuation measurements. Nucl. Instrum. Meth., Amsterdan, 147(3): 507-511 (apud ATOMINDEX, 1978, Vienna, $9(9):$ 2318).

KAPLAN, 1. Física Nuclear, Rio de Janeiro, Guanabara Dois. 633 p.

KING, L.G., 1967. Gamma ray attenuation for soil-water-content measurements using ${ }^{241} \mathrm{Am}$. In: Symposium on the use of isotope and radiation techniques in soil physics and irrigation studies. Istanbul, 1967, Anais, Vienna, IAEA, p. 17-29.

KIRKHAN, D. E J.C. COREY, 1973. Recent progress in the design of radiation equipment and $\mathbf{i}$ ts practical implication. In: Soil-moisture and irrigation studies II, Vienna, 1973. Anais, Vienna, IAEA, p. 17-39.

LEDERER, C.M.; J.M.H. HOLLANDER e I. PERLMAN, 1967. Table of isotopes. 6a. ed. New York, John Wiley, 594 p.

NASCIMENTO Fo, V.F., 1977. Características dos principais radioisótopos utilizados em ciências biolögicas. BT-009, Centro de Energia Nuclear na Agricultura, USP/CNEN, 8 p. Piracicaba (SP).

OLESEN, D.E., 1973. Gamma radiation for measuring water contents in soil columns with changing bulk density. J. Soiz Sci., 0xford, 24(24): 461-469.

PRICE, W.J., 1958. Scintillations detectors. In: Nuclear Radiation 
Detection. New. York, Mac Graw-Hill, 1958. p. 189-193.

REGINATO, R.J., 1974 a. Gamma radiation measurement of bulk density changes in soil pedon following irrigation. Soiz Sci. Soc. Amer. Proc., Madison, 38: 24-28.

REGINATO, R.J., 1974 b. Count-rate instability in gamma-ray transmission equipment. Soil Sci, Soc. Amer. Proc., Madison, 38: 156-157.

REGINATO, R.J. e K. STUUT, 1970. Temperature stabilization of gamma ray transmission Equipment. Soil Sci. Soc. Amer. Proc., Madison, $152-153$.

REGINATO, R.J. e C.H.M. van BAVEL, 1964. Soil water measurement with gamma attenuation. Soil Sci. Soc. Amer. Proc., Madison, 28: 721-724.

REICHARDT, K., 196a. Determinação da densidade de solos. O Solo, Pi racicaba, $52(1): 3-8$.

REICHARDT, K., 1965 a. Uso da radiação gama na determinação da densidade e umidade do solo. Piracicaba, ESALQ/USP, 34 p. (Tese de Doutoramento) .

REICHARDT, K., 1965 b. Uso da radiação gama na determinação da densidade aparente e da umidade do solo. Piracicaba, ESALQ/USP, 9 p. (mimeografado).

ROSE, R.G., 1964. Gamma-ray attenuation coefficients. Nucleonics, New York, $22(8): 126-127$. 
SANTO, L.T. e G.Y. TSUUJI, (s.d.). Soil bulk density and water content measurements by gamma ray attenuation techniques. Technical Bulletin, No 98. Hawaii Agricultural Experiment Station, Hawaii, p. 1-17.

SAXENA, G.S.; R.E. FRANKLIN e G.S. TAYLOR, 1970. Importance of pulseheight analysis in the gamma ray at tenuation technique for measurement of soil moisture. Soil Sci., New Brunswick, 110(4): 283-286.

SING, B.P. e S. CHANDRA, 1976. Evaluation of the optimal tickness of soil between source and detector in the gamma-ray transmission method. J. HydroZ., Amsterdan, 32: 189-191.

SOANE, B.D., 1967. Dual energy gamma-ray transmission for coincident measurement of water content and dry bulk density in soil. Nature, London, 214: 1273-1274.

STEEL, R.W. e K.L. TORRIE, 1960. Pिinciple and Procedures of Statistics. New York, Mac-Graw Hil 1 Book Company. 481 p.

SWART, J.G. de e P.H. GROENEVELT, 1971. Column scanning wi th $60 \mathrm{keV}$ gamma radiation. Soil Sci., New Brunswick, $112(6):$ 419-424.

VACHAUD, G.; J. CISLER; J.L. THONY e L. de BACKER, 1970. Utilisation de l'emission gama de l'americium-241 pour la mesure de la teneur en eau d'echantillons de sols non satures. In: Symposium on Use of Isotope in Hydrology, Vienna, 1970. Anais, Vienna, IAEA, p. 1-30.

VOMOCIL, J.A., 1954. In situ measurement of soil bulk density. Soiz Sci,, New Brunswick, 77: 341-342. 
WACK, B., 1967. Mesure de la densitē et de l'humiditē des sols par transmission de rayonnement. Aplication au controle du compactage. Anais, Istambul, n? 23, 595-601, 1967. 


\section{APENDICE 1}

Valores médios da taxa de contagem (cpm) do feixe emergente e incidente e da densidade superficial $\left(\mathrm{g} / \mathrm{cm}^{2}\right)$ para as diferentes amostras de solo, nos diferentes tratamentos.

\begin{tabular}{|c|c|c|c|c|c|c|c|}
\hline \multirow{2}{*}{ Solo } & \multirow{2}{*}{$\bar{x}\left(\mathrm{~g} / \mathrm{cm}^{2}\right)}$. & \multicolumn{6}{|c|}{ Tratamentos } \\
\hline & & $T_{1}$ & $\mathrm{~T}_{2}$ & $T_{3}$ & $T_{4}$ & $\mathrm{~T}_{5}$ & $T_{6}$ \\
\hline \multirow{6}{*}{ PVA } & 3,6947 & 100512 & 148798 & 173885 & 253870 & 111761 & 161557 \\
\hline & 4,8976 & 95048 & 139877 & 164998 & 241353 & 106247 & 152926 \\
\hline & 6,4741 & 77192 & 114399 & 134972 & 197791 & 86445 & 125693 \\
\hline & 8,3613 & 71079 & 104749 & 123939 & 181913 & 76232 & 115337 \\
\hline & 8,8124 & 66234 & 97577 & 118313 & 171550 & 74052 & 108301 \\
\hline & 10,1579 & 62183 & 91496 & 108734 & 159186 & 69207 & 101036 \\
\hline \multirow{6}{*}{ PM } & 4,4370 & 94469 & 139945 & 165394 & 243028 & 105824 & 152234 \\
\hline & 5,7376 & 89105 & 131248 & 154729 & 226813 & 99338 & 143343 \\
\hline & 7,6824 & 72204 & 106378 & 126020 & 182997 & 79579 & 115428 \\
\hline & 9,4971 & 65551 & 96724. & 114544 & 167030 & 73509 & 106530 \\
\hline & 9,6904 & 61619 & 90960 & 107739 & 157219 & 68564 & 100176 \\
\hline & $\cdot 11,8002$ & 55412 & 81563 & 97283 & 141792 & 62213 & 90511 \\
\hline \multirow{6}{*}{ LVE } & 4,0984 & 97803 & 143863 & 169379 & 246222 & 108144 & 156842 \\
\hline & 5,2653 & 91744 & 135199 & 159978 & 233908 & 102662 & 148998 \\
\hline & 7,3481 & 74604 & 110205 & 130619 & 190121 & 82090 & 119493 \\
\hline & 8,8539 & 69107 & 101514 & 120235 & 177388 & 76888 & 112294 \\
\hline & 8,9770 & 64420 & 95098 & 113389 & 164272 & 71665 & 105043 \\
\hline & 11,0283 & 58966 & 86441 & 102729 & 150450 & 65415 & 95628 \\
\hline
\end{tabular}


Apêndice 1 - continuação

Tratamentos:

Solo $\bar{x}\left(\mathrm{~g} / \mathrm{cm}^{2}\right)$

\begin{tabular}{ccccccc} 
& $T_{1}$ & $T_{2}$ & $T_{3}$ & $T_{4}$ & $T_{5}$ & $T_{6}$ \\
\hline 3,9077 & 99345 & 145680 & 171608 & 252809 & 111442 & 159659 \\
4,9972 & 93592 & 137619 & 162654 & 238280 & 105270 & 150919 \\
6,8734 & 78574 & 115258 & 135376 & 197992 & 86825 & 125792 \\
7,8953 & 74335 & 109269 & 129461 & 189160 & 83633 & 120397 \\
8,4167 & 69429 & 100647 & 118864 & 174208 & 76604 & 110760 \\
9,7678 & 64160 & 94773 & 114778 & 163487 & 72003 & 104116
\end{tabular}

$\begin{array}{lllllll}3,9006 & 99912 & 145843 & 172378 & 252864 & 111046 & 159530\end{array}$

$\begin{array}{lllllll}4,9213 & 94669 & 139430 & 164190 & 240929 & 106457 & 152478\end{array}$

LR

$\begin{array}{lllllll}6,7084 & 78920 & 114418 & 135929 & 198889 & 87083 & 125773\end{array}$

$\begin{array}{lllllll}8,1284 & 72621 & 106795 & 126593 & 184794 & 80627 & 117823\end{array}$

$\begin{array}{lllllll}8,4109 & 69692 & 99616 & 117260 & 173121 & 74264 & 109967\end{array}$

$\begin{array}{lllllll}9,7095 & 64526 & 94888 & 112329 & 164282 & 70826 & 104883\end{array}$

$\begin{array}{lllllll}4,4710 & 96114 & 140425 & 166196 & 243578 & 105338 & 154001\end{array}$

$\begin{array}{lllllll}5,8360 & 88330 & 129800 & 153666 & 324452 & 97066 & 142112\end{array}$

$\begin{array}{lllllll}7,9596 & 71670 & 105771 & 124749 & 181992 & 80327 & 115831\end{array}$

$\begin{array}{llllllll}R & 9,2302 & 67327 & 98768 & 117560 & 171621 & 75528 & 109001\end{array}$

$\begin{array}{lllllll}9,5806 & 63378 & 92738 & 110293 & 160512 & 70049 & 101084\end{array}$

$\begin{array}{lllllll}11,4543 & 56654 & 83263 & 99252 & 144858 & 63805 & 92470\end{array}$

(continua) 
Apêndice 1 - continuação

Tratamentos

Solo $\bar{x}\left(\mathrm{~g} / \mathrm{cm}^{2}\right)$
$\mathrm{T}_{1}$
$T_{1}$

3,6753

4,7626

101970

148042

175083

255719

111782

162215

6,2956

96008

141475

166764

244990

107307

155324

TRE-1

7,7

7,7103

80707

118614

139640

204017

$89013 \quad 128409$

7,7846

74566

109948

129866

190356

83358

120427

7,7846

72572

105548

125895

183912

79230

115878

9,3286

66217

97282

115397

168771

73598

107092

3,6454

102319

148587

179125

255972

112776

162086

4,6764

96480

141466

170784

245334

108283

155314

6,468

79776

116160

140887

199532

88343

127479

TRE-2

7,576

76082

111788

135156

192879

85276

122686

8,0434

71260

104102

125295

178705

78608

111381

9,4392

65722

96697

117722

167130

73688

106014

$\begin{array}{lllllll}3,6721 & 101866 & 149152 & 181171 & 257695 & 113883 & 162789\end{array}$

4,6460

96129

141377

172005

245057

108504

155203

$6,2920 \quad 81691$

117787

144857

205550

89583

128319

TRE-3

$7,4843 \quad 76126$

7

8,7579

111752

73439

106501.

.136368

194274

85615

$80263 \quad 115380$

$68885 \quad 100888$

130296

184185

123615

175294
$77160 \quad 111639$ 
Apēndi ce 1 - continuação

Tratamentos:

\begin{tabular}{|c|c|c|c|c|c|c|c|}
\hline \multirow{2}{*}{ Solo } & \multirow{2}{*}{$\bar{x}\left(\mathrm{~g} / \mathrm{cm}^{2}\right)$} & \\
\hline & & $T_{1}$ & $T_{2}$ & $T_{3}$ & $T_{4}$ & $T_{5}$ & $T_{6}$ \\
\hline \multirow{6}{*}{ TRE -4} & 3,4881 & $103: 64$ & 150287 & 184067 & 259800 & 114386 & 163843 \\
\hline & 4,5839 & $970 \div 2$ & 142137 & 174304 & 247220 & 109193 & 156127 \\
\hline & 6,0091 & 83332 & 119876 & 149011 & 209787 & 92125 & 132441 \\
\hline & 7,1681 & 78496 & 114788 & 141639 & 200180 & 88504 & 126826 \\
\hline & 7,5495 & 74579 & 107917 & 132221 & 186820 & 81928 & 117080 \\
\hline & 8,8343 & 68931 & 100916 & 324540 & 175749 & 77488 & 111075 \\
\hline & 'o solo & 138078 & 203262 & 238921 & 351890 & 155946 & 22890 \\
\hline & 'o ägua & 138058 & 203291 & 239305 & 351860 & 151929 & 218938 \\
\hline
\end{tabular}




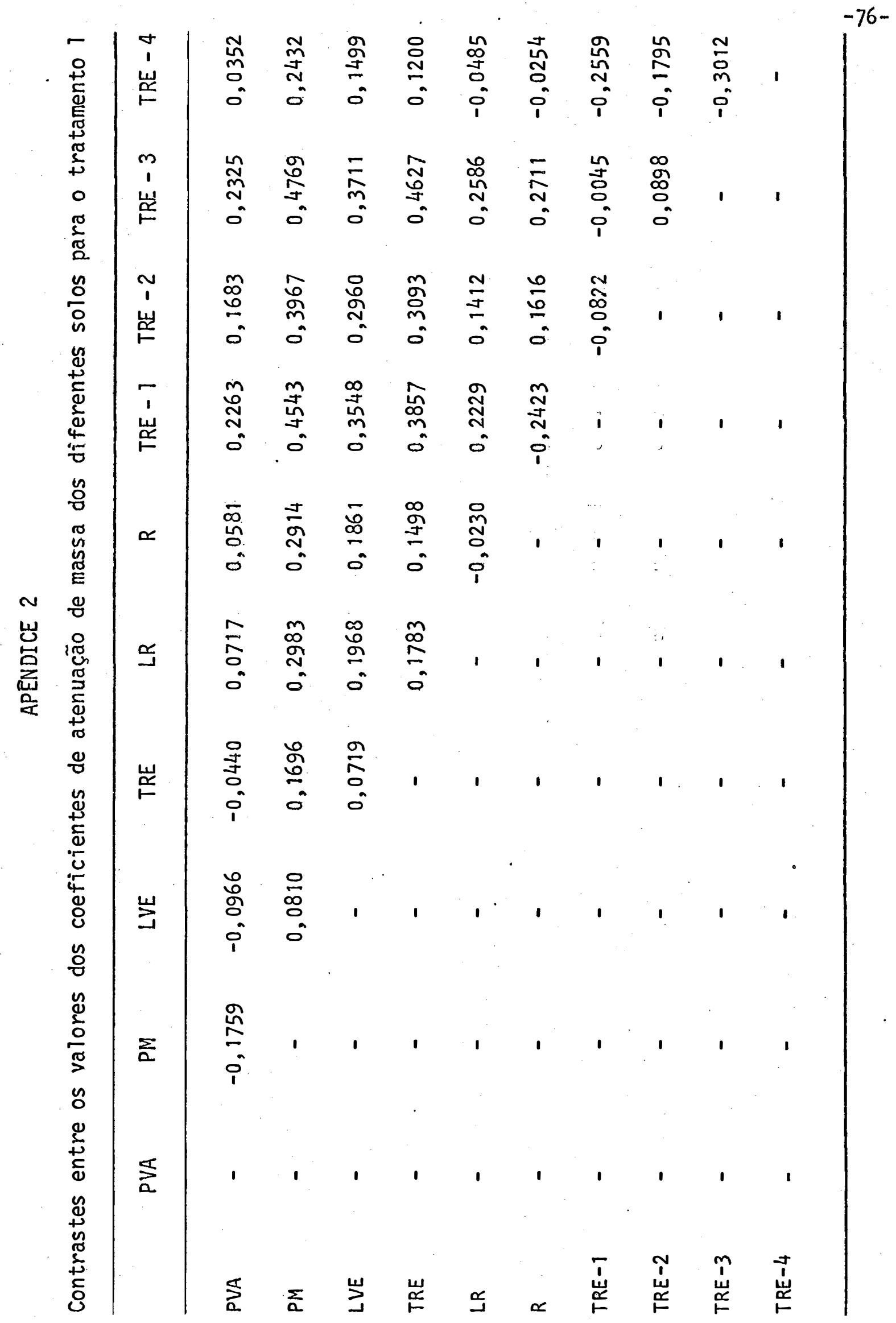




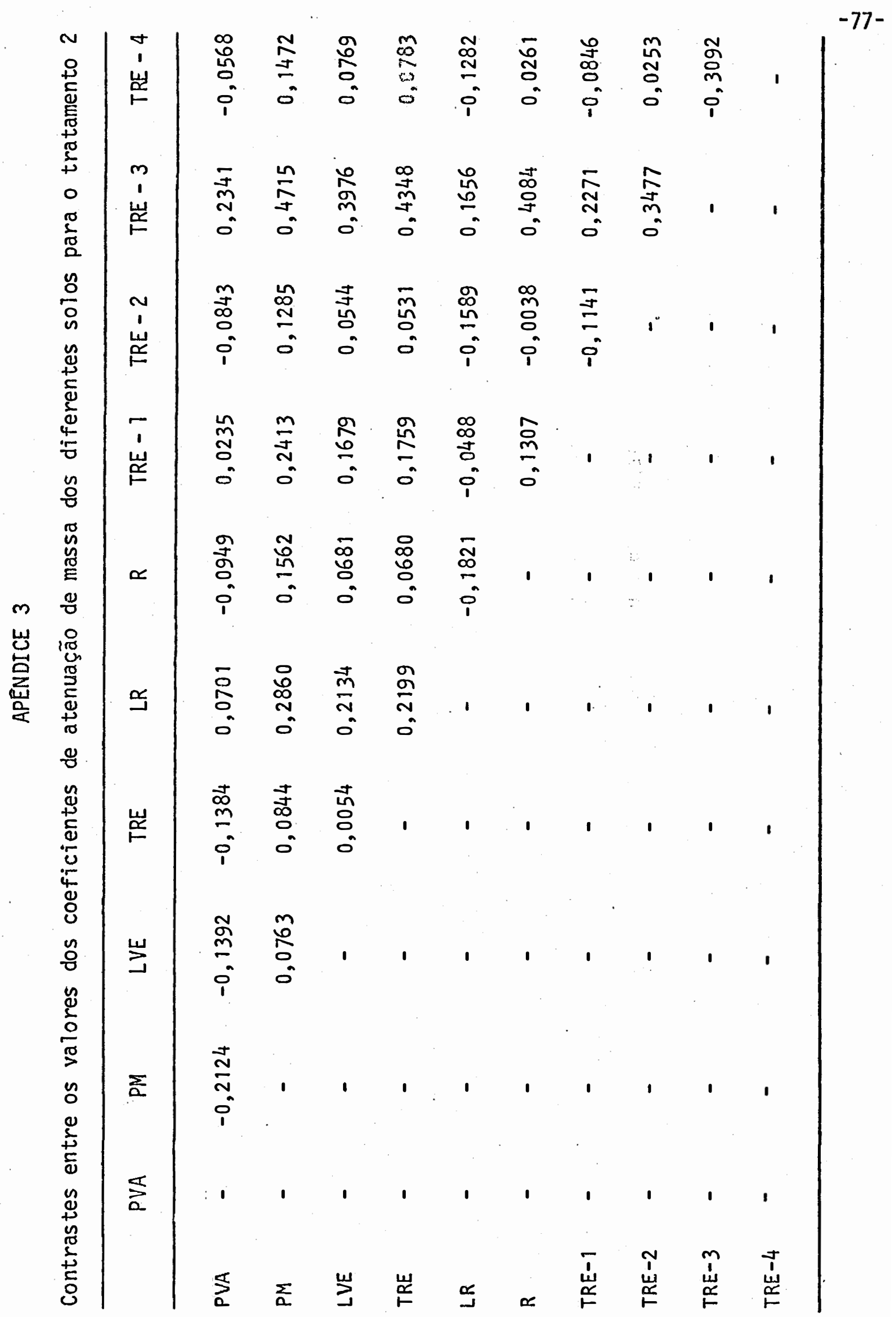




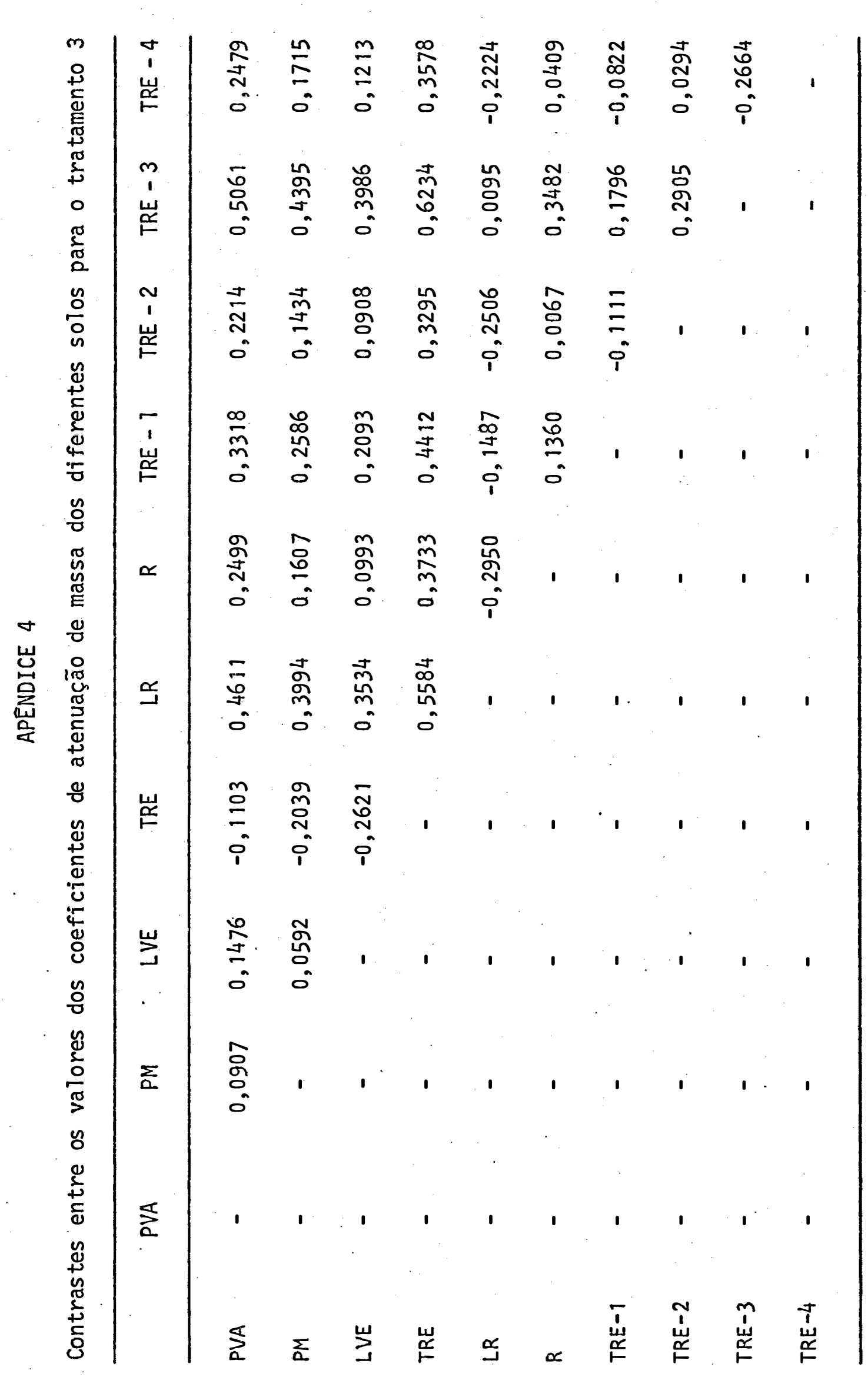




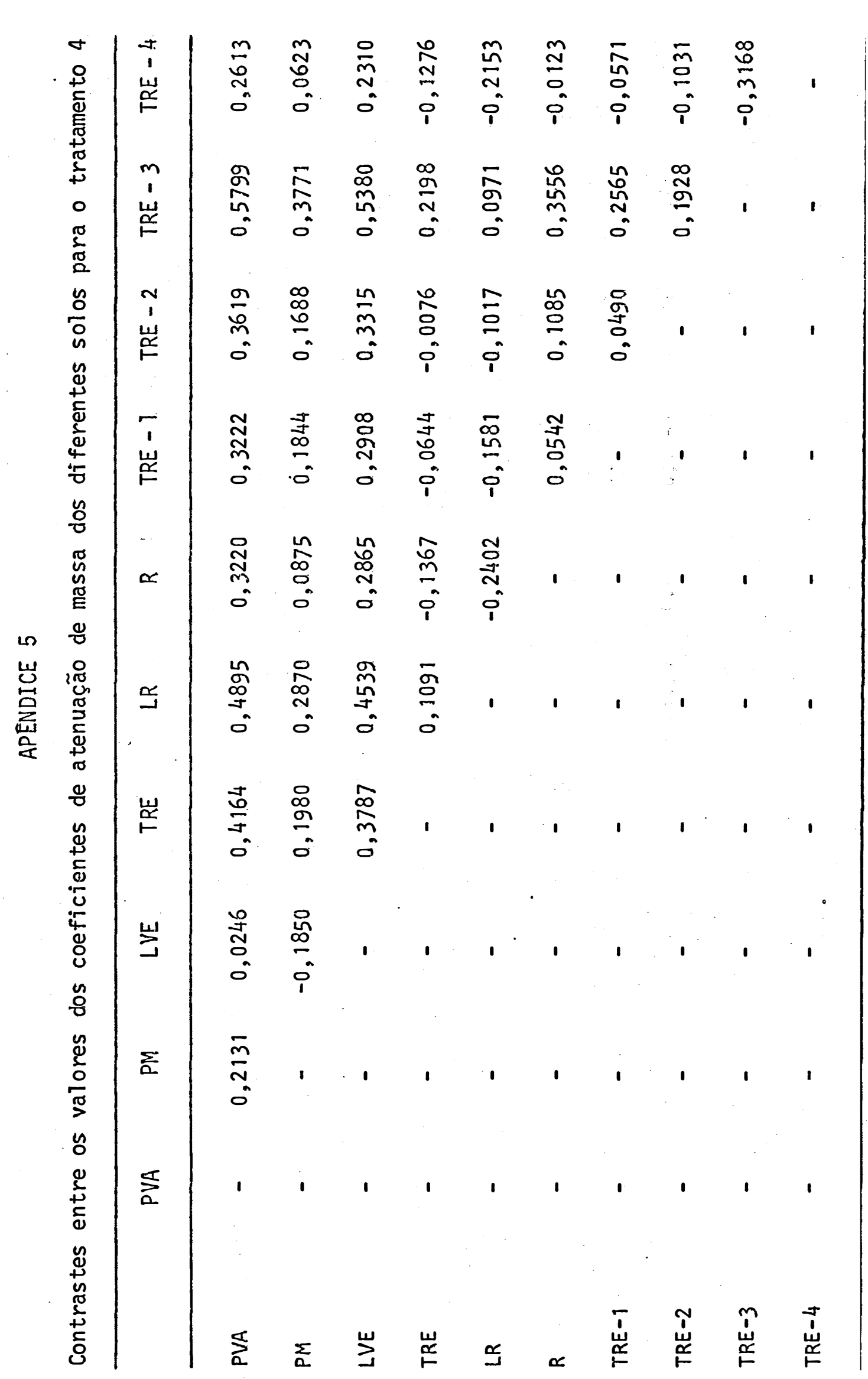




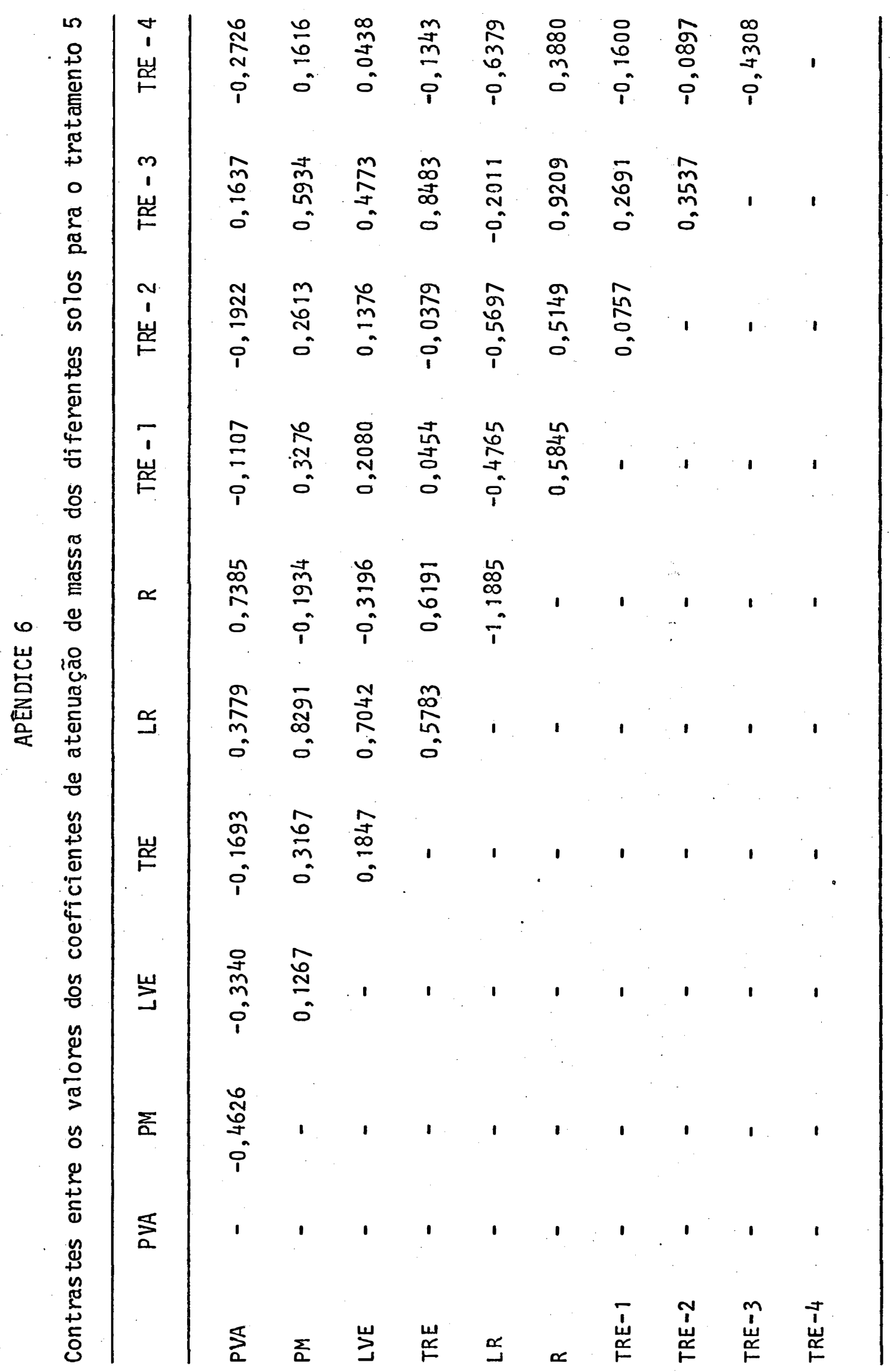




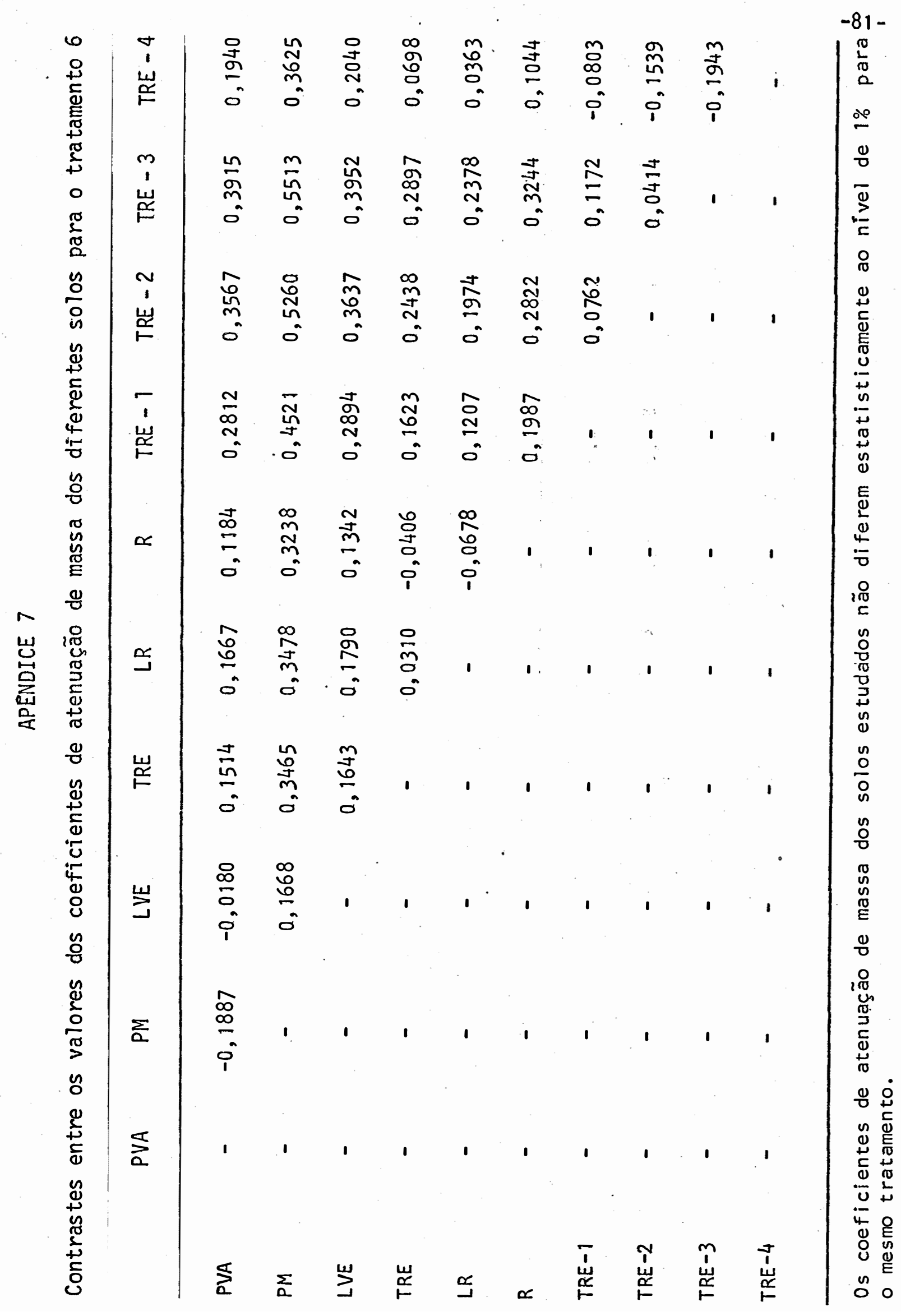




\section{APENDICE. 8}

Contrastes obtidos entre os valores dos coeficientes de atenuação de massa geral ( 10 solos), para os diversos solos.

\begin{tabular}{lcccccc}
\hline & $T_{1}$ & $T_{2}$ & $T_{3}$ & $T_{4}$ & $T_{5}$ & $T_{6}$ \\
\hline$T_{1}$ & - & $-0,0158$ & $-0,1109$ & $-0,2849$ & 0,1397 & $-0,5712$ \\
$T_{2}$ & - & - & $-0,1271$ & $-0,3668$ & 0,2040 & $-0,7428$ \\
$T_{3}$ & - & - & - & $-0,2151$ & 0,3083 & $-0,5722$ \\
$T_{4}$ & - & - & - & - & 0,5364 & $-0,3848$ \\
$T_{5}$ & - & - & - & - & - & $-0,8780$ \\
$T_{6}$ & - & - & - & - & - & - \\
\hline
\end{tabular}

Os coeficientes de atenuação de massa geral do solo não diferem estatistí camente ao nival de $1 \%$ para os diferentes tratamentos. 


\section{APENDICE 9}

Contrastes entre os coeficientes de atenuação de massa da ăgua para os 6 tratamentos.

\begin{tabular}{ccccccc}
\hline & $T_{1}$ & $T_{2}$ & $T_{3}$ & $T_{4}$ & $T_{5}$ & $T_{6}$ \\
\hline$T_{1}$ & - & $0,0,995$ & $-0,4639$ & $-0,2454$ & $-0,1474$ & $-0,1784$ \\
$T_{2}$ & - & - & $-0,5393$ & $-0,3246$ & $-0,2326$ & $-0,2656$ \\
$T_{3}$ & - & - & - & 0,1751 & 0,2828 & 0,2715 \\
$T_{4}$ & - & - & - & - & 0,0953 & 0,0773 \\
$T_{5}$ & - & - & - & - & - & $-0,0222$ \\
$T_{6}$ & - & - & - & - & - & - \\
\hline
\end{tabular}

o coeficiente de atenuação de massa da água não difere estatisticamente ao nivel de $1 \%$ para os diferentes solos. 